Poverty Estimates in India: Old and New Methods, 2004-05

Durgesh C. Pathak, Srijit Mishra

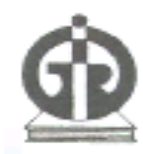

Indira Gandhi Institute of Development Research, Mumbai August 2011

http://www.igidr.ac.in/pdf/publication/WP-2011-015.pdf 


\title{
Poverty Estimates in India: Old and New Methods, 2004-05
}

\author{
Durgesh C. Pathak, Srijit Mishra \\ Indira Gandhi Institute of Development Research (IGIDR) \\ General Arun Kumar Vaidya Marg \\ Goregaon (E), Mumbai- 400065, INDIA \\ Email (corresponding author): $\quad$ srijit@igidr.ac.in
}

\begin{abstract}
This paper provides estimates of poverty and inequality across states as also for different sub-groups of population for 2004-05 by using the old and new methods of the Planning Commission. The new method is critically evaluated with the help of some existing literature and its limitations discussed with regard to doing away with calorie norm, use of median expenditure as a norm for education when the distribution is positively skewed, difficulty in reproducing results for earlier rounds acting as a constraint on comparisons, and using urban poverty ration of the old method as a starting point to decide a consumption basket. More importantly, it discusses the implications on financial transfers across states if the share of poor is only taken into account without accounting for an increase in the total number of poor. Despite these limitations, on grounds of parsimony and prudence the state-specific poverty lines suggested in the new method, as also in the old method, are used to calculate incidence, depth (intensity) and severity (inequality among poor) estimates of poverty for different sub-groups of population, viz., NSS regions, social groups and occupation groups.
\end{abstract}

\section{Keywords:}

Household type (occupation groups), inequality (Gini), NSS regions, Planning Commission, poverty, rural, social groups, urban.

\section{JEL Code:}

D63, I32, I38, I39.

\section{Acknowledgements:}

This paper is dedicated to the memory of Professor Suresh D. Tendulkar who passed away recently on 21 June 2011. The authors thank Sanjay Reddy and M.H. Suryanarayana for discussions. Calculations in the old method were done by both the authors independently and they broadly matched, but the one by DCP has been used who also did the calculations with the new method and generated the maps and figures. Based on joint discussions, a preliminary note was written by DCP. The note has been elaborated on, revised and put into the current form by SM. Usual disclaimers apply. 


\title{
Poverty Estimates in India: Old and New Methods, 2004-05
}

\author{
Durgesh C. Pathak, Srijit Mishra
}

Contents

$\begin{array}{llr} & \text { Abstract } & 2 \\ 1 & \text { Introduction } & 3 \\ 2 & \text { The New Method } & 4 \\ 2.1 & \text { Not Pegged to a Calorie Norm } & 4 \\ 2.2 & \text { Use of Median Expenditure for Health and Education } & 5 \\ 2.3 & \text { Reproducibility of the New Method } & 6 \\ 2.4 & \text { The Sacrosanct 25.7! } & 6 \\ 3 & \text { Impact of Change in Poverty Line on Financial Transfers } & 8 \\ 4 & \text { Poverty and Inequality across States } & 10 \\ 5 & \text { Poverty and Inequality across Sub-groups of Population } & 17 \\ 5.1 & \text { NSS Regions } & 17 \\ 5.2 & \text { Social Groups } & 24 \\ 5.3 & \text { Household Type (Occupation Groups) } & 36 \\ 6 & \text { Concluding Remarks } & 37 \\ & \text { References } & 39\end{array}$

Table 1 All India Poverty Indices, 2004-05

Table 2 Share of Poor across States: Old and New Methods, 2004-05 9

Table 3 Population and Poverty Line for States, 2004-05 11

Table 4 Poverty and Inequality across States with Old and New Methods, 2004- 13 05, Rural and Urban

Table 5 Poverty and Inequality across NSS Regions with Old and New Methods, 19 2004-05, Rural and Urban

Table 6 Share of Poor across NSS Regions, Old and New Methods, 2004-05, Rural and Urban

Table 7 Poverty and Inequality across State-wise Social Groups with Old and 26 New Methods, 2004-05, Rural and Urban

Table 8 Poverty and Inequality across State-wise Occupation Groups with Old 30 and New Methods, 2004-05, Rural and Urban

Figure 1 Map Depicting Incidence of Poor across States in Rural India, 2004-05

(a) Old Method and (b) New Method

Figure 2 Map Depicting Incidence of Poor across States in Urban India, 2004-05

(a) Old Method and (b) New Method

Figure 3 TIP and Lorenz Curves for India with Old and New Methods, 2004-05,

Rural and Urban 


\title{
Poverty Estimates in India: Old and New Methods, 2004-05 ${ }^{1}$
}

\author{
Durgesh C. Pathak, Srijit Mishra² \\ Indira Gandhi Institute of Development Research (IGIDR) \\ Generak AK Vaidya Marg, Goregaon (East), Mumbai-400065, INDIA
}

16 August 2011

The poor are a part of necessary furniture of the earth, a sort of perpetual gymnasium where the rich can practice virtue when they are so inclined.

- Francesco Giucciardini (Discorsi Politici)

But I, being poor, have only my dreams;

I have spread my dreams beneath your feet;

Tread softly because you tread on my dreams...

- W. B. Yeats

\begin{abstract}
This paper provides estimates of poverty and inequality across states as also for different sub-groups of population for 2004-05 by using the old and new methods of the Planning Commission. The new method is critically evaluated with the help of some existing literature and its limitations discussed with regard to doing away with calorie norm, use of median expenditure as a norm for education when the distribution is positively skewed, difficulty in reproducing results for earlier rounds acting as a constraint on comparisons, and using urban poverty ration of the old method as a starting point to decide a consumption basket. More importantly, it discusses the implications on financial transfers across states if the share of poor is only taken into account without accounting for an increase in the total number of poor. Despite these limitations, on grounds of parsimony and prudence the state-specific poverty lines suggested in the new method, as also in the old method, are used to calculate incidence, depth (intensity) and severity (inequality among poor) estimates of poverty for different sub-groups of population, viz., NSS regions, social groups and occupation groups.
\end{abstract}

Keywords: Household type (occupation groups), inequality (Gini), NSS regions, Planning Commission, poverty, rural, social groups, urban.

JEL codes: D63, I32, 138, 139.

\footnotetext{
${ }^{1}$ This paper is dedicated to the memory of Professor Suresh D. Tendulkar who passed away recently on 21 June 2011. The authors thank Sanjay Reddy and M.H. Suryanarayana for discussions. Calculations in the old method were done by both the authors independently and they broadly matched, but the one by DCP has been used who also did the calculations with the new method and generated the maps and figures. Based on joint discussions, a preliminary note was written by DCP. The note has been elaborated on, revised and put into the current form by SM. Usual disclaimers apply.

2 The sequence of authorship is based on first names. DCP is Post-Doctoral Fellow and SM is Associate Professor at IGIDR and they can be contacted at pathakdc@gmail.com and srijit@igidr.ac.in respectively.
} 


\section{Introduction}

In India, the quinquennial rounds of national sample survey (NSS) of consumption expenditure have been instrumental in providing us with an estimation of head count ratio. The Report of the Task Force on Projections of Minimum Needs and Effective Consumption Demands (Government of India, 1979) looked into the age, sex and activity specific nutritional requirements and arrived at a per capita norm of 2400 calorie for rural and 2100 calorie for urban and based on this a monthly per capita expenditure (MPCE) of Rs.49.09 in rural and Rs.56.64 in urban was identified as the poverty line for 1973-74. This was updated to accommodate price changes over time. The Report of the Expert Group on Estimation of Proportion and Number of Poor (Government of India, 1993) proposed the use of independent poverty lines for each state and updating them by looking into the state specific changes in prices. This formed the basis for official estimates of poverty provided by the Planning Commission till recently (hereafter, old method).

Some of the criticism of this approach is that the updated prices may not represent the calories norm that they were initially pegged to, ${ }^{3}$ that the calorie norms should change because of demographic shifts in age and sex and change in occupational patterns, that basic requirements like health, education, sanitation and housing are not included in the calculation of poverty line, that a reference period of 30 days may not be appropriate for low frequency items of consumption expenditure among others. These have been partly addressed in the Report of the Expert Group to Review the Methodology for Estimation of Poverty (Government of India, 2009) leading to a new set of poverty estimates for the year 2004-05 that have now been accepted by the Planning Commission (hereafter, new method).

The current exercise focuses on three points. First, it discusses critically the new methodology in the light of a brief review of some recent literature by various scholars. Second, it analyses the change in shares of poverty across states and union territories (hereafter, states) that will occur due to this shift. It also tries to briefly hint the possible

\footnotetext{
${ }^{3}$ Mishra and Reddy (2011) show that in rural India the incidence of calorie-poor (using the norm of 2400 kilocalorie per person per day) is much higher than the expenditure-poor (using the old estimates) in almost all states. In states of Bihar, Jharkhand and Odisha where incidence of calorie poor is higher, it is because of relatively higher share of consumption from cereals indicating the possibility of other nutritional deficiencies.
} 
repercussions of these changes on poverty reduction efforts in states. Third, it provides estimates of proportion of poor (head count ratio or incidence of poverty), depth (poverty gap or intensity) and the severity (poverty gap squared or inequality among the poor) at various levels of disaggregation like states, NSS regions, social groups and occupational categories.

\section{The New Method}

The new method takes the old poverty estimates using uniform recall period (URP) of 30 days for urban India at 25.7 per cent in 2004-05 as a starting point, as the expert group constituted to work on it considered this to be less controversial. This was imposed on the mixed recall period (MRP) where five low frequency items of clothing, footwear, durables, education and institutional health expenditure had a 365 days recall period from which an average for 30 days was constructed and the other items continued with a 30 days recall period. ${ }^{4}$ The MRP monthly per capita expenditure above the 25.7 percentile constituted the new poverty line and the consumption of items around this constituted the poverty line basket (PLB) for urban India. The items in the PLB and their state-specific prices for rural and urban areas were used to compute the new set of poverty lines. Some of the criticisms of this new method are the following.

\subsection{Not Pegged to a Calorie Norm}

This indirect approach of fixing poverty line through an agreed upon incidence of poor in urban areas raises curious eyebrows. Further, the expert group decided against pegging the poverty lines with calorie norm as it was not correlated (read, not commensurate because of higher deprivations) with nutritional outcomes from other surveys (Government of India, 2009). A background paper for the expert group pointed out that the changes in consumption patterns over time could be indicative of changes in minimum nutritional requirement (Suryanarayana, 2009; also see Suryanarayana and Silva, 2007). There are other interesting queries about the fact that energy intake has shown a secular increase from about 1511 calories in the first decile to 2681 calories in the tenth decile for 2004-05

\footnotetext{
${ }^{4}$ A simple exercise of comparing data values of consumption expenditure in MRP and URP at the unit level reveal that they are equal 0.13 per cent cases, MRP is greater in 80.65 per cent cases and URP is greater in 19.22 per cent cases.
} 
(Suryanarayana, 2009); or, that there is a decline in average calorie intake for the bottom 30 per cent from 1701 in 1993-94 to 1677 in 2004-05 (Radhakrishna, Ravi and Reddy, 2011). Deaton and Drèze (2009) also point out to the decline in calorie and protein consumption over time and suggest that these could be because of better health environment or lower work burden but are puzzled that other nutritional outcomes of mother and children do not show a marked improvement. These suggest that there should have been an expert opinion on an appropriate calorie norm and other nutritional requirement.

The Expert Group, having decided to keep off the poverty-nutrition linkage, decide not to probe further on this. Fine! But, then they go on to state that those around the poverty line can afford consumption expenditure equal to 2100 calorie per capita but their observed calorie intake is around 1776 calorie per capita, which is closer to a norm of 1770 calorie given for India for 2003-05 by the Food and Agriculture Organisation (FAO) and does not have any factoring for age, sex or occupation. It is quite strange to start with discarding the calorie norm and then mentioning some other calorie norm to fortify ones argument. It goes beyond curious eyebrows! Swaminathan (2010) asserts that the claim that the revised poverty line is adequate to meet expenditure requirements with respect to nutrition, education, and health is invalid. In fact, the calorie intake requirement has actually been lowered from the existing norm and one should not overlook the fact that the suggested FAO norm is for light and sedentary activities. This is likely to underestimate poverty for agricultural and other labour in rural areas and casual labourers in urban India who fall under the moderate activity group. The notion of fitting a poverty line that conforms to calorie requirement of sedentary activity on people around the poverty line, who have to work hard for their sustenance, does not seem appropriate.

\subsection{Use of Median Expenditure for Health and Education}

In the old methodology expenses on education of children and health care were kept outside the purview of a poverty line, as these were supposed to have been provided by the state. With an increasing reliance on private providers and even when these services are publicly provided there are expenses that the individual does incur, therefore, including these expenses into the calculation of a poverty line is to be appreciated. However, the usage of median expenditure to be representative of a normative or desirable expenditure 
when the income distribution is positively skewed is not tenable (Swaminathann, 2010). Subramanian (2010: p. 31) further states that:

\begin{abstract}
Costs are likely to rise when treatment/hospitalization tends toward greater completeness/comprehensiveness: the median cost in a poor economy is scarcely likely to be reflective of the cost that would be incurred in order to finance a reasonably comprehensive course of treatment or hospitalization. Second, the proportional incidence of treatment/hospitalization is unlikely to be the probability of onset of illness requiring treatment/hospitalization: the actual incidence of illness requiring treatment will, in an environment of poor affordability, typically be larger than the incidence of illness actually treated. There is therefore good reason to believe that these 'normative' expenditure levels on education and health are underestimates.
\end{abstract}

\title{
2.3 Reproducibility of the New Method
}

The PLB for urban India forms the reference basis for generating comparable PLB for rural India as also urban/rural sector of states. This requires generating price indices, which to an onlooker is a black box. The report of the expert group (Government of India, 2009) and a background paper (Himanshu, 2009) do outline the method using which researchers can replicate a large part of the exercise, but not before they spend a considerable amount of time. Given the public relevance of this exercise, the expert group could have elaborated a bit more, particularly, the base prices for the 23 commodity groups and the amount/share of actual rent and conveyance used for each sector/state. ${ }^{5}$ It would have been a few more tables. Raveendran (2010) refers to the Expert Group on Poverty Statistics/Rio Group (2006) on what determines the credibility of poverty lines and concurs that the new methodology is not easily replicable. It would also render earlier rounds of the national sample survey on consumption expenditure difficult for poverty comparisons.

\subsection{The sacrosanct $25.7 !$}

Another question that bothers is what made the expert group believe that the urban poverty ratio of 25.7 per cent is less controversial while the rural poverty ratio is

\footnotetext{
${ }^{5}$ For 15 commodity groups of cereals, pulses, milk, edible oil, egg, fish and meat, vegetables, fresh fruits, dry fruits, sugar, salt and spice, other food, intoxicants, fuel, clothing and footwear, data were from the same consumption expenditure schedule of $61^{\text {st }}$ round, 2004-05; for education, data were taken from the same round but the employment and unemployment schedule; for institutional and non-institutional medical expenses, data were based on the $60^{\text {th }}$ round, January-June 2004 health schedule; and for the five items of entertainment, personal care, miscellaneous goods, miscellaneous services and durables, data used were consumer price index for industrial workers in urban areas and consumer price index for agricultural labourers in rural areas based on a work done by M.R. Saluja and B. Yadav for the expert group, that has not been shared with the public.
} 
considerably underestimated. The only reason they could cite is based on research by Deaton $(2003,2008)$ providing alternative poverty estimates for 1987-88, 1993-94, 19992000 and 2004-05. There are considerable differences in estimates of urban poverty given by Deaton and the old methodology. As Datta (2010) points out, "Deaton reveals his reservations with the urban poverty lines. In a striking contrast, Tendulkar adopts the urban poverty line, and made it the focal point of poverty estimation in the country."

Table 1: All India Poverty Indices, 2004-05

\begin{tabular}{lcccc}
\hline Indices & Rural: Old & Rural: New & Urban: Old & Urban: New \\
\hline Incidence (official) & 0.282697 & 0.418 & 0.257119 & 0.257 \\
Incidence & 0.281216 & 0.417962 & 0.258435 & 0.256757 \\
Depth & 0.055022 & 0.092435 & 0.062145 & 0.057762 \\
Severity & 0.016251 & 0.029396 & 0.021640 & 0.018781 \\
\hline
\end{tabular}

Note: All India estimates are weighted averages of state-specific estimates computed using unit level data and they may not match with the official estimates. For the old method, as indicated in the official communication, poverty ratio of a neighbouring reference state is imposed on 12 states/union territories as follows: Assam for all the north-east states of Arunachal Pradesh, Manipur, Meghalaya, Mizoram, Nagaland, and Tripura as also Sikkim; Goa or Daman \& Diu; Kerala for Lakshadweep; Punjab urban for rural and urban Chandigarh; and Tamil Nadu for Andaman \& Nicobar Islands and Puducherry. Keeping the poverty ratio of these reference states, a proxy poverty line was imposed on these 12 states for our calculations using unit level data. Further, in the old method the poverty line of Maharashtra is used on the consumption expenditure distribution of Goa, and Dadra \& Nagar Haveli. In the new method, the union territories of Andaman \& Nicobar Islands, Chandigarh, Dadra \& Nagar Haveli, Daman \& Diu and Lakshadweep use the poverty lines of Tamil Nadu, Punjab urban, Maharashtra, Goa and Kerala respectively.

Source: Government of India $(2007,2009)$ and Unit level data, Schedule 1.0, NSS $61^{\text {st }}$ Round, 2004-05

The most intriguing part of 25.7, an agreed-upon incidence of poverty ratio for urban India, is the falling in line of all calculations. To begin with, this urban incidence of poverty gives us a poverty line basket and given the prevailing prices for the basket of commodities in each state one computes state-specific poverty lines. Using these poverty lines and the statespecific population of unit level data, if one computes the weighted average incidence of poverty for urban India, we end up with where we begun, the magic number of 25.7 per cent. The same is also true for rural India. This can be possible in a calibrating exercise. Nevertheless, this adjustment does not hold when one takes the census population as weights, as indicated in the official publication. The differences in incidence, depth and severity between the old and new methods at the all India level are indicated in Table 1.

One reason for the justification of 25.7 is to have given the expert group some starting point when they might have decided against linking it to the existing calorie norms - a pragmatic consideration. Or, as Professor Suresh Tendulkar said "... any poverty line approach was arbitrary, but ... as long as we followed the same procedure consistently, it would be useful for comparison purposes" (Dev, 2011: 114). 
Finally, for practical purposes it is the state-specific poverty lines that are relevant and should be used for calculating FGT measures of poverty, not only at the aggregate all India level by obtaining weighted averages, but also at other sub-group levels. With regard to other sub-groups, using a PLB method for arriving at poverty lines will not only require cumbersome calculations but will also give different values for weighted averages at the all India level. Thus, both on account of parsimony and prudency this should be avoided. Therefore, in our subsequent exercise, state-specific poverty lines provided by the old and new methodologies are used to calculate comparable estimates for incidence, depth and severity of poverty across states and also for NSS regions, social groups and occupational categories, separately for rural and urban areas.

\section{Impact of Change in Poverty Lines on Financial Transfers}

The Report of the Expert Group on Estimation of Proportion and Number of Poor (Government of India, 1993) mentions that poverty estimates calculated by the Planning Commission serve two major purposes: one, they indicate the development effort put by the state, and second, they are used in deciding fund allocation among states. The basic purpose of central plan assistance to states are to bridge the resource gap at the state level, to reduce inter-state disparity through its pattern of assistance, and to coordinate the development efforts of the states in pursuance of the accepted plan objectives and priorities (Gupta and Kalra, 2005).

A portion of plan assistance is based on the special needs of states. A poorer state will need more plan assistance in order to reduce poverty than a rich one. With the adaptation of the new method, there will not only be changes in the incidence (discussed later in the paper) but also in the share of poor across states. The share of poor in the old and new methods for rural, urban and combined areas across states is given in Table 2. It shows that, at a combined level, the five states where the share of poor has increased the most, three, i.e. Andhra Pradesh, Gujarat and Haryana happen to be among those with relatively lower incidence of poverty and higher per capita income. 
Table 2: Share of Poor across States: Old and New Methods, 2004-05

(per cent)

\begin{tabular}{|c|c|c|c|c|c|c|c|c|c|}
\hline \multirow[t]{2}{*}{ State } & \multicolumn{3}{|c|}{ Old } & \multicolumn{6}{|c|}{ New } \\
\hline & Rural & Urban & Combined & Rural & & Urban & & Combine & \\
\hline Andaman \& Nicobar & 0.0269 & 0.0387 & 0.0325 & 0.0027 & $\downarrow$ & 0.0014 & $\downarrow$ & 0.0022 & \\
\hline Andhra Pradesh & 2.7559 & 7.4570 & 4.9949 & 5.7268 & $\uparrow$ & 6.3939 & $\downarrow$ & 5.9797 & \\
\hline Arunachal Pradesh & 0.0866 & 0.0122 & 0.0512 & 0.0892 & $\uparrow$ & 0.0842 & $\uparrow$ & 0.0873 & \\
\hline Assam & 2.4484 & 0.1749 & 1.3657 & 2.7184 & $\uparrow$ & 1.0515 & $\uparrow$ & 2.0865 & \\
\hline Bihar & 15.4600 & 4.1972 & 10.0960 & 13.6315 & $\downarrow$ & 5.1048 & $\uparrow$ & 10.3990 & \\
\hline Chandigarh & 0.0037 & 0.0727 & 0.0365 & 0.0051 & $\uparrow$ & 0.1187 & $\uparrow$ & 0.0481 & \\
\hline Chhattisgarh & 3.2456 & 2.4782 & 2.8801 & 2.9543 & $\downarrow$ & 1.6748 & $\downarrow$ & 2.4693 & \\
\hline Dadra \& Nagar Haveli & 0.0308 & 0.0193 & 0.0253 & 0.0333 & $\uparrow$ & 0.0170 & $\downarrow$ & 0.0271 & \\
\hline Daman \& Diu & 0.0029 & 0.0156 & 0.0089 & 0.0010 & $\downarrow$ & 0.0119 & $\downarrow$ & 0.0051 & \\
\hline Delhi & 0.0283 & 2.9766 & 1.4325 & 0.0431 & $\uparrow$ & 2.3545 & $\downarrow$ & 0.9194 & \\
\hline Goa & 0.0174 & 0.1888 & 0.0990 & 0.0583 & $\uparrow$ & 0.2136 & $\uparrow$ & 0.1172 & \\
\hline Gujarat & 2.8554 & 3.4504 & 3.1388 & 3.9835 & $\uparrow$ & 5.2192 & $\uparrow$ & 4.4520 & \\
\hline Haryana & 0.9534 & 1.2661 & 1.1023 & 1.2045 & $\uparrow$ & 1.9658 & $\uparrow$ & 1.4931 & \\
\hline Himachal Pradesh & 0.2739 & 0.0260 & 0.1558 & 0.4379 & $\uparrow$ & 0.0372 & $\uparrow$ & 0.2860 & \\
\hline Jammu \& Kashmir & 0.1558 & 0.2537 & 0.2024 & 0.3463 & $\uparrow$ & 0.3569 & $\uparrow$ & 0.3503 & \\
\hline Jharkhand & 4.6780 & 1.6446 & 3.2333 & 3.5280 & $\downarrow$ & 1.9423 & $\uparrow$ & 2.9269 & \\
\hline Karnataka & 3.3801 & 7.9404 & 5.5519 & 4.1334 & $\uparrow$ & 6.3269 & $\downarrow$ & 4.9650 & \\
\hline Kerala & 1.4685 & 2.1132 & 1.7755 & 1.5135 & $\uparrow$ & 1.9518 & $\downarrow$ & 1.6797 & \\
\hline Lakshadweep & 0.0022 & 0.0069 & 0.0044 & 0.0000 & $\downarrow$ & 0.0036 & $\downarrow$ & 0.0014 & \\
\hline Madhya Pradesh & 7.9623 & 9.3251 & 8.6114 & 7.8169 & $\downarrow$ & 7.6815 & $\downarrow$ & 7.7656 & \\
\hline Maharashtra & 7.7732 & 18.0933 & 12.6882 & 8.4844 & $\uparrow$ & 14.4967 & $\downarrow$ & 10.7636 & \\
\hline Manipur & 0.1688 & 0.0270 & 0.1013 & 0.2023 & $\uparrow$ & 0.2574 & $\uparrow$ & 0.2232 & \\
\hline Meghalaya & 0.1959 & 0.0221 & 0.1131 & 0.0836 & $\downarrow$ & 0.1502 & $\uparrow$ & 0.1088 & \\
\hline Mizoram & 0.0460 & 0.0216 & 0.0343 & 0.0323 & $\downarrow$ & 0.0470 & $\uparrow$ & 0.0379 & \\
\hline Nagaland & 0.1739 & 0.0163 & 0.0988 & 0.0532 & $\downarrow$ & 0.0192 & $\uparrow$ & 0.0403 & $v$ \\
\hline Odisha & 6.9159 & 3.3533 & 5.2192 & 6.0410 & $\downarrow$ & 2.8296 & $\downarrow$ & 4.8236 & \\
\hline Puducherry & 0.0354 & 0.1948 & 0.1113 & 0.0241 & $\downarrow$ & 0.0883 & $\downarrow$ & 0.0484 & $\downarrow$ \\
\hline Punjab & 0.6774 & 0.7191 & 0.6972 & 1.1197 & $\uparrow$ & 2.1464 & $\uparrow$ & 1.5089 & \\
\hline Rajasthan & 3.8883 & 5.7907 & 4.7943 & 5.1267 & $\uparrow$ & 5.3416 & $\downarrow$ & 5.2082 & 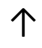 \\
\hline Sikkim & 0.0503 & 0.0031 & 0.0278 & 0.0487 & $\downarrow$ & 0.0220 & $\uparrow$ & 0.0386 & 1 \\
\hline Tamil Nadu & 3.4970 & 8.6916 & 5.9710 & 3.8489 & $\uparrow$ & 7.6675 & $\downarrow$ & 5.2965 & $\downarrow$ \\
\hline Tripura & 0.2776 & 0.0271 & 0.1583 & 0.3767 & $\uparrow$ & 0.1679 & $\uparrow$ & 0.2976 & 1 \\
\hline Uttar Pradesh & 21.4354 & 14.3000 & 18.0371 & 18.5277 & $\downarrow$ & 16.2282 & $\uparrow$ & 17.6559 & $\downarrow$ \\
\hline Uttarakhand & 1.2276 & 1.0997 & 1.1667 & 0.7152 & $\downarrow$ & 0.7926 & $\downarrow$ & 0.7445 & $\checkmark$ \\
\hline West Bengal & 7.8016 & 3.9828 & 5.9829 & 7.0878 & $\downarrow$ & 7.2337 & $\uparrow$ & 7.1431 & \\
\hline All India & 100.0000 & 100.0000 & 100.0000 & 100.0000 & & 100.0000 & & 100.0000 & \\
\hline
\end{tabular}

Note: For the old method, official figures of poor population are used to calculate share of poor across states. This with incidence also gives the overall population. For the new method, unit level data is used to calculate incidence of poor and this is imposed on the overall population to arrive at the share of poor. The unit level estimates for the new method match with the official estimates, which are available for the first decimal place only. The arrows, $\uparrow$ and $\downarrow$ indicate increase and decrease respectively in the share of new when compared with the old. Source: Government of India $(2007,2009)$.

Among the poorer states, one observes an increase in the share of poor for Rajasthan. This is so because of an increase in the share of poor in rural areas. The urban areas of Bihar, Jharkhand and Uttar Pradesh also witness an increase in the share of poor. At the aggregate level the states of Bihar, Chhattisgarh, Jharkhand, Madhya Pradesh, Odisha, Uttaranchal and Uttar Pradesh that are known to have higher incidences of poor show a decline in their 
share of poor. These will have important public policy implications on welfare related interventions that are assigned on the basis of the share of poor.

\section{Poverty and Inequality across States}

Now we take up a discussion on poverty and of inequality across states of India. The poverty measures are computed in the old as also new methods using Foster, Greer and Thorbecke (1984; hereafter FGT) class of measures,

$$
F G T_{(\propto)}=1 / N \sum_{i}^{N}\left(\left(z-Y_{i}\right) / z\right)^{\propto} ; \propto \geq 0
$$

where $F G T_{\alpha}$ is the alpha class of poverty measure, $N$ is total population, $z$ is the poverty line, $y_{i}$ is the consumption expenditure for the $i^{\text {th }}$ poor and $\alpha$ is a 'poverty aversion' parameter (larger $\alpha$ gives greater weights to poorer people). This measure can be decomposed at population sub-group level as

$$
F G T_{(\propto)}=\sum_{k=1}^{K}\left(\frac{N_{k}}{N}\right) F G T_{(\propto) k} ; \propto \geq 0
$$

where $\frac{N_{k}}{N}$ is the number of persons in the subgroup $k$ divided by the total number of persons, the subgroup population share.

The state-specific population poverty lines for the old and new methods are given in Table 3. The measures of incidence, depth and severity for poverty and inequality measured through Gini coefficient for rural and urban areas across states are computed and given in Table 4. State-specific broad shifts in incidence of poverty are also indicated through maps in Figures 1 and 2 for rural and urban areas respectively.

Figure 3 has four graphs - two TIP (three I's of poverty, see Jenkins and Lambert, 1997) and two Lorenz curves for rural and urban areas. The TIP curves indicate incidence, intensity (depth) and inequality among the poor (severity) and the Lorenz curves are a graphical representation of the Gini coefficient. In each of the four graphs the old and new methods are plotted separately. Comparing the new measures of poverty and inequality with that of the old, some broad observations are as follows. We begin with the rural areas. 
Table 3: Population and Poverty Lines for States, 2004-05

\begin{tabular}{|c|c|c|c|c|c|c|}
\hline \multirow[t]{3}{*}{ State } & \multicolumn{2}{|c|}{ Population (Lakhs) } & \multicolumn{4}{|c|}{ Poverty Line (₹) } \\
\hline & \multirow[t]{2}{*}{ Rural } & \multirow[t]{2}{*}{ Urban } & \multicolumn{2}{|c|}{ Rural } & \multicolumn{2}{|c|}{ Urban } \\
\hline & & & Old & New & Old & New \\
\hline Andaman \& Nicobar Islands & 2.63 & 1.42 & - & 441.69 & - & 559.77 \\
\hline Andhra Pradesh & 579.17 & 219.35 & 292.95 & 433.43 & 542.89 & 563.16 \\
\hline Arunachal Pradesh & 8.68 & 2.87 & - & 547.14 & - & 618.45 \\
\hline Assam & 244.02 & 38.71 & 387.64 & 478.00 & 378.84 & 600.03 \\
\hline Bihar & 799.05 & 93.59 & 354.36 & 433.43 & 435.00 & 526.18 \\
\hline Chandigarh & 1.07 & 9.43 & - & 642.51 & - & 642.51 \\
\hline Chhattisgarh & 175.22 & 47.29 & 322.41 & 398.92 & 560.00 & 513.70 \\
\hline Dadra \& Nagar Haveli & 1.71 & 0.81 & 362.25 & 484.89 & 665.90 & 631.85 \\
\hline Daman \& Diu & 1.39 & 0.66 & - & 608.76 & - & 671.15 \\
\hline Delhi & 9.05 & 146.64 & 410.38 & 541.39 & 612.91 & 642.47 \\
\hline Goa & 6.78 & 7.71 & 362.25 & 608.76 & 665.90 & 671.15 \\
\hline Gujarat & 332.76 & 208.64 & 353.93 & 501.58 & 541.16 & 659.18 \\
\hline Haryana & 158.44 & 70.39 & 414.76 & 529.42 & 504.49 & 626.41 \\
\hline Himachal Pradesh & 57.27 & 6.56 & 394.28 & 520.40 & 504.49 & 605.74 \\
\hline Jammu \& Kashmir & 80.22 & 27.61 & 391.26 & 522.30 & 553.77 & 602.89 \\
\hline Jharkhand & 223.1 & 65.36 & 366.56 & 404.79 & 451.24 & 531.35 \\
\hline Karnataka & 359.98 & 195.99 & 324.17 & 417.84 & 599.66 & 588.06 \\
\hline Kerala & 244.81 & 85.08 & 430.12 & 537.31 & 559.39 & 584.70 \\
\hline Lakshadweep & 0.42 & 0.28 & - & 537.31 & - & 584.70 \\
\hline Madhya Pradesh & 476.35 & 175.67 & 327.78 & 408.41 & 570.15 & 532.26 \\
\hline Maharashtra & 578.59 & 453.59 & 362.25 & 484.89 & 665.90 & 631.85 \\
\hline Manipur & 16.82 & 5.98 & - & 578.11 & - & 641.13 \\
\hline Meghalaya & 19.52 & 4.88 & - & 503.32 & - & 745.73 \\
\hline Mizoram & 4.58 & 4.77 & - & 639.27 & - & 699.75 \\
\hline Nagaland & 17.33 & 3.61 & - & 687.30 & - & 782.93 \\
\hline Odisha & 324.55 & 60.35 & 325.79 & 407.78 & 528.49 & 497.31 \\
\hline Puducherry & 3.43 & 7.14 & - & 384.45 & - & 506.17 \\
\hline Punjab & 165.26 & 91.98 & 410.38 & 543.51 & 466.16 & 642.51 \\
\hline Rajasthan & 467.13 & 144.23 & 374.57 & 478.00 & 559.63 & 568.15 \\
\hline Sikkim & 5.01 & 0.68 & - & 531.50 & - & 741.68 \\
\hline Tamil Nadu & 334.83 & 311.40 & 351.86 & 441.69 & 547.42 & 559.77 \\
\hline Tripura & 27.67 & 5.99 & - & 450.49 & - & 555.70 \\
\hline Uttar Pradesh & 1416.26 & 381.98 & 365.84 & 435.14 & 483.26 & 532.12 \\
\hline Uttarakhand & 66.48 & 24.25 & 478.02 & 486.24 & 637.67 & 602.39 \\
\hline West Bengal & 605.33 & 237.44 & 382.82 & 445.38 & 449.32 & 572.51 \\
\hline All India & 7814.91 & 3142.33 & 356.30 & 446.68 & 538.60 & 578.80 \\
\hline
\end{tabular}

Note: Population totals are rounded up at two decimals. The above population has been used for computations in Table 2 . It has not been used in our other calculations using unit level data.

Source: Government of India (2007, 2009)

The states of Meghalaya, Nagaland and Uttarakhand indicate a decline in the incidence of poverty. The former two did not have a poverty line of their own as in the old method the poverty ratio of Assam was used. One also observes a decline in the incidence of poverty in the union territories of Andaman \& Nicobar Islands, Daman \& Diu and Lakshadweep. These used the poverty ratio of their neighbouring states in the old method and in the new method the incidences are independently computed by using the poverty lines of the neighbouring states. 
The maximum increase is for Goa (398 per cent; from 5.64 per cent to 28.09 per cent). It is to be noted that the old method used the poverty line of Maharashtra whereas the new method has a state-specific poverty line.

Increase in incidence of poverty is relatively higher for well-performing states (that is, those with higher per capita gross state domestic product, GSDP). For instance, head count ratio of poor in Punjab increases from 9 per cent in the old method to 22 per cent in the new method, a 13 percentage point increase. The correlation coefficient between the Per Capita Gross Domestic Product of major states and the percentage change in their rural poverty line is 0.5828 and it is significant at one per cent level.

As indicated earlier, the four states with the maximum share of rural poor in the old method (Uttar Pradesh, Bihar, Madhya Pradesh and West Bengal) have a reduction in their share of rural poor in the new method. The share of Maharashtra, the fifth largest in the old methodology, has increased and it has the third largest share in the new method.

Now, we take up some observations on urban areas. In the urban case as the incidence in poverty in the old method was a starting point the changes at the aggregate level will cancel out. In some states, it will increase and in the rest it will decrease.

In the states of Chhattisgarh, Karnataka, Madhya Pradesh, Maharashtra, Odisha and Uttarakhand the urban poverty line in the new method is lower than that in the old method. Needless to say, these are also the states where incidence of poverty has also declined. The other major states where incidence of urban poverty has declined are Andhra Pradesh, Kerala, Rajasthan and Tamil Nadu. The major states where urban poverty seems to have increased are Assam, Bihar, Gujarat, Haryana, Himachal Pradesh, Jammu \& Kashmir and Uttar Pradesh among others. As indicated earlier, these will have implications on allocation of resources for various welfare schemes, given a budget constraint. 
Table 4: Poverty and Inequality across States with Old and New Methods, 2004-05, Rural and Urban

\begin{tabular}{|c|c|c|c|c|c|c|c|c|c|c|c|c|c|c|c|c|}
\hline \multirow[t]{4}{*}{ State } & \multicolumn{8}{|c|}{ Rural } & \multicolumn{8}{|c|}{ Urban } \\
\hline & \multicolumn{6}{|c|}{ Poverty } & \multicolumn{2}{|c|}{ Inequality } & \multicolumn{6}{|c|}{ Poverty } & \multicolumn{2}{|c|}{ Inequality } \\
\hline & \multicolumn{3}{|c|}{ Old Method } & \multicolumn{3}{|c|}{ New Method } & \multirow[t]{2}{*}{ Old } & \multirow[t]{2}{*}{ New } & \multicolumn{3}{|c|}{ Old Method } & \multicolumn{3}{|c|}{ New Method } & \multirow[t]{2}{*}{ Old } & \multirow[t]{2}{*}{ New } \\
\hline & $\alpha=0$ & $\alpha=1$ & $\alpha=2$ & $\alpha=0$ & $\alpha=1$ & $\alpha=2$ & & & $\alpha=0$ & $\alpha=1$ & $\alpha=2$ & $\alpha=0$ & $\alpha=1$ & $\alpha=2$ & & \\
\hline Andaman \& Nicobar Is & 22.49 & 3.23 & 0.79 & 3.29 & 0.22 & 0.02 & 0.3360 & 0.3081 & 21.96 & 3.68 & 0.88 & 0.81 & 0.01 & 0.00 & 0.3756 & 0.3430 \\
\hline Andhra Pradesh & 10.47 & 1.95 & 0.68 & 32.29 & 6.97 & 2.27 & 0.2938 & 0.2677 & 27.36 & 5.74 & 1.80 & 23.37 & 4.81 & 1.49 & 0.3748 & 0.3627 \\
\hline Arunachal Pradesh & 21.97 & 4.31 & 1.33 & 33.55 & 7.41 & 2.45 & 0.2800 & 0.2619 & 3.43 & 0.46 & 0.11 & 23.53 & 4.64 & 1.25 & 0.2480 & 0.2351 \\
\hline Assam & 22.09 & 3.65 & 0.93 & 36.38 & 7.03 & 2.01 & 0.1986 & 0.1924 & 3.64 & 0.45 & 0.10 & 21.78 & 4.23 & 1.14 & 0.3201 & 0.3095 \\
\hline Bihar & 42.59 & 8.14 & 2.21 & 55.71 & 12.68 & 3.91 & 0.2077 & 0.1943 & 36.09 & 7.43 & 2.23 & 43.73 & 11.43 & 3.86 & 0.3330 & 0.3201 \\
\hline Chandigarh & 7.54 & 0.00 & 0.00 & 29.44 & 6.70 & 2.40 & 0.2465 & 0.2562 & 6.20 & 1.09 & 0.28 & 10.09 & 2.24 & 0.67 & 0.3608 & 0.3659 \\
\hline Chhattisgarh & 40.77 & 9.24 & 3.14 & 55.06 & 13.69 & 4.92 & 0.2982 & 0.2644 & 42.18 & 12.30 & 4.79 & 28.39 & 7.20 & 2.58 & 0.4392 & 0.3717 \\
\hline Dadra \& Nagar Haveli & 39.64 & 8.50 & 3.33 & 63.63 & 18.02 & 7.14 & 0.3532 & 0.3345 & 19.17 & 6.24 & 2.26 & 16.81 & 4.98 & 1.63 & 0.3003 & 0.3087 \\
\hline Daman \& Diu & 4.53 & 0.75 & 0.23 & 2.41 & 0.47 & 0.09 & 0.2630 & 0.2518 & 19.06 & 3.63 & 0.85 & 14.43 & 2.08 & 0.32 & 0.2524 & 0.2382 \\
\hline Delhi & 6.89 & 0.31 & 0.01 & 15.57 & 1.93 & 0.35 & 0.2779 & 0.2965 & 16.34 & 2.62 & 0.71 & 12.87 & 1.99 & 0.53 & 0.3362 & 0.3343 \\
\hline Goa & 5.64 & 0.34 & 0.05 & 28.09 & 5.56 & 1.66 & 0.3213 & 0.2984 & 19.71 & 4.64 & 1.80 & 22.21 & 4.30 & 1.54 & 0.4195 & 0.3568 \\
\hline Gujarat & 18.89 & 3.35 & 0.92 & 39.09 & 9.34 & 3.16 & 0.2731 & 0.2662 & 13.31 & 2.37 & 0.65 & 20.05 & 3.92 & 1.15 & 0.3098 & 0.3125 \\
\hline Haryana & 13.25 & 2.34 & 0.64 & 24.82 & 4.73 & 1.33 & 0.3396 & 0.3261 & 14.48 & 3.26 & 1.06 & 22.39 & 4.93 & 1.62 & 0.3656 & 0.3414 \\
\hline Himachal Pradesh & 10.53 & 1.60 & 0.38 & 24.97 & 4.22 & 1.12 & 0.3096 & 0.2893 & 3.19 & 0.86 & 0.33 & 4.55 & 1.07 & 0.41 & 0.3231 & 0.2803 \\
\hline Jammu \& Kashmir & 4.27 & 0.64 & 0.15 & 14.10 & 2.11 & 0.52 & 0.2473 & 0.2168 & 7.40 & 1.71 & 0.49 & 10.36 & 2.12 & 0.56 & 0.2476 & 0.2528 \\
\hline Jharkhand & 46.15 & 9.88 & 2.94 & 51.64 & 11.12 & 3.37 & 0.2275 & 0.2086 & 20.25 & 4.29 & 1.31 & 23.82 & 5.77 & 1.90 & 0.3552 & 0.3360 \\
\hline Karnataka & 20.67 & 2.86 & 0.64 & 37.49 & 6.51 & 1.67 & 0.2663 & 0.2457 & 32.61 & 8.73 & 3.25 & 25.88 & 6.19 & 2.13 & 0.3685 & 0.3687 \\
\hline Kerala & 13.20 & 2.76 & 0.97 & 20.19 & 4.37 & 1.47 & 0.3809 & 0.3469 & 19.99 & 4.55 & 1.56 & 18.39 & 4.04 & 1.33 & 0.4102 & 0.3956 \\
\hline Lakshadweep & 11.43 & 0.13 & 0.04 & 0.34 & 0.10 & 0.03 & 0.3115 & 0.2532 & 19.95 & 5.75 & 2.84 & 10.31 & 3.76 & 1.83 & 0.3939 & 0.2647 \\
\hline Madhya Pradesh & 36.79 & 8.01 & 2.52 & 53.59 & 12.57 & 4.16 & 0.2675 & 0.2518 & 42.72 & 12.07 & 4.62 & 35.05 & 8.59 & 2.93 & 0.3980 & 0.3676 \\
\hline Maharashtra & 29.57 & 6.31 & 1.99 & 47.54 & 11.87 & 4.23 & 0.3120 & 0.2874 & 32.10 & 9.13 & 3.56 & 25.62 & 6.48 & 2.29 & 0.3776 & 0.3688 \\
\hline Manipur & 22.01 & 2.92 & 0.57 & 39.28 & 5.71 & 1.26 & 0.1602 & 0.1523 & 3.59 & 0.28 & 0.04 & 34.51 & 5.12 & 1.03 & 0.1774 & 0.1650 \\
\hline Meghalaya & 21.95 & 2.69 & 0.52 & 13.98 & 1.40 & 0.23 & 0.1618 & 0.1497 & 3.62 & 0.34 & 0.06 & 24.68 & 2.80 & 0.53 & 0.2635 & 0.2612 \\
\hline Mizoram & 22.09 & 3.27 & 0.83 & 23.04 & 3.49 & 0.89 & 0.2010 & 0.1856 & 3.62 & 0.37 & 0.07 & 7.89 & 1.00 & 0.22 & 0.2490 & 0.2291 \\
\hline Nagaland & 22.05 & 2.79 & 0.55 & 10.02 & 1.02 & 0.19 & 0.2293 & 0.2056 & 3.30 & 0.24 & 0.03 & 4.26 & 0.54 & 0.10 & 0.2422 & 0.2336 \\
\hline Odisha & 46.91 & 12.11 & 4.33 & 60.78 & 17.37 & 6.63 & 0.2852 & 0.2659 & 44.72 & 13.40 & 5.41 & 37.59 & 9.60 & 3.50 & 0.3535 & 0.3402 \\
\hline Puducherry & 22.69 & 2.44 & 0.37 & 22.91 & 3.99 & 0.84 & 0.3471 & 0.3263 & 21.96 & 3.65 & 0.92 & 9.92 & 1.33 & 0.29 & 0.3156 & 0.3202 \\
\hline Punjab & 9.02 & 1.19 & 0.26 & 22.12 & 3.76 & 0.97 & 0.2942 & 0.2854 & 6.29 & 0.67 & 0.12 & 18.71 & 3.17 & 0.77 & 0.4021 & 0.3378 \\
\hline Rajasthan & 18.32 & 2.96 & 0.74 & 35.84 & 7.01 & 2.00 & 0.2496 & 0.2213 & 32.31 & 7.18 & 2.30 & 29.69 & 5.75 & 1.68 & 0.3715 & 0.3222 \\
\hline Sikkim & 22.07 & 3.47 & 0.76 & 31.77 & 5.62 & 1.43 & 0.2728 & 0.2539 & 3.44 & 0.71 & 0.25 & 25.95 & 3.35 & 0.89 & 0.2561 & 0.2447 \\
\hline Tamil Nadu & 22.99 & 3.80 & 1.00 & 37.54 & 7.43 & 2.13 & 0.3222 & 0.2758 & 22.46 & 4.70 & 1.46 & 19.74 & 4.09 & 1.25 & 0.3609 & 0.3644 \\
\hline Tripura & 22.08 & 3.38 & 0.84 & 44.46 & 9.58 & 2.90 & 0.2185 & 0.2114 & 3.47 & 0.43 & 0.09 & 22.47 & 3.80 & 0.96 & 0.3415 & 0.3134 \\
\hline Uttar Pradesh & 33.32 & 6.33 & 1.81 & 42.72 & 9.16 & 2.77 & 0.2902 & 0.2524 & 30.13 & 7.05 & 2.34 & 34.06 & 7.80 & 2.53 & 0.3691 & 0.3545 \\
\hline Uttarakhand & 40.65 & 7.77 & 2.11 & 35.13 & 5.80 & 1.41 & 0.2851 & 0.2394 & 36.50 & 8.47 & 2.59 & 26.20 & 5.09 & 1.41 & 0.3268 & 0.3163 \\
\hline West Bengal & 28.37 & 5.31 & 1.46 & 38.23 & 7.92 & 2.35 & 0.2738 & 0.2555 & 13.50 & 2.48 & 0.68 & 24.42 & 5.29 & 1.64 & 0.3833 & 0.3725 \\
\hline All India & 28.12 & 5.50 & 1.63 & 41.80 & 9.24 & 2.94 & 0.3045 & 0.2808 & 25.84 & 6.21 & 2.16 & 25.68 & 5.78 & 1.88 & 0.3764 & 0.3643 \\
\hline
\end{tabular}

Note: Calculations use poverty lines and assumptions given in official publications (see Table 3 and note in Table 1), but the state-specific incidences do not match, particularly for the old method.

Source: Unit level data, Schedule 1.0, NSS $61^{\text {st }}$ Round, 2004-05. 
Figure 1: Map Depicting Incidence of Poor across States in Rural India, 2004-05 (a) Old Method and (b) New Method

(1a) Old Method
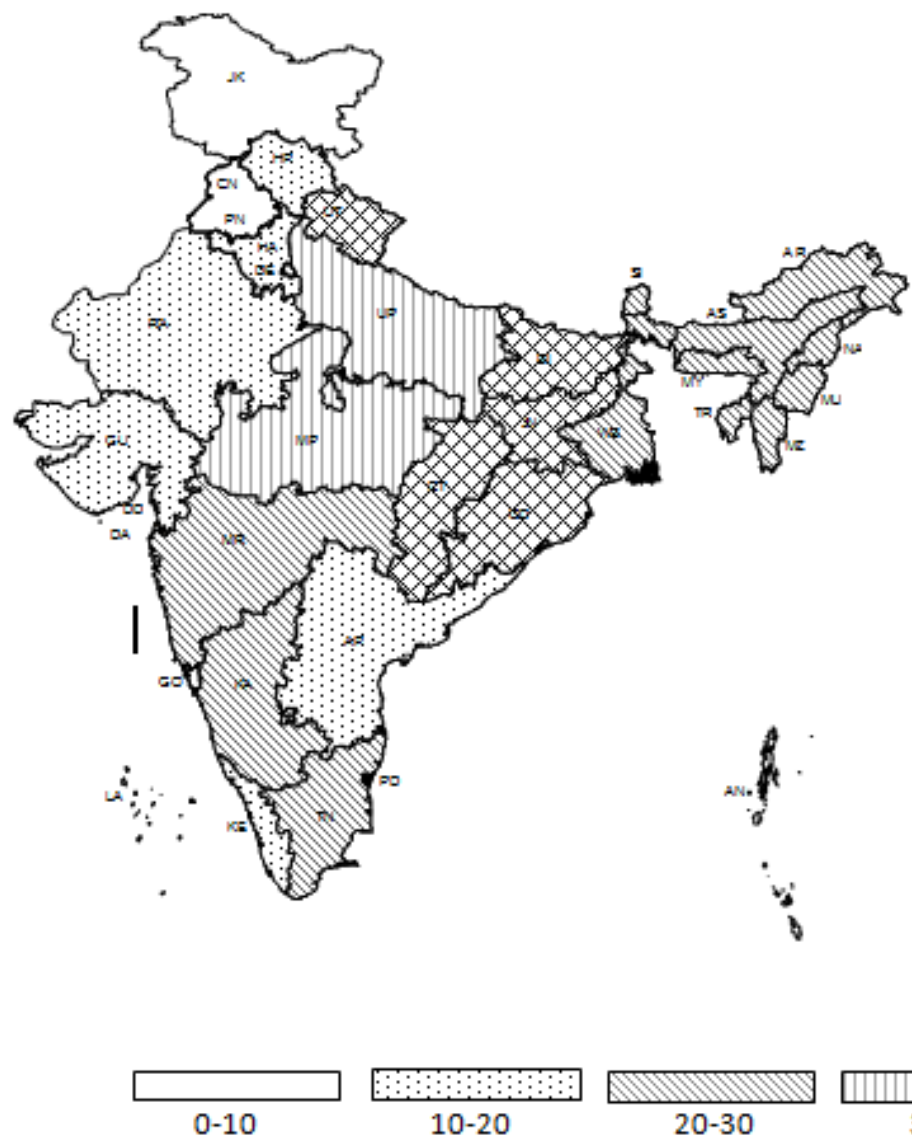

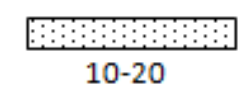

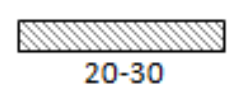

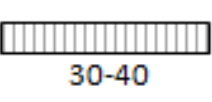

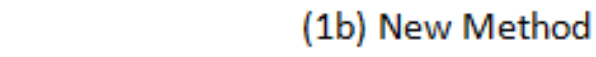

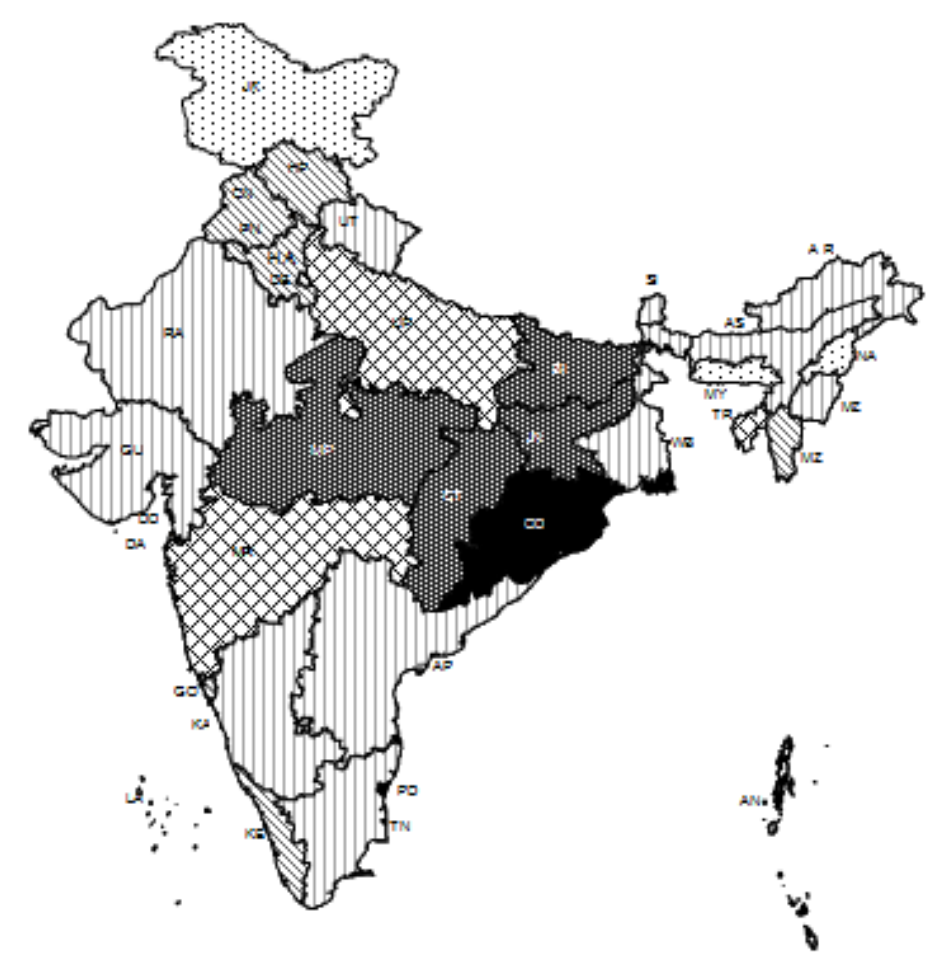

$P X X X X X X$
$50-60$
60-70 
Figure 2: Map Depicting Incidence of Poor across States in Urban India, 2004-05 (a) Old Method and (b) New Method

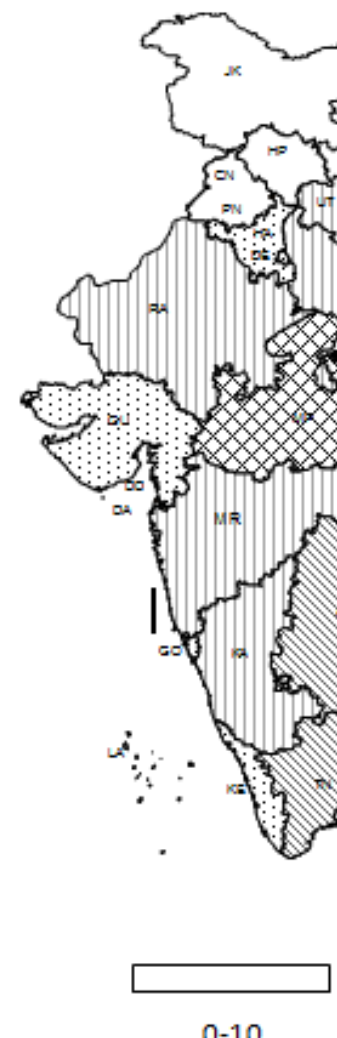

(2a) Old Method<smiles>[1H]</smiles>

.

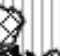

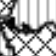

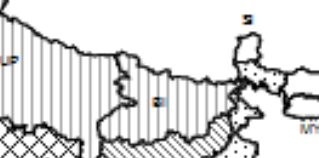

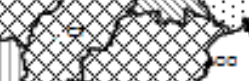
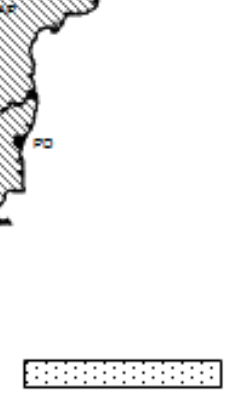

10-20
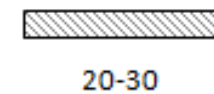
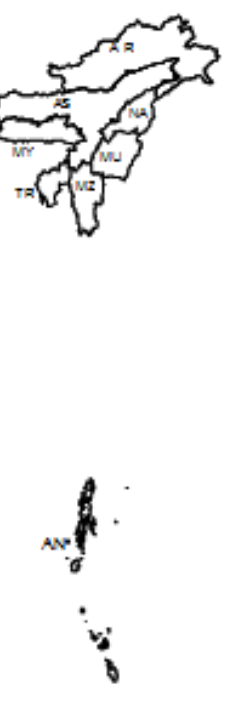

$-30$
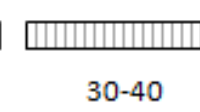

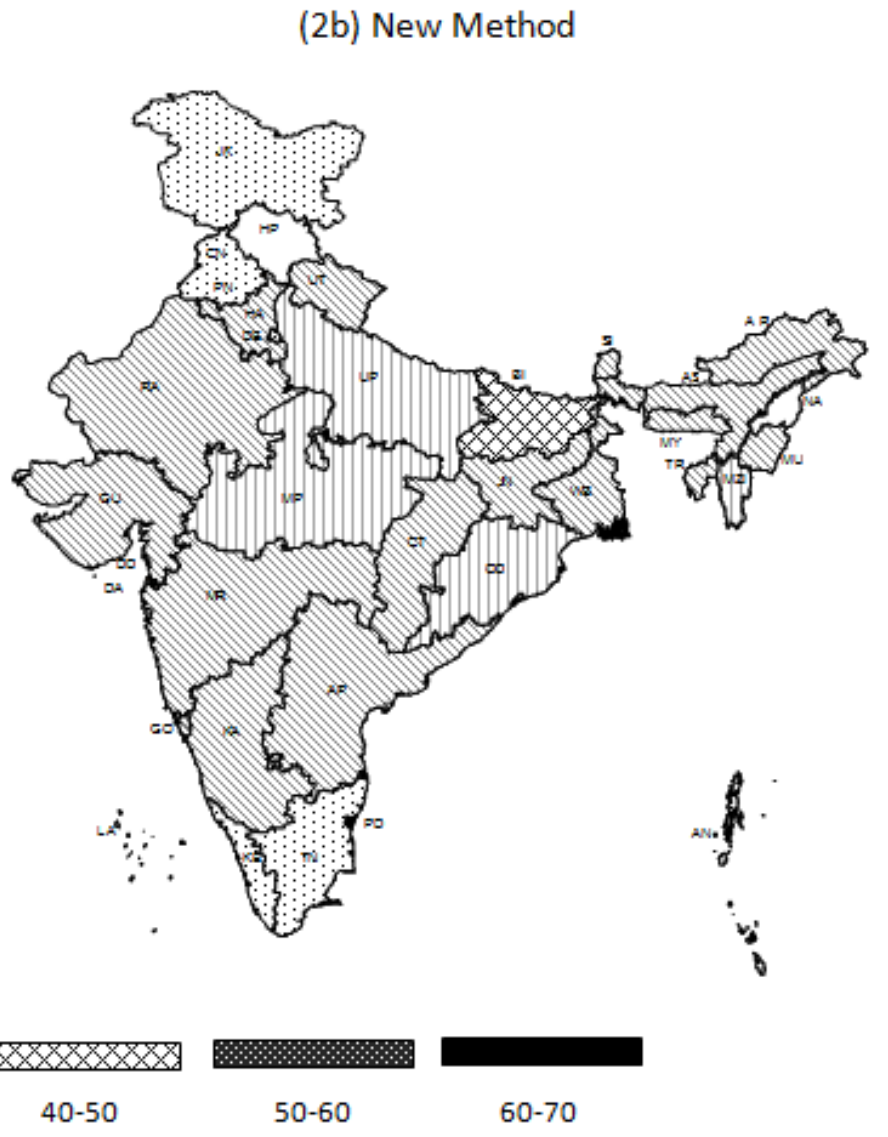


Figure 3: TIP and Lorenz Curves for India with Old and New Methods, 2004-05, Rural and Urban

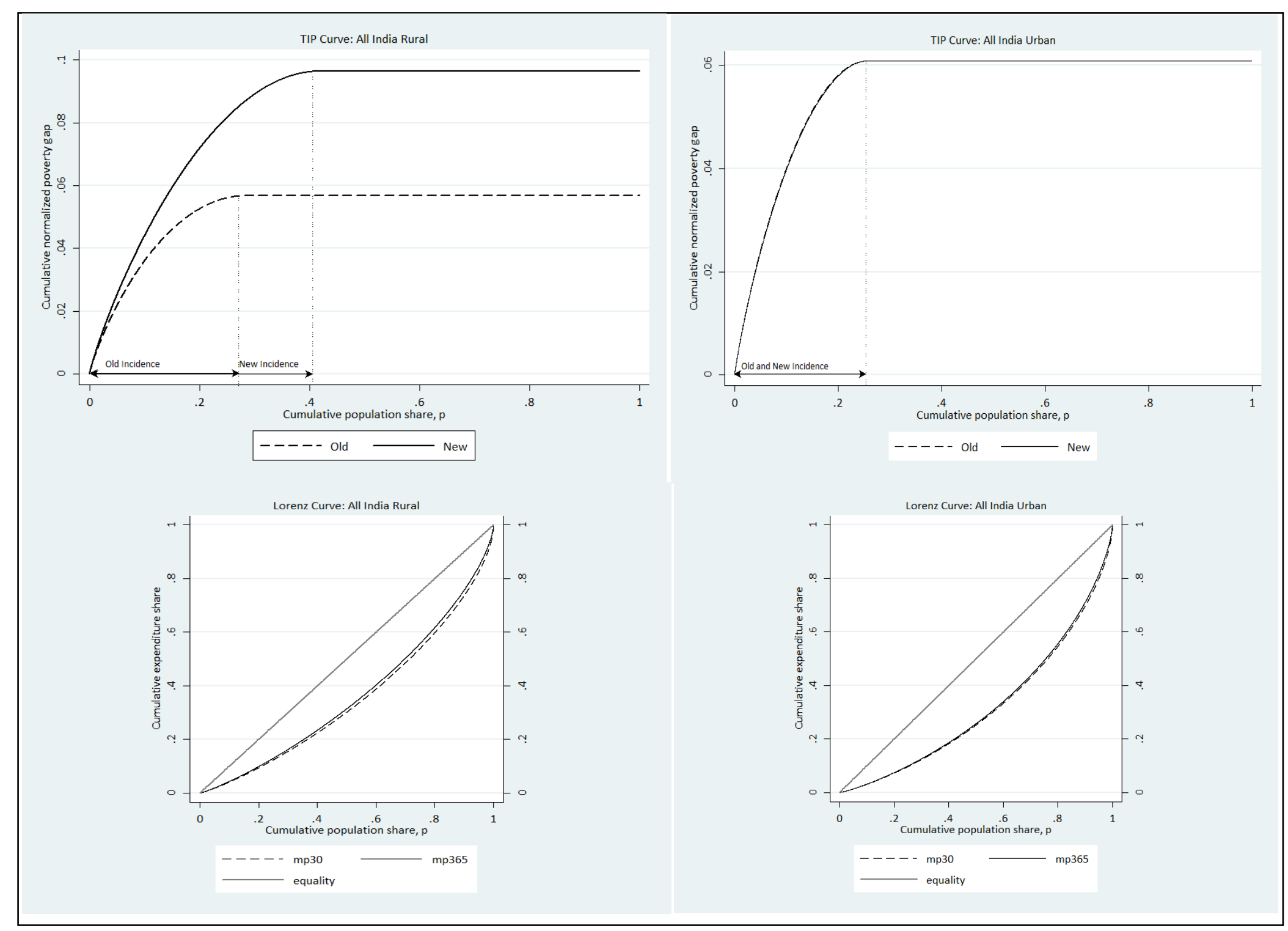




\section{Poverty and Inequality across Sub-groups of Population}

\subsection{NSS Regions}

The poorest two NSS regions of rural India in 2004-05 are southern and northern Odisha (headcount ratio or HCR of 81 per cent and 72 per cent respectively), see Table 5 . The two regions together include the undivided districts of Koraput, Bolangir and Kalahandi (the KBK districts that have received public policy and media attention for hunger and starvation deaths), and Kandhamal that came into discussion because of communal strife in recent years. They also are the mineral and resource-rich areas with a greater concentration of the tribal population. The remaining region from Odisha comprising the coastal districts also has incidence of poor which is greater than the all India average, which is 41.7 per cent, under the new method. For a discussion on poverty scenario in Odisha see Mishra (2009b).

Further, in the new method, there are 30 more rural regions where the incidence of poverty is greater than two-fifths. They include the hills region (one of the three) from Assam, the south western and inland southern regions (two of the four) from Andhra Pradesh, both the regions from Bihar, Chhattisgarh, Dadra \& Nagar Haveli, the eastern and dry areas regions (two of the five) from Gujarat, Jharkhand, the inland northern region (one of the four) from Karnataka, all the six regions from Madhya Pradesh, five of the six regions from Maharashtra (it excludes western Maharashtra region only), the hills region (one of the two) from Manipur, the southern and western regions (two of the four) from Rajasthan, the coastal northern region (one of the four) from Tamil Nadu, Tripura, eastern and southern regions (two of the four) from Uttar Pradesh, and eastern plains region (one of the four) from West Bengal.

When it comes to the share of poor across regions, it is eastern region of Uttar Pradesh that stands out (Table 6). ${ }^{6}$ Under the new method, it accounts for nearly 10 per cent of the country's rural poor. The two regions of Bihar, the northern region of Uttar Pradesh and Jharkhand account for another 22 per cent of the rural poor. The eastern plains region of West Bengal, Chhattisgarh, central region of Uttar Pradesh, inland northern region of

\footnotetext{
${ }^{6}$ For a discussion on poverty scenario in Uttar Pradesh see Pathak (2010).
} 
Karnataka, and northern region of Odisha account for another 14 per cent of the rural poor. This means that ten regions account for 46 per cent share of the rural poor.

In urban areas, inland central region of Maharashtra has the highest incidence of poor. ${ }^{7}$ Under the new method, it is 61 per cent. The hills region of Manipur has 51 per cent incidence of poverty. Eleven more regions (inland northern Karnataka, southern Uttar Pradesh, southern Odisha, inland northern Maharashtra, eastern plains of West Bengal, northern Madhya Pradesh, central Bihar, eastern Uttar Pradesh, inland eastern Maharashtra and south western Andhra Pradesh) have poverty incidence greater than two-fifths. Including all these, a total of 38 regions have poverty incidence greater than 25 per cent.

With regard to share of poor in urban areas, western Uttar Pradesh has the highest share. In the new method it is 8 per cent. This along with inland northern of Karnataka, central plains of West Bengal, eastern Uttar Pradesh and central Bihar account for 25 per cent share of urban poor. Inland western, inland eastern and inland central regions of Maharashtra accounting for ten per cent of the urban poor, which increases to more than 18 per cent if we include the other three regions of Maharashtra.

\footnotetext{
${ }^{7}$ For a discussion on socio-economic inequities and calorie deprivation in Maharashtra see Mishra (2009a) and Mishra and Hari (2009) respectively.
} 
Table 5: Poverty and Inequality across NSS Regions with Old and New Methods, 2004-05, Rural and Urban

\begin{tabular}{|c|c|c|c|c|c|c|c|c|c|c|c|c|c|c|c|c|c|}
\hline \multicolumn{9}{|c|}{ Rural } & \multicolumn{9}{|c|}{ Urban } \\
\hline \multirow{3}{*}{$\begin{array}{l}\text { NSS } \\
\text { Region }\end{array}$} & \multicolumn{6}{|c|}{ Poverty } & \multicolumn{2}{|c|}{ Inequality } & \multirow{3}{*}{$\begin{array}{l}\text { NSS } \\
\text { Region }\end{array}$} & \multicolumn{6}{|c|}{ Poverty } & \multicolumn{2}{|c|}{ Inequality } \\
\hline & \multicolumn{3}{|c|}{ Old Method } & \multicolumn{3}{|c|}{ New Method } & \multirow[t]{2}{*}{ Old } & \multirow[t]{2}{*}{ New } & & \multicolumn{3}{|c|}{ Old Method } & \multicolumn{3}{|c|}{ New Method } & \multirow[t]{2}{*}{ Old } & \multirow[t]{2}{*}{ New } \\
\hline & $\alpha=0$ & $\alpha=1$ & $\alpha=2$ & $\alpha=0$ & $\alpha=1$ & $\alpha=2$ & & & & $\alpha=0$ & $\alpha=1$ & $\alpha=2$ & $\alpha=0$ & $\alpha=1$ & $\alpha=2$ & & \\
\hline AN1 & 22.49 & 3.23 & 0.79 & 3.29 & 0.22 & 0.02 & 0.3360 & 0.3081 & AN1 & 21.96 & 3.68 & 0.88 & 0.81 & 0.01 & 0.00 & 0.3756 & 0.3430 \\
\hline AP1 & 6.97 & 1.53 & 0.63 & 23.58 & 5.26 & 1.85 & 0.2826 & 0.2624 & AP1 & 21.93 & 4.57 & 1.49 & 19.53 & 4.03 & 1.29 & 0.3778 & 0.3517 \\
\hline AP2 & 11.05 & 1.66 & 0.49 & 34.38 & 6.73 & 1.98 & 0.2931 & 0.2611 & AP2 & 28.19 & 5.48 & 1.57 & 21.07 & 3.96 & 1.06 & 0.3854 & 0.3811 \\
\hline AP3 & 22.44 & 4.38 & 1.44 & 54.45 & 12.78 & 4.27 & 0.2697 & 0.2443 & AP3 & 41.34 & 10.18 & 3.56 & 40.45 & 9.21 & 3.09 & 0.3252 & 0.3335 \\
\hline AP4 & 11.52 & 2.37 & 0.81 & 40.87 & 9.68 & 3.26 & 0.3155 & 0.2863 & AP4 & 37.20 & 8.11 & 2.42 & 34.52 & 7.74 & 2.61 & 0.2885 & 0.3234 \\
\hline AS1 & 20.74 & 3.14 & 0.70 & 35.45 & 6.55 & 1.71 & 0.2089 & 0.2001 & AS1 & 4.01 & 0.45 & 0.08 & 21.15 & 4.55 & 1.26 & 0.3601 & 0.3141 \\
\hline AS2 & 22.85 & 4.04 & 1.11 & 35.55 & 7.32 & 2.23 & 0.1927 & 0.1886 & AS2 & 3.53 & 0.48 & 0.12 & 21.23 & 3.95 & 1.08 & 0.2919 & 0.3068 \\
\hline AS3 & 23.24 & 2.48 & 0.43 & 58.12 & 7.21 & 1.38 & 0.1216 & 0.1182 & AS3 & 1.43 & 0.06 & 0.00 & 36.69 & 5.37 & 1.00 & 0.2091 & 0.2137 \\
\hline BI1 & 41.60 & 7.80 & 2.09 & 53.74 & 12.21 & 3.77 & 0.2134 & 0.1987 & BI1 & 38.60 & 9.43 & 3.01 & 45.32 & 12.96 & 4.72 & 0.3064 & 0.3059 \\
\hline $\mathrm{B} / 2$ & 44.11 & 8.67 & 2.41 & 58.72 & 13.39 & 4.13 & 0.1972 & 0.1859 & $\mathrm{~B} 12$ & 35.12 & 6.64 & 1.93 & 43.10 & 10.83 & 3.52 & 0.3405 & 0.3241 \\
\hline CN1 & 7.54 & 0.00 & 0.00 & 15.47 & 3.74 & 1.29 & 0.2465 & 0.2562 & CN1 & 6.20 & 1.09 & 0.28 & 10.09 & 2.24 & 0.67 & 0.3608 & 0.3659 \\
\hline CT1 & 40.77 & 9.24 & 3.14 & 55.06 & 13.69 & 4.92 & 0.2982 & 0.2644 & $\mathrm{CT} 1$ & 34.62 & 10.64 & 4.08 & 28.39 & 7.20 & 2.58 & 0.4392 & 0.3717 \\
\hline DA1 & 39.64 & 8.50 & 3.33 & 63.63 & 18.02 & 7.14 & 0.3532 & 0.3345 & DA1 & 19.17 & 6.24 & 2.26 & 16.81 & 4.98 & 1.63 & 0.3003 & 0.3087 \\
\hline DE1 & 6.89 & 0.31 & 0.01 & 15.57 & 1.93 & 0.35 & 0.2779 & 0.2965 & DE1 & 16.34 & 2.62 & 0.71 & 12.87 & 1.99 & 0.53 & 0.3362 & 0.3343 \\
\hline GO1 & 5.64 & 0.34 & 0.05 & 28.09 & 5.56 & 1.66 & 0.3213 & 0.2984 & GO1 & 19.71 & 4.64 & 1.80 & 22.21 & 4.30 & 1.54 & 0.4195 & 0.3568 \\
\hline GU1 & 26.15 & 4.85 & 1.49 & 51.18 & 13.23 & 4.63 & 0.2704 & 0.2672 & GU1 & 15.64 & 2.99 & 0.99 & 24.94 & 5.08 & 1.61 & 0.2768 & 0.3038 \\
\hline GU2 & 21.57 & 3.28 & 0.76 & 38.03 & 9.47 & 3.08 & 0.2893 & 0.2967 & GU2 & 16.48 & 3.06 & 0.79 & 21.93 & 4.76 & 1.41 & 0.3442 & 0.3436 \\
\hline GU3 & 17.93 & 3.18 & 0.81 & 39.79 & 9.31 & 3.01 & 0.3075 & 0.2861 & GU3 & 8.04 & 1.43 & 0.42 & 14.08 & 2.55 & 0.71 & 0.2996 & 0.3085 \\
\hline GU4 & 24.97 & 4.94 & 1.42 & 48.34 & 11.63 & 4.28 & 0.2159 & 0.2236 & GU4 & 28.49 & 4.90 & 1.50 & 27.47 & 6.59 & 2.17 & 0.2535 & 0.2662 \\
\hline GU5 & 2.71 & 0.37 & 0.06 & 16.70 & 2.43 & 0.57 & 0.2181 & 0.2041 & GU5 & 12.45 & 2.02 & 0.52 & 22.50 & 3.72 & 1.02 & 0.2496 & 0.2321 \\
\hline HA1 & 12.69 & 2.12 & 0.54 & 22.95 & 4.36 & 1.20 & 0.3617 & 0.3612 & HA1 & 11.21 & 2.78 & 0.98 & 18.16 & 3.93 & 1.40 & 0.3560 & 0.3464 \\
\hline $\mathrm{HA} 2$ & 14.14 & 2.69 & 0.78 & 27.81 & 5.32 & 1.53 & 0.2873 & 0.2394 & $\mathrm{HA} 2$ & 23.32 & 4.57 & 1.26 & 33.86 & 7.63 & 2.22 & 0.3785 & 0.2888 \\
\hline HP1 & 10.53 & 1.60 & 0.38 & 24.97 & 4.22 & 1.12 & 0.3096 & 0.2893 & HP1 & 3.19 & 0.86 & 0.33 & 4.55 & 1.07 & 0.41 & 0.3231 & 0.2803 \\
\hline JK1 & 2.93 & 0.32 & 0.05 & 4.97 & 0.95 & 0.25 & 0.2552 & 0.2275 & JK1 & 4.13 & 0.98 & 0.31 & 4.65 & 0.90 & 0.26 & 0.2667 & 0.2736 \\
\hline JK2 & 9.26 & 1.64 & 0.51 & 32.72 & 4.39 & 1.03 & 0.1465 & 0.1510 & JK2 & 3.95 & 0.56 & 0.12 & 9.26 & 1.04 & 0.18 & 0.1876 & 0.2112 \\
\hline JK3 & 3.96 & 0.59 & 0.13 & 14.63 & 2.19 & 0.54 & 0.2382 & 0.2025 & JK3 & 9.20 & 2.14 & 0.60 & 13.19 & 2.78 & 0.73 & 0.2196 & 0.2147 \\
\hline JN1 & 46.15 & 9.88 & 2.94 & 51.64 & 11.12 & 3.37 & 0.2275 & 0.2086 & JN1 & 20.25 & 4.29 & 1.31 & 23.82 & 5.77 & 1.90 & 0.3552 & 0.3360 \\
\hline
\end{tabular}


Table 5: Poverty and Inequality across NSS Regions with Old and New Methods, 2004-05, Rural and Urban

\begin{tabular}{|c|c|c|c|c|c|c|c|c|c|c|c|c|c|c|c|c|c|}
\hline \multicolumn{9}{|c|}{ Rural } & \multicolumn{9}{|c|}{ Urban } \\
\hline \multirow{3}{*}{$\begin{array}{l}\text { NSS } \\
\text { Region }\end{array}$} & \multicolumn{6}{|c|}{ Poverty } & \multicolumn{2}{|c|}{ Inequality } & \multirow{3}{*}{$\begin{array}{l}\text { NSS } \\
\text { Region }\end{array}$} & \multicolumn{6}{|c|}{ Poverty } & \multicolumn{2}{|c|}{ Inequality } \\
\hline & \multicolumn{3}{|c|}{ Old Method } & \multicolumn{3}{|c|}{ New Method } & \multirow[t]{2}{*}{ Old } & \multirow[t]{2}{*}{ New } & & \multicolumn{3}{|c|}{ Old Method } & \multicolumn{3}{|c|}{ New Method } & \multirow[t]{2}{*}{ Old } & \multirow[t]{2}{*}{ New } \\
\hline & $\alpha=0$ & $\alpha=1$ & $\alpha=2$ & $\alpha=0$ & $\alpha=1$ & $\alpha=2$ & & & & $\alpha=0$ & $\alpha=1$ & $\alpha=2$ & $\alpha=0$ & $\alpha=1$ & $\alpha=2$ & & \\
\hline KA1 & 20.26 & 3.04 & 0.75 & 26.98 & 6.43 & 2.04 & 0.3821 & 0.3151 & KA1 & 42.88 & 12.03 & 4.07 & 38.16 & 8.57 & 2.55 & 0.4453 & 0.4281 \\
\hline KA2 & 5.10 & 0.55 & 0.07 & 17.81 & 2.00 & 0.38 & 0.2313 & 0.2211 & $\mathrm{KA} 2$ & 28.96 & 5.34 & 1.38 & 20.49 & 3.16 & 0.76 & 0.2743 & 0.2800 \\
\hline KA3 & 15.15 & 1.72 & 0.35 & 27.47 & 3.98 & 0.90 & 0.2540 & 0.2484 & KA3 & 14.07 & 2.71 & 0.84 & 7.91 & 1.50 & 0.45 & 0.3335 & 0.3391 \\
\hline KA4 & 27.35 & 4.00 & 0.90 & 49.60 & 8.97 & 2.33 & 0.2296 & 0.2036 & KA4 & 57.04 & 17.01 & 6.71 & 49.47 & 12.73 & 4.58 & 0.3238 & 0.3049 \\
\hline KE1 & 21.12 & 4.31 & 1.47 & 30.31 & 6.76 & 2.30 & 0.3550 & 0.3138 & KE1 & 33.49 & 8.94 & 3.33 & 30.88 & 8.08 & 2.94 & 0.4235 & 0.3813 \\
\hline LA1 & 11.43 & 0.13 & 0.04 & 0.34 & 0.10 & 0.03 & 0.3115 & 0.2532 & LA1 & 19.95 & 5.75 & 2.84 & 10.31 & 3.76 & 1.83 & 0.3939 & 0.2647 \\
\hline MP1 & 48.02 & 11.11 & 3.44 & 59.72 & 14.22 & 4.51 & 0.2508 & 0.2361 & MP1 & 48.83 & 14.85 & 6.30 & 28.29 & 7.18 & 2.44 & 0.3093 & 0.3050 \\
\hline MP2 & 50.40 & 12.11 & 4.17 & 64.53 & 17.67 & 6.62 & 0.2521 & 0.2460 & MP2 & 32.62 & 9.47 & 3.52 & 36.63 & 10.45 & 4.08 & 0.3284 & 0.3445 \\
\hline MP3 & 25.09 & 5.12 & 1.67 & 42.10 & 9.41 & 3.10 & 0.3029 & 0.2886 & MP3 & 47.55 & 12.81 & 4.91 & 28.55 & 6.81 & 2.18 & 0.4615 & 0.4017 \\
\hline MP4 & 49.45 & 11.56 & 3.71 & 64.46 & 16.91 & 6.04 & 0.2522 & 0.2312 & MP4 & 43.65 & 11.05 & 3.65 & 39.62 & 9.03 & 3.10 & 0.3380 & 0.3075 \\
\hline MP5 & 23.78 & 3.98 & 1.05 & 53.22 & 10.46 & 2.93 & 0.2120 & 0.2032 & MP5 & 57.14 & 15.31 & 5.78 & 38.99 & 8.54 & 2.50 & 0.3321 & 0.3195 \\
\hline MP6 & 22.87 & 3.64 & 0.92 & 40.10 & 7.34 & 2.06 & 0.2185 & 0.2128 & MP6 & 34.62 & 10.64 & 4.08 & 44.50 & 10.77 & 3.66 & 0.3632 & 0.3298 \\
\hline MR1 & 26.03 & 5.71 & 1.88 & 44.03 & 11.49 & 4.36 & 0.3204 & 0.3151 & MR1 & 14.51 & 2.75 & 0.78 & 7.86 & 1.36 & 0.35 & 0.3597 & 0.3394 \\
\hline MR3 & 37.94 & 8.74 & 3.06 & 54.91 & 15.29 & 6.00 & 0.2846 & 0.2676 & MR3 & 48.17 & 15.30 & 6.54 & 44.84 & 12.80 & 5.18 & 0.3619 & 0.3478 \\
\hline MR4 & 42.64 & 9.72 & 3.05 & 61.30 & 16.39 & 5.88 & 0.3277 & 0.2668 & MR4 & 66.17 & 25.03 & 11.19 & 60.29 & 18.37 & 7.08 & 0.3395 & 0.3295 \\
\hline MR5 & 33.45 & 6.14 & 1.62 & 53.81 & 12.93 & 4.19 & 0.2822 & 0.2623 & MR5 & 46.88 & 14.74 & 5.96 & 41.22 & 11.31 & 4.10 & 0.3708 & 0.3604 \\
\hline MR6 & 47.05 & 12.03 & 4.41 & 63.13 & 19.96 & 8.26 & 0.3422 & 0.3265 & MR6 & 35.77 & 10.53 & 4.27 & 31.44 & 8.34 & 3.23 & 0.2902 & 0.3026 \\
\hline MU1 & 13.02 & 1.50 & 0.27 & 24.53 & 3.02 & 0.58 & 0.1655 & 0.1529 & MU1 & 3.17 & 0.23 & 0.03 & 33.55 & 4.78 & 0.93 & 0.1762 & 0.1627 \\
\hline MU2 & 32.60 & 4.59 & 0.92 & 56.65 & 8.87 & 2.05 & 0.1276 & 0.1248 & MU2 & 10.91 & 1.16 & 0.16 & 51.36 & 11.05 & 2.88 & 0.1811 & 0.1944 \\
\hline MY1 & 21.95 & 2.69 & 0.52 & 13.98 & 1.40 & 0.23 & 0.1618 & 0.1497 & MY1 & 3.62 & 0.34 & 0.06 & 24.68 & 2.80 & 0.53 & 0.2635 & 0.2612 \\
\hline MZ1 & 22.09 & 3.27 & 0.83 & 23.04 & 3.49 & 0.89 & 0.2010 & 0.1856 & MZ1 & 3.62 & 0.37 & 0.07 & 7.89 & 1.00 & 0.22 & 0.2490 & 0.2291 \\
\hline NA1 & 22.05 & 2.79 & 0.55 & 10.02 & 1.02 & 0.19 & 0.2293 & 0.2056 & NA1 & 3.30 & 0.24 & 0.03 & 4.26 & 0.54 & 0.10 & 0.2422 & 0.2336 \\
\hline OD1 & 27.39 & 5.34 & 1.55 & 44.64 & 9.52 & 2.98 & 0.2561 & 0.2311 & OD1 & 44.11 & 12.27 & 4.72 & 36.99 & 8.90 & 3.08 & 0.3426 & 0.3382 \\
\hline OD2 & 72.66 & 24.31 & 10.04 & 80.70 & 30.32 & 13.67 & 0.2678 & 0.2612 & OD2 & 55.03 & 19.73 & 9.19 & 46.39 & 15.11 & 6.46 & 0.4664 & 0.3915 \\
\hline OD3 & 59.07 & 14.58 & 4.98 & 71.58 & 20.88 & 7.72 & 0.2812 & 0.2700 & OD3 & 42.90 & 13.22 & 5.32 & 36.12 & 9.10 & 3.28 & 0.3339 & 0.3281 \\
\hline PD1 & 22.69 & 2.44 & 0.37 & 22.91 & 3.99 & 0.84 & 0.3471 & 0.3263 & PD1 & 21.96 & 3.65 & 0.92 & 9.92 & 1.33 & 0.29 & 0.3156 & 0.3202 \\
\hline PN1 & 4.37 & 0.51 & 0.08 & 15.66 & 2.12 & 0.44 & 0.2825 & 0.2799 & PN1 & 5.11 & 0.51 & 0.08 & 16.16 & 2.40 & 0.54 & 0.4147 & 0.3310 \\
\hline PN2 & 14.60 & 2.00 & 0.47 & 29.87 & 5.71 & 1.61 & 0.3047 & 0.2835 & PN2 & 8.78 & 1.02 & 0.21 & 24.07 & 4.80 & 1.24 & 0.3674 & 0.3473 \\
\hline
\end{tabular}


Table 5: Poverty and Inequality across NSS Regions with Old and New Methods, 2004-05, Rural and Urban

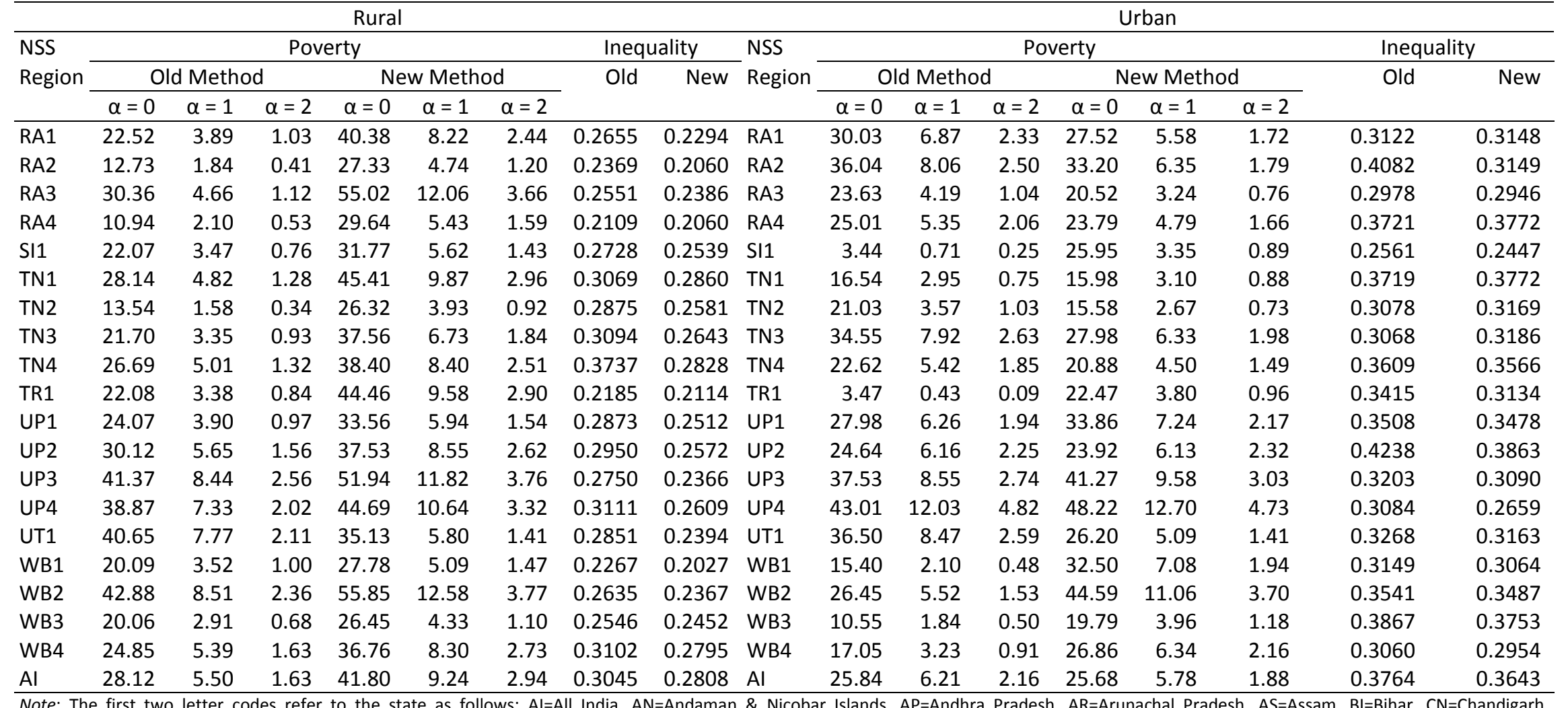

Note: The first two letter codes refer to the state as follows: Al=All India, AN=Andaman \& Nicobar Islands, AP=Andhra Pradesh, AR=Arunachal Pradesh, AS=Assam, Bl=Bihar, CN=Chandigarh, $\mathrm{CT}=$ Chhattisgarh, DA=Dadra \& Nagar Haveli, DD=Daman \& Diu, DE=Delhi, GO=Goa, GU=Gujarat, HA=Haryana, HP=Himachal Pradesh, JK=Jammu \& Kashmir, JN=Jharkhand, KA=Karnataka, KE=Kerala, $\mathrm{LA}=$ Lakshadweep, MP=Madhya Pradesh, MR=Maharashtra, MU=Manipur, MY=Meghalaya, MZ=Mizoran, NA=Nagaland, OD=Odisha, PD=Puducherry, PN=Punjab, RA=Rajasthan, SI=Sikkim, TN=Tamil Nadu, TR=Tripura, UP=Uttar Pradesh, UT=Uttarakhand, and WB=West Bengal. And the number refers to the region within the state. In those states with more than one region they refer to the following: AP1=Coastal, AP2=Inland Northern, AP3=South Western, AP4=Inland Southern, AS1=Plains Eastern, AS2=Plains Western, AS3=Hills, BI1=Northern, BI2=Central, GU1=Eastern, GU2=Plains Northern, GU3=Plains Southern, GU4=Dry Areas, GU5=Saurashtra, HA1=Eastern, HA2=Western, JK1=Mountainous, JK2=Outer Hills, JK3=Jhelam Valley, KA1=Coastal \& Ghats, KA2=Inland Eastern, KA3=Inland Southern, KA4=Inland Northern, KE1=Northern, KE2=Southern, MP1=Vindhya, MP2=Central, MP3=Malwa, MP4=South, MP5=South Western, MP6=Northern, MR1=Coastal, MR2=Inland Western, MR3=Inland Northern, MR4=Inland Central, MR5=Inland Eastern, MR6=Eastern, MU1=Plains, MU2=Hills, OD1=Coastal, OD2=Southern, OD3=Northern, PN1=Northern, PN2=Southern, RA1=Western, RA2=North Eastern, RA3=Southern, RA4=South Eastern, TN1=Coastal Northern, TN2=Coastal, TN3=Southern, TN4=Inland, UP1=Western, UP2=Central, UP3=Eastern, UP4=Southern, WB1=Himalayan, WB2=Eastern Plains, WB3=Central Plains and WB4=Western Plains. Al refers to All-India. In the old method, there are no independent estimates for 12 smaller states/union territories; poverty ratio of a neighbouring reference state has been used. For details, see notes in Tables 1 and 4.

Source: Unit level data, Schedule 1.0, NSS 61 ${ }^{\text {st }}$ Round, 2004-05. 
Table 6: Share of Poor across NSS Regions, Old and New Methods, 2004-05, Rural and Urban

\begin{tabular}{|c|c|c|c|c|c|c|c|c|c|}
\hline \multicolumn{5}{|c|}{ Rural } & \multicolumn{5}{|c|}{ Urban } \\
\hline \multirow{2}{*}{$\begin{array}{l}\text { NSS } \\
\text { Region }\end{array}$} & \multicolumn{2}{|c|}{ Share of Poor } & \multicolumn{2}{|c|}{ Rank } & \multirow{2}{*}{$\begin{array}{l}\text { NSS } \\
\text { Region }\end{array}$} & \multicolumn{2}{|c|}{ Share of Poor } & \multicolumn{2}{|c|}{ Rank } \\
\hline & Old (\%) & New (\%) & Old & New & & Old (\%) & New (\%) & Old & New \\
\hline UP3 & 11.444 & 9.694 & 1 & 1 & UP1 & 6.643 & 8.218 & 1 & 1 \\
\hline BI1 & 9.137 & 7.965 & 2 & 2 & KA4 & 5.078 & 4.502 & 2 & 2 \\
\hline $\mathrm{BI} 2$ & 6.318 & 5.675 & 3 & 3 & WB3 & 2.277 & 4.369 & 18 & 3 \\
\hline UP1 & 5.310 & 4.994 & 4 & 4 & UP3 & 3.752 & 4.219 & 4 & 4 \\
\hline JN1 & 4.677 & 3.530 & 5 & 5 & $\mathrm{BI} 2$ & 2.883 & 3.619 & 11 & 5 \\
\hline WB2 & 3.724 & 3.272 & 6 & 6 & MR2 & 4.218 & 3.306 & 3 & 6 \\
\hline CT1 & 3.245 & 2.956 & 8 & 7 & MR5 & 3.591 & 3.229 & 5 & 7 \\
\hline UP2 & 3.445 & 2.896 & 7 & 8 & MR4 & 3.461 & 3.224 & 7 & 8 \\
\hline KA4 & 2.249 & 2.751 & 12 & 9 & RA2 & 3.327 & 3.134 & 8 & 9 \\
\hline OR3 & 3.044 & 2.489 & 9 & 10 & TN1 & 2.690 & 2.656 & 13 & 10 \\
\hline MR4 & 2.479 & 2.404 & 10 & 11 & UP2 & 2.532 & 2.513 & 15 & 11 \\
\hline AP2 & 1.068 & 2.242 & 28 & 12 & AP1 & 2.673 & 2.435 & 14 & 12 \\
\hline OR1 & 1.873 & 2.060 & 15 & 13 & TN3 & 2.890 & 2.393 & 10 & 13 \\
\hline RA1 & 1.666 & 2.015 & 17 & 14 & DE1 & 2.923 & 2.355 & 9 & 14 \\
\hline MP1 & 2.279 & 1.912 & 11 & 15 & MR3 & 2.356 & 2.242 & 17 & 15 \\
\hline AP1 & 0.806 & 1.840 & 35 & 16 & AP2 & 2.767 & 2.115 & 12 & 16 \\
\hline WB3 & 1.959 & 1.742 & 14 & 17 & MR1 & 3.547 & 1.964 & 6 & 17 \\
\hline MR5 & 1.518 & 1.648 & 19 & 18 & JN1 & 1.615 & 1.942 & 26 & 18 \\
\hline RA2 & 1.113 & 1.612 & 27 & 19 & WB2 & 1.118 & 1.927 & 33 & 19 \\
\hline MP4 & 1.822 & 1.602 & 16 & 20 & TN4 & 2.039 & 1.925 & 20 & 20 \\
\hline AS2 & 1.500 & 1.574 & 20 & 21 & GU2 & 1.380 & 1.878 & 27 & 21 \\
\hline WB4 & 1.567 & 1.564 & 18 & 22 & MP3 & 2.082 & 1.863 & 19 & 22 \\
\hline OR2 & 1.997 & 1.496 & 13 & 23 & CT1 & 2.433 & 1.675 & 16 & 23 \\
\hline MP3 & 1.234 & 1.398 & 23 & 24 & RA1 & 1.704 & 1.597 & 24 & 24 \\
\hline TN1 & 1.234 & 1.343 & 24 & 25 & MP6 & 1.949 & 1.552 & 21 & 25 \\
\hline GU1 & 1.010 & 1.333 & 30 & 26 & BI1 & 1.238 & 1.486 & 30 & 26 \\
\hline MR3 & 1.363 & 1.331 & 21 & 27 & OR1 & 1.618 & 1.387 & 25 & 27 \\
\hline MR2 & 0.706 & 1.320 & 39 & 28 & GU5 & 0.746 & 1.379 & 41 & 28 \\
\hline MP2 & 1.292 & 1.116 & 22 & 29 & MP2 & 1.787 & 1.371 & 22 & 29 \\
\hline RA3 & 0.864 & 1.057 & 33 & 30 & UP4 & 1.115 & 1.278 & 34 & 30 \\
\hline AP3 & 0.610 & 0.999 & 44 & 31 & PU1 & 0.389 & 1.257 & 49 & 31 \\
\hline MP5 & 0.660 & 0.997 & 42 & 32 & KE1 & 1.237 & 1.167 & 31 & 32 \\
\hline TN4 & 1.012 & 0.982 & 29 & 33 & HA1 & 0.703 & 1.165 & 43 & 33 \\
\hline AS1 & 0.849 & 0.979 & 34 & 34 & GU3 & 0.645 & 1.156 & 44 & 34 \\
\hline UP4 & 1.231 & 0.955 & 25 & 35 & AP3 & 1.131 & 1.131 & 32 & 35 \\
\hline KE1 & 0.982 & 0.951 & 31 & 36 & MP4 & 1.283 & 1.093 & 28 & 36 \\
\hline TN3 & 0.793 & 0.926 & 36 & 37 & OR3 & 1.268 & 1.092 & 29 & 37 \\
\hline KA3 & 0.725 & 0.888 & 38 & 38 & MP5 & 1.098 & 1.003 & 35 & 38 \\
\hline MR1 & 0.766 & 0.874 & 37 & 39 & KA3 & 1.724 & 0.992 & 23 & 39 \\
\hline MR6 & 0.939 & 0.850 & 32 & 40 & PU2 & 0.317 & 0.890 & 53 & 40 \\
\hline GU4 & 0.623 & 0.814 & 43 & 41 & HA2 & 0.540 & 0.801 & 47 & 41 \\
\hline GU2 & 0.682 & 0.811 & 40 & 42 & MP1 & 0.957 & 0.800 & 37 & 42 \\
\hline MP6 & 0.674 & 0.797 & 41 & 43 & UT1 & 1.080 & 0.793 & 36 & 43 \\
\hline UT1 & 1.227 & 0.716 & 26 & 44 & KE2 & 0.837 & 0.785 & 39 & 44 \\
\hline PU2 & 0.499 & 0.688 & 47 & 45 & AP4 & 0.751 & 0.713 & 40 & 45 \\
\hline HA1 & 0.562 & 0.685 & 45 & 46 & TN2 & 0.916 & 0.693 & 38 & 46 \\
\hline
\end{tabular}


Table 6: Share of Poor across NSS Regions, Old and New Methods, 2004-05, Rural and Urban

\begin{tabular}{|c|c|c|c|c|c|c|c|c|c|}
\hline \multicolumn{5}{|c|}{ Rural } & \multicolumn{5}{|c|}{ Urban } \\
\hline \multirow{2}{*}{$\begin{array}{l}\text { NSS } \\
\text { Region }\end{array}$} & \multicolumn{2}{|c|}{ Share of Poor } & \multicolumn{2}{|c|}{ Rank } & \multirow{2}{*}{$\begin{array}{l}\text { NSS } \\
\text { Region }\end{array}$} & \multicolumn{2}{|c|}{ Share of Poor } & \multicolumn{2}{|c|}{ Rank } \\
\hline & Old (\%) & New (\%) & Old & New & & Old (\%) & New (\%) & Old & New \\
\hline GU3 & 0.457 & 0.685 & 49 & 47 & AS2 & 0.096 & 0.592 & 67 & 47 \\
\hline AP4 & 0.271 & 0.649 & 55 & 48 & KA1 & 0.609 & 0.554 & 45 & 48 \\
\hline TN2 & 0.457 & 0.600 & 50 & 49 & MR6 & 0.593 & 0.533 & 46 & 49 \\
\hline KE2 & 0.486 & 0.563 & 48 & 50 & WB4 & 0.320 & 0.515 & 52 & 50 \\
\hline HA2 & 0.392 & 0.520 & 51 & 51 & GU1 & 0.309 & 0.503 & 54 & 51 \\
\hline WB1 & 0.550 & 0.513 & 46 & 52 & WB1 & 0.196 & 0.422 & 63 & 52 \\
\hline RA4 & 0.244 & 0.446 & 56 & 53 & AS1 & 0.073 & 0.394 & 68 & 53 \\
\hline HP1 & 0.274 & 0.438 & 54 & 54 & OR2 & 0.407 & 0.351 & 48 & 54 \\
\hline PU1 & 0.179 & 0.432 & 58 & 55 & RA4 & 0.348 & 0.339 & 51 & 55 \\
\hline TR1 & 0.278 & 0.377 & 53 & 56 & GU4 & 0.308 & 0.303 & 55 & 56 \\
\hline GU5 & 0.082 & 0.343 & 65 & 57 & JK3 & 0.200 & 0.293 & 61 & 57 \\
\hline KA1 & 0.314 & 0.282 & 52 & 58 & KA2 & 0.386 & 0.279 & 50 & 58 \\
\hline JK3 & 0.090 & 0.225 & 63 & 59 & RA3 & 0.307 & 0.272 & 56 & 59 \\
\hline KA2 & 0.091 & 0.215 & 62 & 60 & MU1 & 0.251 & 0.237 & 58 & 60 \\
\hline AS3 & 0.099 & 0.166 & 60 & 61 & GO1 & 0.185 & 0.214 & 64 & 61 \\
\hline MU2 & 0.077 & 0.134 & 66 & 62 & TR1 & 0.266 & 0.168 & 57 & 62 \\
\hline JK2 & 0.038 & 0.089 & 69 & 63 & MY1 & 0.217 & 0.150 & 59 & 63 \\
\hline AR1 & 0.087 & 0.089 & 64 & 64 & CN1 & 0.724 & 0.119 & 42 & 64 \\
\hline MY1 & 0.196 & 0.084 & 57 & 65 & PO1 & 0.196 & 0.088 & 62 & 65 \\
\hline MU1 & 0.091 & 0.068 & 61 & 66 & AR1 & 0.127 & 0.084 & 66 & 66 \\
\hline GO1 & 0.017 & 0.058 & 76 & 67 & AS3 & 0.003 & 0.066 & 78 & 67 \\
\hline NA1 & 0.174 & 0.053 & 59 & 68 & JK1 & 0.043 & 0.050 & 69 & 68 \\
\hline SI1 & 0.050 & 0.049 & 67 & 69 & MZ1 & 0.212 & 0.047 & 60 & 69 \\
\hline DE1 & 0.028 & 0.043 & 73 & 70 & HP1 & 0.025 & 0.037 & 72 & 70 \\
\hline DA1 & 0.031 & 0.033 & 71 & 71 & SI1 & 0.030 & 0.022 & 71 & 71 \\
\hline MZ1 & 0.046 & 0.032 & 68 & 72 & MU2 & 0.014 & 0.021 & 75 & 72 \\
\hline JK1 & 0.028 & 0.032 & 74 & 73 & NA1 & 0.160 & 0.019 & 65 & 73 \\
\hline PO1 & 0.036 & 0.024 & 70 & 74 & DA1 & 0.019 & 0.017 & 73 & 74 \\
\hline CN1 & 0.031 & 0.005 & 72 & 75 & JK2 & 0.006 & 0.014 & 77 & 75 \\
\hline AN1 & 0.027 & 0.003 & 75 & 76 & DD1 & 0.016 & 0.012 & 74 & 76 \\
\hline DD1 & 0.004 & 0.001 & 77 & 77 & LA1 & 0.007 & 0.004 & 76 & 77 \\
\hline LA1 & 0.003 & 0.000 & 78 & 78 & AN1 & 0.039 & 0.001 & 70 & 78 \\
\hline
\end{tabular}

Note: The NSS Region Codes are as in Table 5.

Source Unit level data, Schedule 1.0, NSS $61^{\text {st }}$ Round, 2004-05. 


\subsection{Social Groups}

The poorest social group is scheduled tribes from rural Orissa (Table 7). In the new method their incidence of poverty is 84 per cent. The other vulnerable groups in rural areas are scheduled tribes of Madhya Pradesh (80 per cent), scheduled castes of Bihar (77 per cent) and scheduled tribes of Maharashtra (72 per cent). Besides these, there are nine more social groups with incidence of poverty greater than 60 per cent under the new method. They are the scheduled tribes of Andhra Pradesh, Bihar, Chhattisgarh, Dadra \& Nagar Haveli and Jharkhand and the scheduled castes of Jharkhand, Madhya Pradesh, Mizoram and Odisha. In addition, seventeen more social groups have a poverty incidence greater than 50 per cent of which eight are scheduled tribes, two are scheduled castes and seven are backward classes. Another 21 social groups have incidence of poverty greater that 40 per cent, of which three are scheduled tribes, ten are scheduled castes, six are backward classes and two are others. Further, in rural areas under the new method scheduled tribes are the poorest groups in twenty states/union territories. Scheduled castes are the poorest in thirteen states (Assam, Bihar, Haryana, Himachal Pradesh, Jharkhand, Karnataka, Mizoram, Puducherry, Punjab, Sikkim, Tamil Nadu, Uttar Pradesh and Uttarakhand). ${ }^{8}$ Backward classes are the poorest in five (Arunachal Pradesh, Daman \& Diu, Delhi, Goa and Nagaland) and other classes in two (Andaman and Nicobar Island and Chandigarh), but one should be cautious while reading the results for sub-groups in smaller states/union territories with lower sample size.

The poorest social group in urban areas is scheduled castes of Bihar with an incidence of poverty of 71 per cent under the new method. Scheduled castes of Dadra \& Nagar Haveli, Goa, Madhya Pradesh and Odisha also indicate a poverty incidence of 60 per cent or more. Another eight social groups indicate a poverty incidence greater than 50 per cent of which eight are from among scheduled tribes (Andhra Pradesh, Bihar, Dadra \& Nagar Haveli, Karnataka and Odisha) and three from among scheduled castes (Jharkhand, Rajasthan and Sikkim). With an incidence of poverty between 25 to 50 per cent there are another 24 states/union territories of which 11 are scheduled castes, five are scheduled tribes, seven are backward classes and one is 'others'. Overall, in 23 states/union territories the

\footnotetext{
${ }^{8}$ For a larger discussion on scheduled castes using earlier data sources see the papers and references therein in a special issues of the Journal of Indian School of Political Economy (Betéille, 2000). A recent discourse on social exclusion is an edited book by Thorat and Newman (2009).
} 
scheduled castes have the highest incidence of poverty, six are scheduled tribes (Andhra Pradesh, Karnataka, Lakshadweep, Meghalaya, Mizoram and West Bengal), three are backward classes (Gujarat, Himachal Pradesh and Manipur), and three are other classes (Andaman \& Nicobar Islands, Arunachal Pradesh and Daman \& Diu, but as indicated earlier we should careful in interpreting these result for states/union territories where such subgroups have smaller sample sizes).

Poverty across social groups at all India level indicates an increase in incidence of poverty in rural areas when we compare the computations in the old method to that of the new. For scheduled tribes, scheduled castes, backward classes and other classes the percentage point change (new minus old) is 16.6 per cent, 16.4 per cent, 14.0 per cent and 9.6 per cent respectively; whereas the simple percentage change (percentage point change/old) is 36.6 per cent, 44.3 per cent, 54.0 per cent and 55.1 per cent respectively. The latter being higher for lower bases even with lower percentage point increase is a statistical artefact and should be left at that. In urban areas, the differences in incidence of poverty between the two methods is less than one percentage point for each and every social group, but just to mention, it has increased for scheduled tribes and other classes and decreased for scheduled castes and backward classes. 
Table 7: Poverty and Inequality across State-wise Social Groups with Old and New Methods, 2004-05, Rural and Urban

\begin{tabular}{|c|c|c|c|c|c|c|c|c|c|c|c|c|c|c|c|c|c|}
\hline \multirow{4}{*}{$\begin{array}{l}\text { NSS } \\
\text { Region }\end{array}$} & \multicolumn{8}{|c|}{ Rural } & \multicolumn{9}{|c|}{ Urban } \\
\hline & \multicolumn{6}{|c|}{ Poverty } & \multicolumn{2}{|c|}{ Inequality } & \multirow{3}{*}{$\begin{array}{l}\text { NSS } \\
\text { Region }\end{array}$} & \multicolumn{6}{|c|}{ Poverty } & \multicolumn{2}{|c|}{ Inequality } \\
\hline & \multicolumn{3}{|c|}{ Old Method } & \multicolumn{3}{|c|}{ New Method } & \multirow[t]{2}{*}{ Old } & \multirow[t]{2}{*}{ New } & & \multicolumn{3}{|c|}{ Old Method } & \multicolumn{3}{|c|}{ New Method } & \multirow[t]{2}{*}{ Old } & \multirow[t]{2}{*}{ New } \\
\hline & $\alpha=0$ & $\alpha=1$ & $\alpha=2$ & $\alpha=0$ & $\alpha=1$ & $\alpha=2$ & & & & $\alpha=0$ & $\alpha=1$ & $\alpha=2$ & $\alpha=0$ & $\alpha=1$ & $\alpha=2$ & & \\
\hline AN-ST & - & - & - & - & - & - & - & - & AN-ST & . & - & - & - & - & - & - & \\
\hline AN-SC & - & - & - & - & - & - & - & - & AN-SC & - & - & - & - & - & - & - & \\
\hline AN-BC & - & - & - & - & - & - & - & 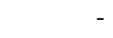 & AN-BC & - & - & - & - & - & - & - & \\
\hline AN-OC & 22.65 & 3.25 & 0.80 & 3.32 & 0.22 & 0.02 & 0.3369 & 0.3089 & AN-OC & 22.45 & 3.76 & 0.90 & 0.83 & 0.01 & 0.00 & 0.3800 & 0.3435 \\
\hline AP-ST & 28.29 & 6.90 & 2.91 & 60.29 & 17.50 & 7.08 & 0.2928 & 0.2629 & AP-ST & 51.90 & 13.30 & 4.59 & 50.11 & 11.73 & 3.88 & 0.3031 & 0.2732 \\
\hline AP-SC & 15.52 & 2.86 & 1.04 & 41.83 & 9.29 & 3.14 & 0.2570 & 0.2325 & AP-SC & 37.37 & 7.78 & 2.18 & 34.99 & 6.80 & 1.82 & 0.3221 & 0.3074 \\
\hline$A P-O C$ & 3.76 & 0.46 & 0.10 & 16.15 & 2.95 & 0.79 & 0.2911 & 0.2733 & $\mathrm{AP}-\mathrm{OC}$ & 20.21 & 4.45 & 1.44 & 16.49 & 3.52 & 1.07 & 0.4042 & 0.3917 \\
\hline AR-ST & 19.23 & 4.17 & 1.35 & 29.68 & 6.77 & 2.39 & 0.2795 & 0.2593 & AR-ST & 4.69 & 0.96 & 0.29 & 23.47 & 5.81 & 1.98 & 0.2573 & 0.2518 \\
\hline AR-SC & 2.97 & 0.30 & 0.03 & 2.97 & 0.66 & 0.15 & 0.1144 & 0.1076 & AR-SC & - & - & - & 13.64 & 2.72 & 0.57 & 0.1166 & 0.1135 \\
\hline$A R-B C$ & 30.56 & 9.18 & 3.37 & 51.12 & 10.47 & 3.44 & 0.2087 & 0.1796 & AR-BC & - & - & - & 8.77 & 1.53 & 0.27 & 0.0909 & 0.0915 \\
\hline AR-OC & 31.22 & 4.54 & 1.15 & 46.36 & 9.52 & 2.62 & 0.2797 & 0.2683 & AR-OC & 3.53 & 0.24 & 0.03 & 26.99 & 4.54 & 0.99 & 0.2611 & 0.2444 \\
\hline AS-ST & 12.62 & 1.74 & 0.37 & 28.76 & 4.11 & 0.99 & 0.1589 & 0.1556 & AS-ST & 2.93 & 0.14 & 0.01 & 29.80 & 6.51 & 1.54 & 0.2301 & 0.2455 \\
\hline AS-SC & 25.71 & 4.42 & 1.11 & 45.32 & 8.85 & 2.49 & 0.1949 & 0.1893 & AS-SC & 5.09 & 1.42 & 0.48 & 37.24 & 7.20 & 2.04 & 0.2861 & 0.2853 \\
\hline AS-BC & 18.15 & 3.27 & 0.81 & 31.92 & 6.59 & 1.88 & 0.2095 & 0.1994 & AS-BC & 5.39 & 0.53 & 0.09 & 26.74 & 5.57 & 1.64 & 0.4092 & 0.2986 \\
\hline AS-OC & 26.10 & 4.32 & 1.14 & 38.75 & 7.86 & 2.33 & 0.2067 & 0.2006 & AS-OC & 2.87 & 0.26 & 0.04 & 15.58 & 2.85 & 0.74 & 0.2880 & 0.3044 \\
\hline BI-ST & 56.19 & 6.65 & 1.01 & 59.33 & 12.96 & 3.13 & 0.1477 & 0.1575 & BI-ST & 57.24 & 5.60 & 0.55 & 57.24 & 12.18 & 2.59 & 0.2972 & 0.2931 \\
\hline $\mathrm{BI}-\mathrm{OC}$ & 26.36 & 3.70 & 0.82 & 35.75 & 6.62 & 1.65 & 0.2260 & 0.2024 & $\mathrm{BI}-\mathrm{OC}$ & 17.22 & 3.57 & 1.14 & 22.98 & 5.45 & 1.89 & 0.2798 & 0.2682 \\
\hline CN-ST & - & - & - & - & - & - & - & & $\mathrm{CN}-\mathrm{ST}$ & 22.54 & 0.13 & 0.08 & 23.38 & 3.02 & 0.45 & 0.2628 & 0.3290 \\
\hline $\mathrm{CN}-\mathrm{SC}$ & - & - & - & 1.98 & 0.42 & 0.09 & 0.2254 & 0.2306 & CN-SC & 15.62 & 1.98 & 0.32 & 28.22 & 4.90 & 1.14 & 0.3339 & 0.3344 \\
\hline$C N-B C$ & & - & & 7.14 & 0.55 & 0.06 & 0.1852 & 0.1934 & $\mathrm{CN}-\mathrm{BC}$ & 11.78 & 4.33 & 1.60 & 13.21 & 5.86 & 2.75 & 0.3283 & 0.3326 \\
\hline $\mathrm{CN}-\mathrm{OC}$ & 14.02 & 0.00 & 0.00 & 24.75 & 6.54 & 2.33 & 0.2309 & 0.2403 & $\mathrm{CN}-\mathrm{OCC}$ & 2.14 & 0.47 & 0.11 & 3.93 & 0.98 & 0.28 & 0.3280 & 0.3316 \\
\hline CT-ST & 54.82 & 13.49 & 4.85 & 65.47 & 18.27 & 7.05 & 0.2731 & 0.2366 & CT-ST & 42.12 & 16.96 & 8.66 & 32.73 & 12.92 & 6.14 & 0.3914 & 0.3358 \\
\hline CT-SC & 31.99 & 6.55 & 1.89 & 48.55 & 10.82 & 3.31 & 0.3297 & 0.2491 & CT-SC & 52.73 & 18.17 & 7.10 & 44.63 & 10.81 & 2.96 & 0.3310 & 0.3464 \\
\hline CT-BC & 34.09 & 7.13 & 2.38 & 50.96 & 11.64 & 4.04 & 0.2855 & 0.2685 & CT-BC & 53.86 & 13.91 & 4.84 & 32.45 & 7.29 & 2.33 & 0.4357 & 0.3348 \\
\hline CT-OC & 28.28 & 6.34 & 1.68 & 38.71 & 8.63 & 2.75 & 0.3119 & 0.3035 & CT-OC & 22.32 & 5.19 & 1.63 & 13.97 & 2.46 & 0.80 & 0.4356 & 0.3637 \\
\hline DA-ST & 43.77 & 9.35 & 3.69 & 69.91 & 19.84 & 7.89 & 0.2895 & 0.2640 & DA-ST & 56.90 & 20.09 & 7.51 & 50.36 & 15.64 & 5.20 & 0.4206 & 0.3803 \\
\hline DA-SC & - & - & - & - & - & - & 0.2377 & 0.2151 & DA-SC & 83.59 & 12.98 & 2.54 & 66.02 & 10.64 & 1.73 & 0.0646 & 0.0654 \\
\hline DA-BC & 21.71 & 5.33 & 1.31 & 21.71 & 8.34 & 3.21 & 0.2776 & 0.3414 & DA-BC & - & - & - & - & - & - & 0.1063 & 0.0595 \\
\hline DA-OC & 4.99 & 1.32 & 0.35 & 14.73 & 3.28 & 1.01 & 0.2638 & 0.2410 & DA-OC & 2.29 & 0.33 & 0.06 & 1.98 & 0.45 & 0.16 & 0.2301 & 0.2666 \\
\hline DD-ST & 4.75 & 0.00 & 0.00 & & - & - & 0.1322 & 0.1320 & DD-ST & 4.19 & 0.00 & 0.00 & 4.19 & 0.39 & 0.04 & 0.0482 & 0.0495 \\
\hline DD-SC & & & & & - & - & 0.2498 & 0.2263 & DD-SC & 10.96 & 1.52 & 0.34 & 3.29 & 0.77 & 0.18 & 0.1841 & 0.1696 \\
\hline DD-BC & 8.79 & 2.07 & 0.64 & 6.62 & 1.29 & 0.26 & 0.1636 & 0.1583 & DD-BC & 35.82 & 5.35 & 1.40 & 14.04 & 2.73 & 0.58 & 0.2296 & 0.2374 \\
\hline $\mathrm{DD}-\mathrm{OC}$ & & 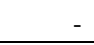 & & . & 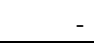 & - & 0.2550 & 0.2502 & DD-OC & 16.86 & 3.77 & 0.84 & 16.86 & 2.23 & 0.30 & 0.2584 & 0.2371 \\
\hline
\end{tabular}


Table 7: Poverty and Inequality across State-wise Social Groups with Old and New Methods, 2004-05, Rural and Urban

\begin{tabular}{|c|c|c|c|c|c|c|c|c|c|c|c|c|c|c|c|c|c|}
\hline \multirow{4}{*}{$\begin{array}{l}\text { NSS } \\
\text { Region }\end{array}$} & \multicolumn{8}{|c|}{ Rural } & \multicolumn{9}{|c|}{ Urban } \\
\hline & \multicolumn{6}{|c|}{ Poverty } & \multicolumn{2}{|c|}{ Inequality } & \multirow{3}{*}{$\begin{array}{l}\text { NSS } \\
\text { Region }\end{array}$} & \multicolumn{6}{|c|}{ Poverty } & \multicolumn{2}{|c|}{ Inequality } \\
\hline & \multicolumn{3}{|c|}{ Old Method } & \multicolumn{3}{|c|}{ New Method } & \multirow[t]{2}{*}{ Old } & \multirow[t]{2}{*}{ New } & & \multicolumn{3}{|c|}{ Old Method } & \multicolumn{3}{|c|}{ New Method } & \multirow[t]{2}{*}{ Old } & \multirow[t]{2}{*}{ New } \\
\hline & $\alpha=0$ & $\alpha=1$ & $\alpha=2$ & $\alpha=0$ & $\alpha=1$ & $\alpha=2$ & & & & $\alpha=0$ & $\alpha=1$ & $\alpha=2$ & $\alpha=0$ & $\alpha=1$ & $\alpha=2$ & & \\
\hline DE-ST & - & - & - & - & - & - & - & - & DE-ST & - & - & - & - & - & - & 0.2221 & 0.2335 \\
\hline DE-SC & - & - & - & - & - & - & 0.1338 & 0.1931 & DE-SC & 40.54 & 6.22 & 1.69 & 26.15 & 4.07 & 1.12 & 0.2314 & 0.2216 \\
\hline DE-BC & - & - & - & 27.01 & 0.75 & 0.02 & 0.1754 & 0.1727 & DE-BC & 20.26 & 3.21 & 0.80 & 22.70 & 3.28 & 0.83 & 0.2285 & 0.2377 \\
\hline DE-OC & 10.63 & 0.47 & 0.02 & 15.51 & 2.74 & 0.53 & 0.2893 & 0.3118 & DE-OC & 6.28 & 1.13 & 0.31 & 6.14 & 0.99 & 0.25 & 0.3164 & 0.3164 \\
\hline GO-ST & 49.83 & 0.46 & 0.00 & 49.83 & 18.17 & 6.63 & 0.4079 & 0.3225 & GO-ST & & & - & - & & & & \\
\hline GO-SC & & & & - & & . & 0.0780 & 0.1148 & GO-SC & 42.01 & 14.25 & 6.61 & 62.35 & 14.74 & 6.11 & 0.2855 & 0.2377 \\
\hline GO-BC & 22.14 & 3.74 & 0.63 & 58.58 & 12.87 & 5.33 & 0.1833 & 0.2246 & GO-BC & 30.96 & 2.45 & 0.53 & 9.60 & 1.64 & 0.38 & 0.2177 & 0.2841 \\
\hline GO-OC & 2.46 & 0.01 & 0.00 & 25.19 & 4.53 & 1.16 & 0.2994 & 0.2933 & GO-OC & 13.53 & 2.95 & 0.98 & 15.63 & 2.50 & 0.75 & 0.4282 & 0.3480 \\
\hline GU-ST & 34.28 & 7.63 & 2.63 & 57.07 & 17.04 & 6.76 & 0.2640 & 0.2549 & GU-ST & 21.04 & 6.21 & 2.63 & 31.17 & 8.40 & 3.30 & 0.3042 & 0.4307 \\
\hline GU-SC & 22.82 & 3.17 & 0.61 & 49.26 & 10.58 & 3.11 & 0.2191 & 0.2062 & GU-SC & 17.83 & 3.70 & 1.12 & 18.73 & 4.88 & 1.59 & 0.2647 & 0.2505 \\
\hline GU-BC & 18.46 & 2.94 & 0.66 & 41.73 & 9.30 & 2.91 & 0.2350 & 0.2258 & GU-BC & 23.80 & 3.84 & 0.97 & 36.50 & 6.65 & 1.85 & 0.2784 & 0.2603 \\
\hline GU-OC & 4.50 & 0.51 & 0.09 & 13.68 & 2.17 & 0.53 & 0.2721 & 0.2642 & GU-OC & 6.89 & 1.17 & 0.29 & 11.37 & 2.12 & 0.58 & 0.2966 & 0.2990 \\
\hline HA-ST & 0.00 & 0.00 & 0.00 & 0.00 & 0.00 & 0.00 & 0.1160 & 0.1423 & HA-ST & 0.00 & 0.00 & 0.00 & 22.23 & 0.45 & 0.01 & 0.2963 & 0.2886 \\
\hline HA-SC & 26.00 & 5.05 & 1.51 & 47.51 & 10.04 & 3.08 & 0.2316 & 0.2181 & HA-SC & 33.25 & 8.43 & 2.84 & 46.86 & 11.83 & 4.32 & 0.2778 & 0.2600 \\
\hline $\mathrm{HA}-\mathrm{BC}$ & 13.74 & 2.16 & 0.50 & 25.74 & 4.54 & 1.14 & 0.2727 & 0.2410 & $\mathrm{HA}-\mathrm{BC}$ & 20.53 & 4.74 & 1.62 & 36.47 & 7.55 & 2.35 & 0.3447 & 0.2872 \\
\hline $\mathrm{HA}-\mathrm{OC}$ & 3.89 & 0.57 & 0.13 & 8.17 & 1.15 & 0.26 & 0.3628 & 0.3573 & $\mathrm{HA}-\mathrm{OC}$ & 5.69 & 0.92 & 0.22 & 8.08 & 1.52 & 0.41 & 0.3405 & 0.3189 \\
\hline HP-ST & 15.71 & 3.75 & 1.37 & 35.37 & 7.89 & 2.86 & 0.3460 & 0.3211 & HP-ST & 2.42 & 0.45 & 0.08 & 2.42 & 0.69 & 0.20 & 0.1700 & 0.1875 \\
\hline HP-SC & 19.89 & 3.10 & 0.71 & 39.45 & 7.37 & 2.05 & 0.2653 & 0.2434 & HP-SC & 5.02 & 1.27 & 0.43 & 9.24 & 1.67 & 0.49 & 0.2343 & 0.2021 \\
\hline HP-BC & 8.79 & 1.12 & 0.20 & 19.00 & 3.09 & 0.75 & 0.2471 & 0.2295 & HP-BC & 9.80 & 1.71 & 0.43 & 10.84 & 2.62 & 0.76 & 0.2023 & 0.1941 \\
\hline HP-OC & 5.72 & 0.75 & 0.16 & 18.28 & 2.58 & 0.57 & 0.3232 & 0.3018 & HP-OC & 1.84 & 0.65 & 0.31 & 2.53 & 0.71 & 0.34 & 0.3321 & 0.2896 \\
\hline JK-ST & - & & & 26.52 & 3.03 & 0.35 & 0.2770 & 0.2695 & JK-ST & - & - & - & - & - & - & 0.2465 & 0.2873 \\
\hline JK-SC & 4.54 & 0.57 & 0.09 & 14.71 & 1.67 & 0.35 & 0.2266 & 0.2095 & JK-SC & 10.79 & 2.15 & 0.58 & 13.79 & 2.13 & 0.49 & 0.2186 & 0.1975 \\
\hline JK-BC & 9.78 & 1.91 & 0.45 & 23.52 & 4.55 & 1.37 & 0.2500 & 0.2073 & JK-BC & 3.12 & 0.88 & 0.25 & 3.12 & 0.81 & 0.21 & 0.1735 & 0.1456 \\
\hline JK-OC & 3.05 & 0.38 & 0.11 & 11.78 & 1.65 & 0.37 & 0.2488 & 0.2178 & JK-OC & 7.38 & 1.73 & 0.50 & 10.50 & 2.20 & 0.59 & 0.2449 & 0.2515 \\
\hline JN-ST & 54.12 & 12.63 & 3.98 & 60.56 & 14.64 & 4.83 & 0.2131 & 0.2116 & JN-ST & 42.49 & 11.32 & 3.69 & 47.20 & 14.12 & 5.07 & 0.3396 & 0.3278 \\
\hline JN-SC & 57.55 & 13.70 & 4.36 & 60.97 & 14.95 & 4.79 & 0.2156 & 0.2071 & JN-SC & 48.78 & 8.33 & 2.17 & 52.55 & 10.64 & 3.08 & 0.3445 & 0.3020 \\
\hline$J N-B C$ & 40.00 & 7.63 & 2.05 & 46.67 & 8.49 & 2.28 & 0.2150 & 0.1886 & $J N-B C$ & 17.39 & 3.69 & 1.15 & 21.98 & 5.42 & 1.81 & 0.2809 & 0.2822 \\
\hline $\mathrm{JN}-\mathrm{OC}$ & 36.92 & 7.31 & 2.13 & 37.45 & 8.02 & 2.33 & 0.2830 & 0.2452 & $\mathrm{JN}-\mathrm{OC}$ & 8.22 & 1.79 & 0.58 & 10.30 & 2.38 & 0.78 & 0.3358 & 0.3049 \\
\hline KA-ST & 21.39 & 2.23 & 0.40 & 50.53 & 8.11 & 1.77 & 0.1726 & 0.1581 & KA-ST & 61.87 & 20.02 & 9.50 & 55.70 & 16.28 & 6.90 & 0.3111 & 0.3084 \\
\hline KA-SC & 31.33 & 4.64 & 1.04 & 57.37 & 10.63 & 2.92 & 0.2072 & 0.2114 & KA-SC & 50.32 & 15.83 & 6.62 & 41.22 & 11.39 & 4.40 & 0.2791 & 0.2715 \\
\hline KA-BC & 20.80 & 3.16 & 0.75 & 35.85 & 6.27 & 1.63 & 0.2459 & 0.2340 & KA-BC & 38.23 & 10.21 & 3.60 & 32.14 & 7.21 & 2.30 & 0.3047 & 0.3108 \\
\hline KA-OC & 13.69 & 1.57 & 0.31 & 23.72 & 3.81 & 0.91 & 0.3118 & 0.2677 & KA-OC & 20.96 & 4.77 & 1.62 & 14.31 & 3.24 & 1.06 & 0.3773 & 0.3748 \\
\hline KE-ST & 40.15 & 17.31 & 9.63 & 56.86 & 23.21 & 12.24 & 0.3357 & 0.3277 & KE-ST & 21.79 & 3.10 & 0.69 & 21.79 & 3.66 & 1.35 & 0.3941 & 0.3771 \\
\hline KE-SC & 21.63 & 3.95 & 1.10 & 30.82 & 6.80 & 2.11 & 0.3184 & 0.2741 & KE-SC & 33.40 & 6.50 & 2.19 & 33.00 & 8.11 & 3.08 & 0.2593 & 0.2735 \\
\hline KE-BC & 13.55 & 2.62 & 0.80 & 21.34 & 4.31 & 1.30 & 0.3834 & 0.3397 & KE-BC & 23.99 & 5.73 & 1.99 & 21.19 & 4.77 & 1.54 & 0.4177 & 0.3690 \\
\hline KE-OC & 7.14 & 1.54 & 0.67 & 10.82 & 2.18 & 0.84 & 0.3660 & 0.3462 & KE-OC & 7.17 & 1.38 & 0.43 & 7.86 & 1.25 & 0.34 & 0.3652 & 0.3929 \\
\hline
\end{tabular}


Table 7: Poverty and Inequality across State-wise Social Groups with Old and New Methods, 2004-05, Rural and Urban

\begin{tabular}{|c|c|c|c|c|c|c|c|c|c|c|c|c|c|c|c|c|c|}
\hline \multicolumn{9}{|c|}{ Rural } & \multicolumn{9}{|c|}{ Urban } \\
\hline \multirow{3}{*}{$\begin{array}{l}\text { NSS } \\
\text { Region }\end{array}$} & \multicolumn{6}{|c|}{ Poverty } & \multicolumn{2}{|c|}{ Inequality } & \multirow{3}{*}{$\begin{array}{l}\text { NSS } \\
\text { Region }\end{array}$} & \multicolumn{6}{|c|}{ Poverty } & \multicolumn{2}{|c|}{ Inequality } \\
\hline & \multicolumn{3}{|c|}{ Old Method } & \multicolumn{3}{|c|}{ New Method } & \multirow[t]{2}{*}{ Old } & \multirow[t]{2}{*}{ New } & & \multicolumn{3}{|c|}{ Old Method } & \multicolumn{3}{|c|}{ New Method } & \multirow[t]{2}{*}{ Old } & \multirow[t]{2}{*}{ New } \\
\hline & $\alpha=0$ & $\alpha=1$ & $\alpha=2$ & $\alpha=0$ & $\alpha=1$ & $\alpha=2$ & & & & $\alpha=0$ & $\alpha=1$ & $\alpha=2$ & $\alpha=0$ & $\alpha=1$ & $\alpha=2$ & & \\
\hline$\overline{L A-S T}$ & 11.84 & 0.14 & 0.04 & 0.35 & 0.10 & 0.03 & 0.3143 & 0.2542 & LA-ST & 20.53 & 5.91 & 2.93 & 10.61 & 3.87 & 1.88 & 0.3958 & 0.2627 \\
\hline LA-SC & - & & - & - & - & - & & - & LA-SC & - & - & 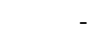 & - & - & - & & \\
\hline LA-BC & - & - & - & - & - & - & & - & $L A-B C$ & - & - & - & - & - & - & 0.0946 & 0.0809 \\
\hline LA-OC & - & & - & - & - & - & 0.0250 & 0.0138 & LA-OC & - & - & . & - & - & - & 0.2379 & 0.2140 \\
\hline MP-ST & 58.38 & 13.53 & 4.30 & 80.02 & 20.91 & 7.20 & 0.2229 & 0.1912 & MP-ST & 44.69 & 16.72 & 7.38 & 42.60 & 13.36 & 5.24 & 0.3221 & 0.3460 \\
\hline MP-SC & 43.28 & 10.35 & 3.69 & 62.55 & 15.82 & 5.74 & 0.2319 & 0.2108 & MP-SC & 68.38 & 21.74 & 9.21 & 59.65 & 17.08 & 6.54 & 0.3162 & 0.2876 \\
\hline MP-OC & 13.23 & 2.05 & 0.57 & 22.89 & 3.82 & 0.99 & 0.2685 & 0.2578 & MP-OC & 21.27 & 4.56 & 1.41 & 14.56 & 2.71 & 0.75 & 0.4031 & 0.3466 \\
\hline MR-ST & 56.31 & 15.05 & 5.58 & 72.28 & 24.20 & 10.27 & 0.3036 & 0.2612 & MR-ST & 40.93 & 13.46 & 5.82 & 34.81 & 10.14 & 3.90 & 0.3192 & 0.3345 \\
\hline MR-SC & 44.77 & 10.29 & 3.28 & 65.88 & 18.18 & 6.83 & 0.2781 & 0.2721 & MR-SC & 42.77 & 13.71 & 5.95 & 36.02 & 10.34 & 4.10 & 0.3244 & 0.3113 \\
\hline MR-BC & 24.09 & 4.10 & 1.09 & 44.19 & 9.07 & 2.75 & 0.2861 & 0.2676 & MR-BC & 35.62 & 9.60 & 3.67 & 26.79 & 6.64 & 2.34 & 0.3248 & 0.3150 \\
\hline MR-OC & 18.62 & 3.54 & 1.00 & 33.89 & 7.36 & 2.33 & 0.3154 & 0.2835 & MR-OC & 26.83 & 7.28 & 2.65 & 21.41 & 5.01 & 1.63 & 0.3903 & 0.3813 \\
\hline MU-ST & 31.70 & 4.46 & 0.89 & 55.89 & 8.80 & 2.02 & 0.1349 & 0.1326 & MU-ST & 3.51 & 0.41 & 0.06 & 24.03 & 3.70 & 0.89 & 0.1492 & 0.1590 \\
\hline MU-SC & 11.95 & 0.43 & 0.02 & 11.95 & 0.74 & 0.05 & 0.0973 & 0.0862 & MU-SC & 2.59 & 0.32 & 0.06 & 23.47 & 4.14 & 0.88 & 0.1439 & 0.1293 \\
\hline MU-BC & 13.75 & 1.61 & 0.30 & 25.20 & 3.07 & 0.59 & 0.1662 & 0.1523 & MU-BC & 2.85 & 0.21 & 0.03 & 36.58 & 5.35 & 1.06 & 0.1810 & 0.1630 \\
\hline MU-OC & 12.39 & 1.41 & 0.28 & 22.76 & 2.61 & 0.53 & 0.1513 & 0.1317 & MU-OC & 12.54 & 0.81 & 0.07 & 36.10 & 5.84 & 1.12 & 0.1814 & 0.1682 \\
\hline MY-ST & 22.55 & 2.81 & 0.55 & 14.84 & 1.50 & 0.25 & 0.1623 & 0.1508 & MY-ST & 3.73 & 0.34 & 0.06 & 26.09 & 3.04 & 0.57 & 0.2594 & 0.2504 \\
\hline MY-OC & 14.73 & 1.02 & 0.09 & 0.46 & 0.06 & 0.01 & 0.1325 & 0.1191 & MY-OC & 3.19 & 0.38 & 0.06 & 21.77 & 1.99 & 0.40 & 0.2595 & 0.2674 \\
\hline MZ-ST & 22.31 & 3.33 & 0.85 & 23.03 & 3.53 & 0.90 & 0.2016 & 0.1859 & MZ-ST & 3.66 & 0.37 & 0.07 & 7.95 & 1.01 & 0.22 & 0.2492 & 0.2292 \\
\hline MZ-SC & - & & & 68.45 & 8.84 & 1.14 & 0.2060 & 0.2790 & MZ-SC & - & - & . & 6.50 & 1.26 & 0.24 & 0.1918 & 0.2017 \\
\hline MZ-BC & 10.88 & 0.44 & 0.02 & 23.94 & 1.25 & 0.07 & 0.1209 & 0.1098 & MZ-BC & - & - & - & & - & - & 0.0969 & 0.0722 \\
\hline MZ-OC & & & & & - & 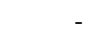 & & & MZ-OC & - & - & . & - & - & - & 0.1364 & 0.1400 \\
\hline NA-ST & 20.30 & 2.27 & 0.38 & 8.79 & 0.64 & 0.08 & 0.2251 & 0.2018 & NA-ST & 0.80 & 0.07 & 0.01 & 2.00 & 0.18 & 0.03 & 0.2293 & 0.2219 \\
\hline NA-SC & & & & & - & & & & NA-SC & 17.11 & 0.83 & 0.04 & 17.11 & 2.00 & 0.26 & 0.1640 & 0.1489 \\
\hline NA-BC & 86.43 & 21.24 & 6.46 & 51.41 & 13.75 & 3.80 & 0.1434 & 0.1488 & NA-BC & - & - & & & - & - & 0.1822 & 0.1733 \\
\hline $\mathrm{NA}-\mathrm{OC}$ & 34.70 & 8.90 & 2.84 & 34.70 & 8.40 & 2.81 & 0.2966 & 0.3123 & $\mathrm{NA}-\mathrm{OC}$ & 14.53 & 1.22 & 0.18 & 14.53 & 2.47 & 0.54 & 0.3046 & 0.2905 \\
\hline OD-ST & 75.84 & 23.46 & 9.24 & 84.43 & 30.46 & 13.04 & 0.2357 & 0.2206 & OD-ST & 64.62 & 21.99 & 9.45 & 53.41 & 16.71 & 6.42 & 0.3175 & 0.3301 \\
\hline OD-SC & 49.93 & 13.33 & 4.70 & 67.89 & 19.01 & 7.22 & 0.2508 & 0.2270 & OD-SC & 74.53 & 24.87 & 10.64 & 63.74 & 18.10 & 6.94 & 0.3110 & 0.2971 \\
\hline OD-BC & 37.07 & 7.73 & 2.38 & 52.60 & 12.55 & 4.19 & 0.2681 & 0.2445 & OD-BC & 48.56 & 14.72 & 6.24 & 42.37 & 10.81 & 4.24 & 0.3293 & 0.3187 \\
\hline OD-OC & 23.54 & 4.07 & 1.15 & 37.06 & 7.36 & 2.15 & 0.2765 & 0.2649 & OD-OC & 29.66 & 7.53 & 2.56 & 23.77 & 4.96 & 1.45 & 0.3358 & 0.3170 \\
\hline PD-ST & & & & & & & & & PD-ST & & - & & & - & - & 0.0027 & 0.0806 \\
\hline PD-SC & 42.79 & 4.57 & 0.68 & 41.05 & 7.15 & 1.44 & 0.2653 & 0.2664 & PD-SC & 62.47 & 16.50 & 5.34 & 46.94 & 9.17 & 2.30 & 0.2356 & 0.2086 \\
\hline PD-BC & 9.52 & 1.04 & 0.16 & 11.15 & 1.94 & 0.46 & 0.3117 & 0.2889 & PD-BC & 20.01 & 2.87 & 0.62 & 7.56 & 0.79 & 0.14 & 0.3093 & 0.3128 \\
\hline PD-OC & - & & 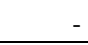 & & 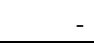 & 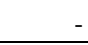 & 0.3029 & 0.3862 & PD-OC & 11.66 & 2.06 & 0.66 & 6.58 & 1.12 & 0.26 & 0.2482 & 0.2818 \\
\hline
\end{tabular}


Table 7: Poverty and Inequality across State-wise Social Groups with Old and New Methods, 2004-05, Rural and Urban

\begin{tabular}{|c|c|c|c|c|c|c|c|c|c|c|c|c|c|c|c|c|c|}
\hline \multirow{4}{*}{$\begin{array}{l}\text { NSS } \\
\text { Region }\end{array}$} & \multicolumn{8}{|c|}{ Rural } & \multicolumn{9}{|c|}{ Urban } \\
\hline & \multicolumn{6}{|c|}{ Poverty } & \multicolumn{2}{|c|}{ Inequality } & \multirow{3}{*}{$\begin{array}{l}\text { NSS } \\
\text { Region }\end{array}$} & \multicolumn{6}{|c|}{ Poverty } & \multicolumn{2}{|c|}{ Inequality } \\
\hline & \multicolumn{3}{|c|}{ Old Method } & \multicolumn{3}{|c|}{ New Method } & \multirow[t]{2}{*}{ Old } & \multirow[t]{2}{*}{ New } & & \multicolumn{3}{|c|}{ Old Method } & \multicolumn{3}{|c|}{ New Method } & \multirow[t]{2}{*}{ Old } & \multirow[t]{2}{*}{ New } \\
\hline & $\alpha=0$ & $\alpha=1$ & $\alpha=2$ & $\alpha=0$ & $\alpha=1$ & $\alpha=2$ & & & & $\alpha=0$ & $\alpha=1$ & $\alpha=2$ & $\alpha=0$ & $\alpha=1$ & $\alpha=2$ & & \\
\hline PN-ST & 30.71 & 3.05 & 0.30 & 30.71 & 9.35 & 2.84 & 0.2030 & 0.2101 & PN-ST & 2.43 & 0.28 & 0.03 & 2.43 & 0.56 & 0.13 & 0.1316 & 0.1162 \\
\hline PN-SC & 14.46 & 1.87 & 0.42 & 38.44 & 6.22 & 1.61 & 0.2433 & 0.2235 & PN-SC & 14.30 & 1.52 & 0.26 & 36.15 & 6.67 & 1.71 & 0.2635 & 0.2690 \\
\hline $\mathrm{PN}-\mathrm{BC}$ & 10.50 & 1.47 & 0.29 & 21.68 & 4.19 & 1.08 & 0.2952 & 0.2852 & PN-BC & 5.75 & 0.54 & 0.10 & 20.24 & 3.07 & 0.66 & 0.2835 & 0.2544 \\
\hline $\mathrm{PN}-\mathrm{OC}$ & 2.26 & 0.30 & 0.07 & 5.14 & 0.87 & 0.22 & 0.2689 & 0.2628 & $\mathrm{PN}-\mathrm{OC}$ & 2.50 & 0.29 & 0.05 & 9.61 & 1.48 & 0.34 & 0.4207 & 0.3331 \\
\hline RA-ST & 32.54 & 4.97 & 1.14 & 59.32 & 12.49 & 3.68 & 0.1861 & 0.1906 & RA-ST & 24.95 & 7.32 & 3.71 & 26.77 & 6.46 & 3.14 & 0.2682 & 0.2695 \\
\hline RA-SC & 28.26 & 5.17 & 1.39 & 48.50 & 10.64 & 3.25 & 0.2537 & 0.2029 & RA-SC & 55.07 & 13.72 & 4.49 & 50.97 & 10.63 & 3.18 & 0.3447 & 0.2976 \\
\hline RA-BC & 12.59 & 2.04 & 0.52 & 27.22 & 4.93 & 1.36 & 0.2511 & 0.2148 & RA-BC & 32.07 & 7.48 & 2.41 & 31.30 & 5.94 & 1.73 & 0.2904 & 0.2814 \\
\hline RA-OC & 7.98 & 0.79 & 0.12 & 21.14 & 2.90 & 0.58 & 0.2281 & 0.2181 & RA-OC & 20.88 & 3.38 & 0.94 & 16.96 & 2.91 & 0.74 & 0.3972 & 0.3238 \\
\hline SI-ST & 62.47 & 16.50 & 5.34 & 34.93 & 6.52 & 1.69 & 0.2611 & 0.2624 & SI-ST & 0.44 & 0.11 & 0.04 & 15.28 & 0.75 & 0.09 & 0.2478 & 0.2358 \\
\hline SI-SC & 20.01 & 2.87 & 0.62 & 41.17 & 5.61 & 1.21 & 0.3148 & 0.2954 & SI-SC & 8.19 & 1.20 & 0.47 & 52.09 & 8.40 & 2.15 & 0.1739 & 0.1678 \\
\hline SI-BC & 11.66 & 2.06 & 0.66 & 30.32 & 5.38 & 1.39 & 0.2818 & 0.2468 & SI-BC & 1.69 & 0.43 & 0.17 & 10.87 & 1.62 & 0.46 & 0.2529 & 0.2241 \\
\hline $\mathrm{SI}-\mathrm{OC}$ & 62.47 & 16.50 & 5.34 & 7.89 & 0.90 & 0.14 & 0.1547 & 0.1507 & $\mathrm{SI}-\mathrm{OC}$ & 6.02 & 1.35 & 0.44 & 38.57 & 5.43 & 1.55 & 0.2427 & 0.2318 \\
\hline TN-ST & 27.18 & 0.94 & 0.05 & 47.26 & 10.17 & 2.45 & 0.1904 & 0.2193 & TN-ST & 33.09 & 11.28 & 4.69 & 34.71 & 10.98 & 4.48 & 0.3303 & 0.3417 \\
\hline TN-SC & 30.37 & 5.21 & 1.47 & 51.24 & 10.18 & 3.02 & 0.2387 & 0.2148 & TN-SC & 41.22 & 9.30 & 2.99 & 40.74 & 8.97 & 2.83 & 0.3096 & 0.2827 \\
\hline TN-BC & 20.24 & 3.28 & 0.82 & 32.61 & 6.40 & 1.79 & 0.3324 & 0.2801 & TN-BC & 20.82 & 4.20 & 1.28 & 17.32 & 3.42 & 1.00 & 0.3307 & 0.3350 \\
\hline $\mathrm{TN}-\mathrm{OC}$ & 18.81 & 3.59 & 0.88 & 22.22 & 5.55 & 1.70 & 0.4724 & 0.3944 & $\mathrm{TN}-\mathrm{OC}$ & 6.96 & 1.39 & 0.35 & 6.51 & 1.64 & 0.61 & 0.3641 & 0.3636 \\
\hline TR-ST & 27.60 & 4.05 & 1.01 & 53.44 & 11.30 & 3.51 & 0.1827 & 0.1792 & TR-ST & & & . & 3.90 & 0.58 & 0.09 & 0.2249 & 0.2210 \\
\hline TR-SC & 22.59 & 3.47 & 0.82 & 45.00 & 10.04 & 3.03 & 0.2088 & 0.1919 & TR-SC & 9.26 & 1.23 & 0.19 & 38.49 & 7.21 & 2.11 & 0.2659 & 0.2451 \\
\hline TR-BC & 17.93 & 2.62 & 0.67 & 37.88 & 7.76 & 2.21 & 0.2239 & 0.2106 & TR-BC & 1.82 & 0.18 & 0.03 & 34.19 & 5.34 & 1.05 & 0.2980 & 0.2814 \\
\hline TR-OC & 19.67 & 3.22 & 0.81 & 41.06 & 8.92 & 2.72 & 0.2372 & 0.2400 & TR-OC & 2.29 & 0.27 & 0.08 & 14.19 & 2.37 & 0.61 & 0.3620 & 0.3260 \\
\hline UP-ST & 32.18 & 3.20 & 0.54 & 41.99 & 5.93 & 1.25 & 0.1936 & 0.2039 & UP-ST & 37.59 & 9.83 & 3.80 & 40.30 & 10.55 & 3.84 & 0.4415 & 0.3969 \\
\hline UP-SC & 44.73 & 9.06 & 2.72 & 56.60 & 12.79 & 4.02 & 0.2610 & 0.2221 & UP-SC & 43.46 & 10.81 & 3.64 & 44.24 & 11.59 & 3.92 & 0.2972 & 0.2829 \\
\hline UP-BC & 32.90 & 6.04 & 1.66 & 42.18 & 8.85 & 2.61 & 0.2796 & 0.2436 & UP-BC & 36.03 & 8.69 & 2.97 & 42.73 & 9.78 & 3.19 & 0.3068 & 0.2840 \\
\hline UP-OC & 19.48 & 3.57 & 1.02 & 26.02 & 5.32 & 1.58 & 0.3166 & 0.2739 & UP-OC & 18.96 & 3.93 & 1.18 & 20.86 & 4.29 & 1.31 & 0.3973 & 0.3834 \\
\hline UT-ST & 44.55 & 7.05 & 1.69 & 32.44 & 4.82 & 0.98 & 0.2006 & 0.1954 & UT-ST & 69.03 & 6.15 & 0.93 & 39.05 & 4.06 & 0.60 & 0.2526 & 0.2574 \\
\hline UT-SC & 53.28 & 10.90 & 3.14 & 46.24 & 8.55 & 2.25 & 0.2490 & 0.2258 & UT-SC & 70.12 & 16.97 & 5.53 & 47.46 & 10.15 & 2.95 & 0.3015 & 0.2882 \\
\hline UT-BC & 44.41 & 9.61 & 2.62 & 43.46 & 7.35 & 1.83 & 0.2668 & 0.2303 & UT-BC & 43.94 & 10.47 & 3.32 & 34.97 & 7.06 & 1.93 & 0.2353 & 0.2330 \\
\hline UT-OC & 33.54 & 5.89 & 1.55 & 27.89 & 4.21 & 0.97 & 0.3032 & 0.2434 & UT-OC & 25.06 & 5.75 & 1.66 & 17.93 & 3.23 & 0.87 & 0.3260 & 0.3102 \\
\hline WB-ST & 42.74 & 8.58 & 2.45 & 54.31 & 12.31 & 3.79 & 0.2051 & 0.1897 & WB-ST & 22.19 & 2.60 & 0.47 & 47.96 & 9.02 & 2.13 & 0.3322 & 0.3335 \\
\hline WB-SC & 28.85 & 5.03 & 1.28 & 37.14 & 7.53 & 2.19 & 0.2405 & 0.2323 & WB-SC & 25.46 & 4.35 & 1.12 & 40.95 & 8.92 & 2.76 & 0.3161 & 0.2874 \\
\hline WB-BC & 17.68 & 3.95 & 1.40 & 28.32 & 5.66 & 1.89 & 0.2839 & 0.2643 & WB-BC & 7.36 & 1.61 & 0.52 & 23.64 & 4.99 & 1.52 & 0.3268 & 0.3296 \\
\hline WB-OC & 27.35 & 5.14 & 1.42 & 37.70 & 7.77 & 2.29 & 0.2903 & 0.2673 & WB-OC & 10.47 & 2.02 & 0.57 & 19.53 & 4.25 & 1.34 & 0.3843 & 0.3756 \\
\hline Al-ST & 45.54 & 10.77 & 3.71 & 62.17 & 16.97 & 6.33 & 0.2717 & 0.2537 & Al-ST & 34.63 & 10.91 & 4.69 & 35.52 & 9.93 & 3.81 & 0.3390 & 0.3513 \\
\hline Al-SC & 37.08 & 7.49 & 2.23 & 53.52 & 12.25 & 3.96 & 0.2634 & 0.2405 & Al-SC & 40.88 & 10.39 & 3.79 & 40.56 & 9.85 & 3.38 & 0.3168 & 0.3016 \\
\hline Al-BC & 25.83 & 4.73 & 1.30 & 39.79 & 8.23 & 2.46 & 0.2938 & 0.2649 & Al-BC & 31.05 & 7.32 & 2.50 & 30.62 & 6.72 & 2.14 & 0.3362 & 0.3263 \\
\hline $\mathrm{Al}-\mathrm{OC}$ & 17.46 & 3.00 & 0.81 & 27.08 & 5.27 & 1.51 & 0.3200 & 0.2990 & $\mathrm{Al}-\mathrm{OC}$ & 16.11 & 3.63 & 1.18 & 16.13 & 3.39 & 1.04 & 0.3804 & 0.3659 \\
\hline $\mathrm{Al}$ & 28.12 & 5.50 & 1.63 & 41.80 & 9.24 & 2.94 & 0.3045 & 0.2808 & $\mathrm{Al}$ & 25.84 & 6.21 & 2.16 & 25.68 & 5.78 & 1.88 & 0.3764 & 0.3643 \\
\hline
\end{tabular}

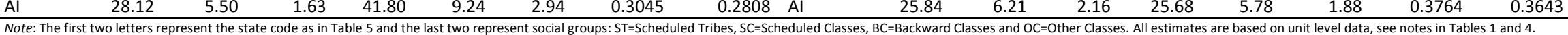
Source: Unit level data, Schedule 1.0, NSS $61^{\mathrm{st}}$ Round, 2004-05. 
Table 8: Poverty and Inequality across State-wise Occupation Groups with Old and New Methods, 2004-05, Rural and Urban

\begin{tabular}{|c|c|c|c|c|c|c|c|c|c|c|c|c|c|c|c|c|c|}
\hline \multicolumn{9}{|c|}{ Rural } & \multicolumn{9}{|c|}{ Urban } \\
\hline \multirow{3}{*}{$\begin{array}{l}\text { NSS } \\
\text { Region }\end{array}$} & \multicolumn{6}{|c|}{ Poverty } & \multicolumn{2}{|c|}{ Inequality } & \multirow{3}{*}{$\begin{array}{l}\text { NSS } \\
\text { Region }\end{array}$} & \multicolumn{6}{|c|}{ Poverty } & \multicolumn{2}{|c|}{ Inequality } \\
\hline & \multicolumn{3}{|c|}{ Old Method } & \multicolumn{3}{|c|}{ New Method } & \multirow[t]{2}{*}{ Old } & \multirow[t]{2}{*}{ New } & & \multicolumn{3}{|c|}{ Old Method } & \multicolumn{3}{|c|}{ New Method } & \multirow[t]{2}{*}{ Old } & \multirow[t]{2}{*}{ New } \\
\hline & $\alpha=0$ & $\alpha=1$ & $\alpha=2$ & $\alpha=0$ & $\alpha=1$ & $\alpha=2$ & & & & $\alpha=0$ & $\alpha=1$ & $\alpha=2$ & $\alpha=0$ & $\alpha=1$ & $\alpha=2$ & & \\
\hline AN-O1 & 12.74 & 2.16 & 0.63 & 5.38 & 0.33 & 0.02 & 0.5381 & 0.4614 & AN-01 & 24.35 & 3.94 & 0.80 & - & - & - & 0.2697 & 0.2935 \\
\hline $\mathrm{AN}-\mathrm{O} 2$ & 47.59 & 7.51 & 2.06 & 6.52 & 0.80 & 0.10 & 0.2276 & 0.1779 & $\mathrm{AN}-\mathrm{O} 2$ & 14.68 & 1.96 & 0.40 & - & - & - & 0.4006 & 0.3488 \\
\hline AN-O3 & 22.35 & 2.52 & 0.58 & 2.62 & 0.13 & 0.01 & 0.1851 & 0.1754 & AN-O3 & 55.23 & 11.31 & 3.15 & 5.58 & 0.08 & 0.00 & 0.1956 & 0.1990 \\
\hline AN-O4 & 34.47 & 5.40 & 1.29 & 4.74 & 0.25 & 0.01 & 0.2142 & 0.1908 & AN-O4 & - & - & - & - & - & - & - & - \\
\hline AN-O9 & 3.59 & 0.25 & 0.03 & - & - & - & 0.2408 & 0.2459 & AN-O9 & 5.29 & 1.53 & 0.55 & - & - & - & 0.2343 & 0.2496 \\
\hline AP-01 & 4.71 & 0.83 & 0.21 & 22.40 & 4.09 & 1.16 & 0.2903 & 0.2630 & AP-01 & 31.95 & 6.26 & 1.81 & 26.53 & 5.24 & 1.47 & 0.3356 & 0.3313 \\
\hline AP-O2 & 15.93 & 2.49 & 0.58 & 46.07 & 9.95 & 3.08 & 0.2314 & 0.2062 & AP-O2 & 17.05 & 3.27 & 0.92 & 13.98 & 2.56 & 0.69 & 0.3556 & 0.3372 \\
\hline AP-O3 & 6.32 & 0.98 & 0.25 & 27.78 & 5.18 & 1.43 & 0.2622 & 0.2238 & AP-O3 & 49.84 & 11.44 & 3.61 & 45.24 & 9.67 & 2.96 & 0.2604 & 0.1925 \\
\hline AP-O4 & 8.78 & 1.37 & 0.35 & 26.05 & 5.51 & 1.69 & 0.3007 & 0.2720 & AP-O4 & & & & & & - & & \\
\hline AP-09 & 8.74 & 4.78 & 3.51 & 18.45 & 6.70 & 3.80 & 0.3600 & 0.3285 & AP-09 & 13.09 & 5.06 & 3.17 & 13.05 & 5.31 & 3.36 & 0.4769 & 0.4552 \\
\hline AR-O1 & 15.55 & 2.35 & 0.55 & 18.37 & 3.71 & 0.97 & 0.3049 & 0.2718 & AR-01 & 2.00 & 0.14 & 0.01 & 19.83 & 3.59 & 0.78 & 0.2338 & 0.2138 \\
\hline AR-O2 & 17.60 & 6.46 & 2.77 & 33.68 & 6.70 & 2.54 & 0.2195 & 0.2260 & AR-O2 & 2.35 & 0.13 & 0.01 & 16.98 & 3.14 & 0.81 & 0.2435 & 0.2305 \\
\hline AR-O3 & 51.42 & 10.42 & 3.63 & 55.33 & 17.62 & 7.11 & 0.2318 & 0.2414 & AR-O3 & 11.01 & 2.15 & 0.56 & 80.31 & 15.04 & 4.01 & 0.1919 & 0.1321 \\
\hline AR-O4 & 22.43 & 4.18 & 1.23 & 37.00 & 7.62 & 2.40 & 0.2624 & 0.2474 & AR-O4 & - & - & - & - & - & - & - & - \\
\hline AR-09 & 19.14 & 4.88 & 1.71 & 24.60 & 7.21 & 2.80 & 0.2769 & 0.2597 & AR-09 & 12.88 & 3.12 & 1.02 & 45.58 & 12.72 & 4.73 & 0.2862 & 0.2929 \\
\hline AS-01 & 26.99 & 4.64 & 1.16 & 40.39 & 8.22 & 2.38 & 0.2115 & 0.2019 & AS-01 & 3.66 & 0.48 & 0.11 & 24.77 & 4.66 & 1.19 & 0.3039 & 0.3224 \\
\hline AS-O2 & 36.64 & 6.47 & 1.76 & 55.37 & 11.88 & 3.57 & 0.1670 & 0.1616 & AS-O2 & 1.00 & 0.06 & 0.01 & 15.58 & 2.47 & 0.58 & 0.3237 & 0.2791 \\
\hline AS-O3 & 39.26 & 7.71 & 2.27 & 61.27 & 13.70 & 4.29 & 0.1800 & 0.1680 & AS-O3 & 23.21 & 3.28 & 0.88 & 77.87 & 19.27 & 6.12 & 0.1536 & 0.1554 \\
\hline AS-O4 & 15.60 & 2.13 & 0.45 & 28.67 & 4.76 & 1.21 & 0.1684 & 0.1640 & AS-O4 & - & - & - & - & - & - & - & - \\
\hline AS-09 & 9.68 & 1.66 & 0.53 & 15.21 & 2.85 & 0.89 & 0.2479 & 0.2308 & AS-09 & 3.99 & 0.48 & 0.09 & 10.85 & 2.62 & 0.82 & 0.2550 & 0.2705 \\
\hline BI-O1 & 37.00 & 5.74 & 1.40 & 52.63 & 10.00 & 2.78 & 0.1837 & 0.1748 & BI-O1 & 36.03 & 6.87 & 1.93 & 47.17 & 11.31 & 3.54 & 0.2726 & 0.2732 \\
\hline $\mathrm{BI}-\mathrm{O} 2$ & 67.48 & 14.51 & 4.19 & 79.29 & 21.16 & 7.11 & 0.1576 & 0.1562 & BI-O2 & 25.19 & 4.31 & 1.01 & 28.39 & 7.10 & 2.19 & 0.3562 & 0.3150 \\
\hline BI-O3 & 58.69 & 9.24 & 2.24 & 78.28 & 16.07 & 4.65 & 0.1459 & 0.1424 & BI-O3 & 80.74 & 22.37 & 8.23 & 83.22 & 28.94 & 11.90 & 0.2488 & 0.2395 \\
\hline BI-O4 & 25.52 & 4.29 & 1.07 & 37.75 & 7.17 & 1.93 & 0.2006 & 0.1803 & BI-O4 & - & - & - & - & - & - & - & - \\
\hline BI-O9 & 41.62 & 8.61 & 2.40 & 54.95 & 13.14 & 4.14 & 0.2514 & 0.2320 & BI-O9 & 23.40 & 4.84 & 1.56 & 26.48 & 7.02 & 2.56 & 0.3618 & 0.3518 \\
\hline $\mathrm{CN}-\mathrm{O} 1$ & 16.78 & 0.01 & 0.00 & 29.61 & 7.83 & 2.79 & 0.2750 & 0.2872 & $\mathrm{CN}-\mathrm{O} 1$ & 10.07 & 1.67 & 0.51 & 15.90 & 3.73 & 1.19 & 0.3742 & 0.3954 \\
\hline $\mathrm{CN}-\mathrm{O} 2$ & - & - & - & - & - & - & - & 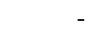 & $\mathrm{CN}-\mathrm{O} 2$ & 4.58 & 0.83 & 0.18 & 7.88 & 1.60 & 0.43 & 0.3342 & 0.3280 \\
\hline $\mathrm{CN}-\mathrm{O} 3$ & - & - & - & - & - & - & 0.0059 & 0.0088 & $\mathrm{CN}-\mathrm{O} 3$ & 16.48 & 3.92 & 0.93 & 17.99 & 6.17 & 2.26 & 0.1163 & 0.1092 \\
\hline $\mathrm{CN}-\mathrm{O} 4$ & - & - & - & 13.15 & 1.01 & 0.11 & 0.2442 & 0.2665 & $\mathrm{CN}-\mathrm{O} 4$ & - & - & - & - & 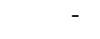 & - & & \\
\hline $\mathrm{CN}-\mathrm{O} 9$ & - & - & - & 1.25 & 0.27 & 0.06 & 0.1868 & 0.1853 & CN-O9 & - & - & - & - & - & - & 0.2908 & 0.3165 \\
\hline CT-O1 & 43.96 & 13.49 & 5.80 & 51.33 & 17.12 & 8.00 & 0.3433 & 0.3447 & CT-O1 & 43.23 & 11.89 & 4.63 & 25.11 & 6.47 & 2.41 & 0.3699 & 0.3198 \\
\hline CT-O2 & 55.45 & 12.49 & 4.05 & 73.28 & 18.92 & 6.62 & 0.2351 & 0.2087 & CT-O2 & 24.12 & 7.07 & 2.61 & 17.36 & 4.00 & 1.34 & 0.4663 & 0.3671 \\
\hline CT-O3 & 24.04 & 4.48 & 1.56 & 38.11 & 8.26 & 2.82 & 0.2210 & 0.2126 & CT-O3 & 92.02 & 29.05 & 11.78 & 71.08 & 18.94 & 6.85 & 0.1676 & 0.1808 \\
\hline CT-O4 & 32.01 & 6.85 & 2.29 & 44.59 & 10.04 & 3.48 & 0.2896 & 0.2532 & CT-O4 & - & - & 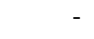 & - & 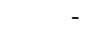 & - & - & \\
\hline CT-O9 & 16.65 & 3.70 & 1.22 & 28.22 & 5.32 & 1.83 & 0.4112 & 0.3101 & CT-O9 & 18.70 & 4.30 & 1.31 & 8.37 & 1.67 & 0.46 & 0.3687 & 0.3736 \\
\hline
\end{tabular}


Table 8: Poverty and Inequality across State-wise Occupation Groups with Old and New Methods, 2004-05, Rural and Urban

\begin{tabular}{|c|c|c|c|c|c|c|c|c|c|c|c|c|c|c|c|c|c|}
\hline \multirow{4}{*}{$\begin{array}{l}\text { NSS } \\
\text { Region }\end{array}$} & \multicolumn{6}{|c|}{ Rural } & & & \multicolumn{9}{|c|}{ Urban } \\
\hline & \multicolumn{6}{|c|}{ Poverty } & \multicolumn{2}{|c|}{ Inequality } & \multirow{3}{*}{$\begin{array}{l}\text { NSS } \\
\text { Region }\end{array}$} & \multicolumn{6}{|c|}{ Poverty } & \multicolumn{2}{|c|}{ Inequality } \\
\hline & \multicolumn{3}{|c|}{ Old Method } & \multicolumn{3}{|c|}{ New Method } & \multirow[t]{2}{*}{ Old } & \multirow[t]{2}{*}{ New } & & \multicolumn{3}{|c|}{ Old Method } & \multicolumn{3}{|c|}{ New Method } & \multirow[t]{2}{*}{ Old } & \multirow[t]{2}{*}{ New } \\
\hline & $\alpha=0$ & $\alpha=1$ & $\alpha=2$ & $\alpha=0$ & $\alpha=1$ & $\alpha=2$ & & & & $\alpha=0$ & $\alpha=1$ & $\alpha=2$ & $\alpha=0$ & $\alpha=1$ & $\alpha=2$ & & \\
\hline DA-01 & 14.82 & 1.67 & 0.19 & 29.37 & 7.31 & 2.00 & 0.3238 & 0.3221 & DA-O1 & 1.99 & 0.40 & 0.08 & 1.06 & 0.19 & 0.03 & 0.1840 & 0.1861 \\
\hline DA-O2 & 84.34 & 11.01 & 2.00 & 93.30 & 30.00 & 10.22 & 0.1325 & 0.1347 & DA-O2 & 22.83 & 8.13 & 3.23 & 22.71 & 7.26 & 2.58 & 0.3270 & 0.3521 \\
\hline DA-O3 & 40.30 & 7.52 & 1.68 & 66.26 & 18.26 & 6.18 & 0.2960 & 0.2767 & DA-03 & 96.25 & 27.62 & 8.26 & 68.75 & 17.11 & 4.30 & 0.0450 & 0.0640 \\
\hline DA-O4 & 34.55 & 2.89 & 0.37 & 71.60 & 13.94 & 3.68 & 0.2709 & 0.2015 & DA-04 & 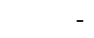 & & - & - & - & - & - & - \\
\hline DA-09 & 30.30 & 18.66 & 12.55 & 48.37 & 20.27 & 13.81 & 0.4184 & 0.3944 & DA-09 & - & - & - & - & - & - & - & - \\
\hline DD-01 & 7.48 & 0.03 & 0.00 & - & - & - & 0.0967 & 0.1005 & DD-01 & 6.71 & 1.85 & 0.58 & 5.62 & 1.19 & 0.26 & 0.1450 & 0.1366 \\
\hline DD-O3 & 18.81 & 5.89 & 1.84 & 18.81 & 3.81 & 0.77 & 0.1536 & 0.1330 & DD-03 & 76.99 & 16.25 & 3.58 & 72.74 & 9.50 & 1.25 & 0.1002 & 0.0945 \\
\hline DD-O4 & 6.05 & 0.15 & 0.04 & 0.53 & 0.03 & 0.00 & 0.1123 & 0.0922 & DD-04 & - & - & - & - & - & - & - & - \\
\hline DD-09 & - & - & - & - & - & - & 0.2746 & 0.2679 & DD-09 & 43.34 & 3.53 & 0.29 & 14.45 & 0.01 & 0.00 & 0.2389 & 0.2273 \\
\hline DE-O1 & 22.89 & 1.01 & 0.05 & 41.20 & 5.41 & 1.06 & 0.2048 & 0.2127 & DE-01 & 17.34 & 2.51 & 0.55 & 12.11 & 1.59 & 0.32 & 0.3226 & 0.3092 \\
\hline DE-O2 & - & - & - & - & - & - & 0.0163 & 0.0182 & $\mathrm{DE}-\mathrm{O} 2$ & 12.20 & 1.81 & 0.44 & 9.53 & 1.44 & 0.32 & 0.3307 & 0.3373 \\
\hline DE-O3 & - & - & - & 46.15 & 4.35 & 0.41 & 0.1017 & 0.0977 & DE-O3 & 57.89 & 12.31 & 4.77 & 57.85 & 10.43 & 4.03 & 0.2305 & 0.2184 \\
\hline DE-O4 & - & - & - & - & - & - & 0.1071 & 0.0816 & DE-O4 & - & - & - & - & - & - & - & - \\
\hline DE-O9 & - & - & - & - & - & - & 0.2685 & 0.2860 & DE-09 & 6.41 & 2.64 & 1.09 & 9.01 & 3.82 & 1.63 & 0.3780 & 0.3653 \\
\hline GO-O1 & - & - & - & 4.20 & 0.81 & 0.18 & 0.3399 & 0.2319 & GO-O1 & 13.64 & 2.34 & 0.68 & 9.79 & 1.84 & 0.52 & 0.4624 & 0.3438 \\
\hline GO-O2 & 19.24 & 3.25 & 0.55 & 57.24 & 13.79 & 5.35 & 0.2647 & 0.2390 & GO-O2 & 9.87 & 2.32 & 0.88 & 13.22 & 2.05 & 0.66 & 0.3612 & 0.3341 \\
\hline GO-09 & - & - & - & 25.59 & 3.17 & 0.66 & 0.2999 & 0.3103 & GO-O9 & 10.50 & 1.38 & 0.18 & 6.63 & 0.33 & 0.02 & 0.2226 & 0.2397 \\
\hline GU-01 & 10.35 & 1.58 & 0.35 & 28.01 & 5.45 & 1.63 & 0.3023 & 0.2556 & GU-01 & 13.93 & 2.42 & 0.63 & 21.45 & 4.00 & 1.14 & 0.2932 & 0.2923 \\
\hline GU-O2 & 29.59 & 5.00 & 1.24 & 57.77 & 14.50 & 4.81 & 0.2007 & 0.1895 & GU-O2 & 7.18 & 1.22 & 0.32 & 11.87 & 2.17 & 0.60 & 0.3027 & 0.3041 \\
\hline GU-O3 & 22.12 & 4.23 & 1.12 & 45.87 & 11.41 & 3.87 & 0.2448 & 0.2440 & GU-O3 & 47.40 & 8.46 & 2.38 & 62.89 & 13.80 & 4.16 & 0.2146 & 0.2042 \\
\hline GU-O4 & 13.32 & 2.36 & 0.69 & 27.35 & 6.33 & 2.22 & 0.2642 & 0.2641 & GU-O4 & - & - & - & - & - & - & - & - \\
\hline GU-09 & 5.60 & 2.07 & 1.19 & 18.36 & 3.47 & 1.50 & 0.3008 & 0.2867 & GU-09 & 5.16 & 2.37 & 1.39 & 6.96 & 2.70 & 1.43 & 0.3646 & 0.3905 \\
\hline $\mathrm{HA}-\mathrm{O} 1$ & 11.68 & 2.38 & 0.66 & 24.89 & 4.99 & 1.44 & 0.2668 & 0.2303 & $\mathrm{HA}-\mathrm{O} 1$ & 11.59 & 2.44 & 0.76 & 18.29 & 3.82 & 1.22 & 0.3432 & 0.3263 \\
\hline $\mathrm{HA}-\mathrm{O} 2$ & 27.97 & 5.62 & 1.64 & 59.36 & 11.34 & 3.37 & 0.2007 & 0.1677 & $\mathrm{HA}-\mathrm{O} 2$ & 11.90 & 2.26 & 0.60 & 19.60 & 3.71 & 1.01 & 0.3685 & 0.3299 \\
\hline $\mathrm{HA}-\mathrm{O} 3$ & 31.71 & 5.60 & 1.66 & 48.48 & 10.42 & 3.11 & 0.2556 & 0.2107 & $\mathrm{HA}-\mathrm{O} 3$ & 50.27 & 14.59 & 5.60 & 67.06 & 19.84 & 7.76 & 0.2443 & 0.2196 \\
\hline $\mathrm{HA}-\mathrm{O} 4$ & 5.32 & 0.80 & 0.16 & 11.57 & 1.66 & 0.37 & 0.2536 & 0.2168 & $\mathrm{HA}-\mathrm{O} 4$ & - & & - & - & & - & - & - \\
\hline HA-O9 & 8.16 & 0.81 & 0.16 & 10.97 & 2.18 & 0.52 & 0.4613 & 0.4745 & HA-O9 & 5.81 & 1.27 & 0.36 & 13.95 & 1.58 & 0.49 & 0.3839 & 0.3718 \\
\hline HP-O1 & 9.63 & 1.08 & 0.20 & 21.85 & 3.10 & 0.70 & 0.3983 & 0.3435 & HP-O1 & 2.78 & 0.57 & 0.18 & 4.43 & 0.79 & 0.24 & 0.2690 & 0.2360 \\
\hline HP-O2 & 35.03 & 4.50 & 0.72 & 54.23 & 11.56 & 3.12 & 0.2505 & 0.2274 & HP-O2 & 1.22 & 0.16 & 0.03 & 1.45 & 0.22 & 0.04 & 0.3267 & 0.2755 \\
\hline HP-O3 & 18.91 & 3.00 & 0.69 & 41.92 & 7.66 & 2.13 & 0.2101 & 0.2033 & HP-O3 & 12.42 & 4.49 & 2.01 & 16.99 & 5.21 & 2.33 & 0.2586 & 0.2304 \\
\hline HP-O4 & 9.30 & 1.51 & 0.40 & 24.08 & 3.98 & 1.04 & 0.2668 & 0.2589 & HP-O4 & - & - & - & - & - & - & - & - \\
\hline HP-O9 & 1.86 & 0.24 & 0.05 & 6.10 & 0.84 & 0.20 & 0.3171 & 0.2916 & HP-O9 & - & - & - & - & - & - & 0.2737 & 0.2533 \\
\hline
\end{tabular}


Table 8: Poverty and Inequality across State-wise Occupation Groups with Old and New Methods, 2004-05, Rural and Urban

\begin{tabular}{|c|c|c|c|c|c|c|c|c|c|c|c|c|c|c|c|c|c|}
\hline \multirow{4}{*}{$\begin{array}{l}\text { NSS } \\
\text { Region }\end{array}$} & \multicolumn{6}{|c|}{ Rural } & & & \multicolumn{9}{|c|}{ Urban } \\
\hline & \multicolumn{6}{|c|}{ Poverty } & \multicolumn{2}{|c|}{ Inequality } & \multirow{3}{*}{$\begin{array}{l}\text { NSS } \\
\text { Region }\end{array}$} & \multicolumn{6}{|c|}{ Poverty } & \multicolumn{2}{|c|}{ Inequality } \\
\hline & \multicolumn{3}{|c|}{ Old Method } & \multicolumn{3}{|c|}{ New Method } & \multirow[t]{2}{*}{ Old } & \multirow[t]{2}{*}{ New } & & \multicolumn{3}{|c|}{ Old Method } & \multicolumn{3}{|c|}{ New Method } & \multirow[t]{2}{*}{ Old } & \multirow[t]{2}{*}{ New } \\
\hline & $\alpha=0$ & $\alpha=1$ & $\alpha=2$ & $\alpha=0$ & $\alpha=1$ & $\alpha=2$ & & & & $\alpha=0$ & $\alpha=1$ & $\alpha=2$ & $\alpha=0$ & $\alpha=1$ & $\alpha=2$ & & \\
\hline JK-O1 & 3.31 & 0.43 & 0.11 & 14.76 & 2.07 & 0.51 & 0.2445 & 0.2222 & $\mathrm{JK}-\mathrm{O} 1$ & 5.14 & 0.84 & 0.22 & 5.40 & 0.78 & 0.19 & 0.2221 & 0.2114 \\
\hline JK-O2 & 10.89 & 1.16 & 0.18 & 17.22 & 3.61 & 0.90 & 0.1532 & 0.1484 & $\mathrm{JK}-\mathrm{O} 2$ & 2.19 & 0.35 & 0.08 & 3.41 & 0.59 & 0.14 & 0.2226 & 0.2366 \\
\hline $\mathrm{JK}-\mathrm{O} 3$ & 11.20 & 1.10 & 0.20 & 31.29 & 4.55 & 1.03 & 0.1590 & 0.1526 & $\mathrm{JK}-\mathrm{O} 3$ & 41.92 & 12.02 & 3.64 & 42.65 & 12.50 & 3.90 & 0.1633 & 0.1547 \\
\hline JK-O4 & 2.25 & 0.43 & 0.13 & 11.94 & 1.55 & 0.36 & 0.2438 & 0.1991 & JK-O4 & & & - & - & & & - & - \\
\hline JK-O9 & 5.52 & 1.04 & 0.23 & 9.43 & 2.00 & 0.59 & 0.2594 & 0.2427 & JK-O9 & 1.49 & 0.12 & 0.01 & 22.22 & 2.81 & 0.36 & 0.2404 & 0.2913 \\
\hline $\mathrm{JN}-\mathrm{O} 1$ & 41.59 & 7.54 & 2.01 & 45.77 & 8.54 & 2.32 & 0.2473 & 0.2122 & $\mathrm{JN}-\mathrm{O} 1$ & 19.37 & 4.27 & 1.30 & 24.87 & 5.80 & 1.85 & 0.3286 & 0.2790 \\
\hline $\mathrm{JN}-\mathrm{O} 3$ & 60.16 & 12.54 & 3.52 & 67.99 & 14.40 & 4.10 & 0.1778 & 0.1600 & $\mathrm{JN}-\mathrm{O} 3$ & 61.58 & 11.98 & 3.65 & 65.81 & 15.95 & 5.33 & 0.2447 & 0.2684 \\
\hline $\mathrm{JN}-\mathrm{O} 4$ & 43.97 & 9.31 & 2.76 & 50.63 & 10.77 & 3.30 & 0.2063 & 0.1902 & $\mathrm{JN}-\mathrm{O} 4$ & - & - & - & - & - & - & - & - \\
\hline $\mathrm{JN}-09$ & 16.28 & 2.83 & 0.66 & 17.14 & 2.75 & 0.56 & 0.2316 & 0.2122 & $\mathrm{JN}-\mathrm{O9}$ & 8.25 & 1.81 & 0.46 & 8.43 & 2.34 & 0.73 & 0.2147 & 0.2064 \\
\hline KA-O1 & 13.15 & 1.74 & 0.36 & 24.73 & 3.77 & 0.84 & 0.2609 & 0.2330 & KA-O1 & 32.23 & 8.05 & 2.82 & 25.25 & 5.30 & 1.64 & 0.3215 & 0.3244 \\
\hline $\mathrm{KA}-\mathrm{O} 2$ & 32.40 & 4.83 & 1.13 & 56.27 & 10.63 & 2.87 & 0.1815 & 0.1629 & KA-O2 & 20.25 & 4.67 & 1.54 & 14.13 & 2.95 & 0.90 & 0.3616 & 0.3538 \\
\hline KA-O3 & 10.67 & 2.20 & 0.59 & 23.98 & 4.50 & 1.47 & 0.2174 & 0.2057 & KA-O3 & 64.69 & 20.52 & 8.53 & 56.75 & 16.30 & 6.06 & 0.2622 & 0.2484 \\
\hline KA-O4 & 14.08 & 1.51 & 0.25 & 26.97 & 3.91 & 0.82 & 0.2594 & 0.2388 & KA-O4 & - & - & - & - & - & - & - & - \\
\hline KA-O9 & 9.10 & 1.03 & 0.38 & 17.11 & 2.73 & 0.79 & 0.4513 & 0.3964 & КА-О9 & 27.69 & 7.50 & 2.80 & 22.04 & 5.60 & 2.63 & 0.4329 & 0.4481 \\
\hline KE-O1 & 7.65 & 1.16 & 0.27 & 11.61 & 1.99 & 0.52 & 0.3601 & 0.3413 & KE-O1 & 15.14 & 3.56 & 1.26 & 13.67 & 3.01 & 1.01 & 0.4131 & 0.3940 \\
\hline KE-O2 & 23.91 & 5.13 & 1.79 & 35.79 & 8.52 & 3.04 & 0.2988 & 0.2414 & KE-O2 & 14.55 & 3.32 & 1.11 & 12.96 & 2.64 & 0.78 & 0.3899 & 0.3822 \\
\hline KE-O9 & 9.41 & 2.22 & 0.95 & 13.17 & 3.10 & 1.16 & 0.4217 & 0.3648 & KE-O9 & 18.03 & 2.47 & 0.78 & 10.48 & 1.70 & 0.53 & 0.3948 & 0.4030 \\
\hline LA-O1 & - & - & - & - & - & - & 0.1834 & 0.1663 & LA-O1 & 18.11 & 3.42 & 0.88 & 4.49 & 1.01 & 0.23 & 0.3063 & 0.2335 \\
\hline LA-O2 & - & - & - & - & - & - & 0.0000 & 0.0000 & LA-O2 & 10.97 & 0.77 & 0.11 & 0.87 & 0.04 & 0.00 & 0.3876 & 0.2087 \\
\hline LA-O3 & - & - & - & - & - & - & 0.2586 & 0.1948 & LA-O3 & 62.40 & 30.35 & 17.66 & 54.20 & 23.68 & 12.32 & 0.4478 & 0.4397 \\
\hline LA-O4 & 0.67 & 0.16 & 0.05 & 0.46 & 0.13 & 0.04 & 0.2657 & 0.2647 & LA-O4 & - & - & - & - & - & - & - & - \\
\hline LA-O9 & 29.15 & 0.16 & 0.05 & 0.35 & 0.10 & 0.03 & 0.2619 & 0.2065 & LA-09 & 19.17 & 6.05 & 2.01 & 19.17 & 3.30 & 0.77 & 0.2979 & 0.3172 \\
\hline MP-01 & 32.67 & 6.88 & 2.26 & 45.07 & 10.25 & 3.38 & 0.2691 & 0.2477 & MP-01 & 48.36 & 13.29 & 4.89 & 37.52 & 8.94 & 2.92 & 0.4088 & 0.3387 \\
\hline MP-O2 & 56.52 & 13.73 & 4.69 & 76.93 & 20.72 & 7.43 & 0.2215 & 0.1925 & MP-O2 & 25.33 & 5.47 & 1.90 & 19.27 & 4.03 & 1.31 & 0.3367 & 0.3482 \\
\hline MP-03 & 49.56 & 11.08 & 3.47 & 67.36 & 17.61 & 6.26 & 0.2378 & 0.2067 & MP-O3 & 78.57 & 27.36 & 11.59 & 74.61 & 20.91 & 7.74 & 0.2625 & 0.2140 \\
\hline MP-O4 & 27.13 & 5.10 & 1.36 & 43.40 & 8.55 & 2.44 & 0.2558 & 0.2392 & MP-O4 & & & - & - & & & - & \\
\hline MP-09 & 11.80 & 2.50 & 0.92 & 20.13 & 4.00 & 1.44 & 0.2793 & 0.2875 & MP-O9 & 30.72 & 9.96 & 3.71 & 25.83 & 6.37 & 1.96 & 0.5082 & 0.4358 \\
\hline MR-O1 & 21.37 & 3.62 & 0.96 & 36.89 & 8.08 & 2.53 & 0.3210 & 0.2945 & MR-O1 & 32.79 & 9.19 & 3.52 & 26.40 & 6.44 & 2.22 & 0.3774 & 0.3775 \\
\hline MR-O2 & 47.32 & 10.39 & 3.18 & 69.46 & 18.63 & 6.78 & 0.2285 & 0.2064 & MR-O2 & 23.04 & 5.60 & 1.91 & 17.10 & 3.56 & 1.06 & 0.3488 & 0.3314 \\
\hline MR-O3 & 30.88 & 5.95 & 1.69 & 46.05 & 12.19 & 4.30 & 0.3065 & 0.2796 & MR-O3 & 76.73 & 26.24 & 11.42 & 66.56 & 20.51 & 8.14 & 0.2472 & 0.2418 \\
\hline MR-O4 & 18.18 & 3.96 & 1.37 & 35.51 & 7.72 & 2.67 & 0.2884 & 0.2529 & MR-O4 & - & - & - & - & - & - & - & - \\
\hline MR-09 & 7.97 & 2.05 & 1.05 & 16.58 & 3.92 & 1.63 & 0.3307 & 0.3185 & MR-09 & 13.72 & 3.96 & 1.81 & 9.50 & 2.91 & 1.27 & 0.4072 & 0.3843 \\
\hline
\end{tabular}


Table 8: Poverty and Inequality across State-wise Occupation Groups with Old and New Methods, 2004-05, Rural and Urban

\begin{tabular}{|c|c|c|c|c|c|c|c|c|c|c|c|c|c|c|c|c|c|}
\hline \multirow{4}{*}{$\begin{array}{l}\text { NSS } \\
\text { Region }\end{array}$} & \multicolumn{6}{|c|}{ Rural } & & & \multicolumn{9}{|c|}{ Urban } \\
\hline & \multicolumn{6}{|c|}{ Poverty } & \multicolumn{2}{|c|}{ Inequality } & \multirow{3}{*}{$\begin{array}{l}\text { NSS } \\
\text { Region }\end{array}$} & \multicolumn{6}{|c|}{ Poverty } & \multicolumn{2}{|c|}{ Inequality } \\
\hline & \multicolumn{3}{|c|}{ Old Method } & \multicolumn{3}{|c|}{ New Method } & \multirow[t]{2}{*}{ Old } & \multirow[t]{2}{*}{ New } & & \multicolumn{3}{|c|}{ Old Method } & \multicolumn{3}{|c|}{ New Method } & \multirow[t]{2}{*}{ Old } & \multirow[t]{2}{*}{ New } \\
\hline & $\alpha=0$ & $\alpha=1$ & $\alpha=2$ & $\alpha=0$ & $\alpha=1$ & $\alpha=2$ & & & & $\alpha=0$ & $\alpha=1$ & $\alpha=2$ & $\alpha=0$ & $\alpha=1$ & $\alpha=2$ & & \\
\hline MU-01 & 14.09 & 2.18 & 0.46 & 24.24 & 3.07 & 0.70 & 0.1743 & 0.1515 & MU-O1 & 5.09 & 0.41 & 0.06 & 43.67 & 6.89 & 1.43 & 0.1625 & 0.1498 \\
\hline MU-02 & 7.02 & 2.10 & 0.65 & 25.31 & 2.90 & 0.94 & 0.1303 & 0.1249 & $\mathrm{MU}-\mathrm{O} 2$ & 1.34 & 0.10 & 0.01 & 17.35 & 2.31 & 0.42 & 0.1805 & 0.1582 \\
\hline $\mathrm{MU}-\mathrm{O} 3$ & 25.67 & 2.54 & 0.56 & 50.49 & 6.88 & 1.49 & 0.1356 & 0.1276 & MU-O3 & 9.47 & 0.66 & 0.05 & 66.58 & 13.56 & 3.00 & 0.1281 & 0.1430 \\
\hline MU-04 & 25.96 & 3.59 & 0.71 & 47.74 & 7.08 & 1.58 & 0.1259 & 0.1236 & MU-O4 & & & 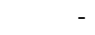 & - & & & - & 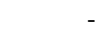 \\
\hline MU-09 & 18.11 & 1.52 & 0.20 & 26.62 & 4.04 & 0.77 & 0.1910 & 0.1917 & MU-09 & 1.70 & 0.18 & 0.04 & 38.67 & 4.60 & 0.89 & 0.1706 & 0.1654 \\
\hline MY-01 & 14.00 & 1.51 & 0.26 & 6.64 & 0.72 & 0.11 & 0.1697 & 0.1634 & MY-O1 & 7.05 & 0.67 & 0.11 & 30.51 & 4.65 & 1.10 & 0.1997 & 0.2367 \\
\hline MY-O3 & 31.99 & 3.43 & 0.54 & 23.01 & 2.16 & 0.30 & 0.1191 & 0.1156 & MY-O3 & 19.50 & 1.98 & 0.31 & 66.09 & 9.61 & 1.92 & 0.1796 & 0.1501 \\
\hline MY-O4 & 24.25 & 2.93 & 0.57 & 15.05 & 1.51 & 0.24 & 0.1489 & 0.1293 & MY-O4 & - & - & - & - & - & - & - & - \\
\hline MY-O9 & 6.20 & 0.87 & 0.16 & 2.63 & 0.28 & 0.06 & 0.1747 & 0.1652 & MY-09 & 3.46 & 0.30 & 0.06 & 20.81 & 1.98 & 0.35 & 0.2973 & 0.2968 \\
\hline MZ-O1 & 5.87 & 0.85 & 0.18 & 6.63 & 0.96 & 0.21 & 0.2387 & 0.2062 & MZ-01 & 5.54 & 0.45 & 0.08 & 12.14 & 1.48 & 0.30 & 0.2400 & 0.2195 \\
\hline MZ-O2 & 5.80 & 0.29 & 0.01 & - & - & - & 0.1796 & 0.1485 & $\mathrm{MZ}-\mathrm{O} 2$ & 1.02 & 0.14 & 0.03 & 2.69 & 0.37 & 0.09 & 0.2321 & 0.2150 \\
\hline MZ-O3 & 13.85 & 3.78 & 1.58 & 7.20 & 3.19 & 1.41 & 0.1579 & 0.1622 & MZ-O3 & 9.93 & 1.39 & 0.27 & 19.06 & 2.78 & 0.69 & 0.1939 & 0.1842 \\
\hline MZ-O4 & 26.46 & 3.91 & 1.00 & 27.33 & 4.20 & 1.08 & 0.1702 & 0.1536 & MZ-O4 & - & - & - & - & - & - & - & - \\
\hline MZ-O9 & 8.52 & 1.32 & 0.30 & 11.05 & 1.18 & 0.21 & 0.1997 & 0.2028 & MZ-09 & 4.58 & 0.52 & 0.07 & 9.19 & 1.04 & 0.19 & 0.2498 & 0.2205 \\
\hline NA-O1 & 20.40 & 4.63 & 1.39 & 15.57 & 2.99 & 0.79 & 0.2693 & 0.2678 & NA-O1 & 6.76 & 0.52 & 0.07 & 7.67 & 1.06 & 0.21 & 0.2550 & 0.2551 \\
\hline NA-O2 & 57.23 & 21.08 & 7.77 & 57.23 & 21.42 & 8.02 & 0.2027 & 0.1718 & NA-O2 & & & - & 1.36 & 0.07 & 0.00 & 0.2287 & 0.2120 \\
\hline NA-O9 & 2.97 & 0.18 & 0.01 & 0.81 & 0.03 & 0.00 & 0.2256 & 0.2023 & NA-O9 & 7.73 & 0.43 & 0.03 & 5.83 & 1.00 & 0.17 & 0.2596 & 0.2582 \\
\hline OD-O1 & 32.78 & 7.71 & 2.52 & 47.07 & 11.90 & 4.20 & 0.2762 & 0.2593 & OD-O1 & 50.16 & 15.71 & 6.44 & 44.42 & 11.53 & 4.29 & 0.3283 & 0.3190 \\
\hline OD-O2 & 64.54 & 18.27 & 6.87 & 78.98 & 24.86 & 10.04 & 0.2369 & 0.2082 & OD-O2 & 20.90 & 4.28 & 1.28 & 14.07 & 2.58 & 0.72 & 0.3151 & 0.2838 \\
\hline OD-O3 & 51.95 & 14.36 & 5.50 & 71.50 & 21.25 & 8.62 & 0.2533 & 0.2324 & OD-O3 & 89.25 & 29.33 & 12.42 & 76.15 & 21.19 & 7.81 & 0.2221 & 0.2095 \\
\hline OD-O4 & 46.11 & 11.10 & 3.78 & 58.95 & 16.06 & 5.81 & 0.2573 & 0.2379 & OD-04 & - & - & - & - & - & - & - & - \\
\hline OD-O9 & 19.78 & 3.66 & 1.08 & 28.53 & 6.35 & 2.08 & 0.3087 & 0.2976 & OD-09 & 26.38 & 7.66 & 3.49 & 22.10 & 5.79 & 2.55 & 0.3651 & 0.3926 \\
\hline PD-O1 & - & $\begin{array}{ll}- \\
-\end{array}$ & - & 2.52 & 0.04 & 0.00 & 0.2761 & 0.2088 & PD-01 & 17.20 & 1.89 & 0.35 & 6.19 & 0.68 & 0.10 & 0.2862 & 0.2853 \\
\hline PD-O2 & 41.67 & 4.16 & 0.58 & 43.25 & 8.09 & 1.72 & 0.3068 & 0.2488 & PD-O2 & 14.88 & 2.28 & 0.47 & 4.73 & 0.45 & 0.08 & 0.2978 & 0.3079 \\
\hline PD-O3 & 20.49 & 2.48 & 0.36 & 14.94 & 2.32 & 0.41 & 0.2934 & 0.2316 & PD-03 & 48.23 & 9.96 & 2.90 & 27.46 & 4.40 & 1.04 & 0.3054 & 0.2378 \\
\hline PD-O4 & & & & 4.97 & 0.12 & 0.00 & 0.2649 & 0.2692 & PD-O4 & & & - & - & & & - & \\
\hline PD-09 & 13.74 & 2.35 & 0.82 & 13.74 & 3.15 & 1.09 & 0.4672 & 0.5187 & PD-09 & 13.41 & 2.84 & 0.82 & 9.10 & 1.02 & 0.28 & 0.3395 & 0.3856 \\
\hline PN-O1 & 6.44 & 1.03 & 0.24 & 17.58 & 2.81 & 0.69 & 0.2906 & 0.2569 & PN-O1 & 4.74 & 0.56 & 0.11 & 15.80 & 2.66 & 0.66 & 0.3350 & 0.3211 \\
\hline $\mathrm{PN}-\mathrm{O} 2$ & 25.78 & 3.13 & 0.64 & 54.97 & 9.76 & 2.53 & 0.1983 & 0.1720 & $\mathrm{PN}-\mathrm{O} 2$ & 4.63 & 0.45 & 0.07 & 17.16 & 2.64 & 0.55 & 0.4675 & 0.3282 \\
\hline $\mathrm{PN}-\mathrm{O} 3$ & 9.54 & 1.67 & 0.40 & 31.05 & 5.25 & 1.45 & 0.2282 & 0.2184 & $\mathrm{PN}-\mathrm{O} 3$ & 25.48 & 2.60 & 0.47 & 50.42 & 9.88 & 2.75 & 0.1963 & 0.1912 \\
\hline $\mathrm{PN}-\mathrm{O} 4$ & 0.94 & 0.03 & 0.00 & 1.90 & 0.23 & 0.04 & 0.2457 & 0.2431 & $\mathrm{PN}-\mathrm{O} 4$ & - & - & - & - & - & - & - & - \\
\hline $\mathrm{PN}-09$ & 1.86 & 0.09 & 0.01 & 6.80 & 0.90 & 0.16 & 0.3282 & 0.3152 & PN-09 & 8.90 & 0.73 & 0.09 & 17.05 & 3.28 & 0.72 & 0.4503 & 0.4339 \\
\hline
\end{tabular}


Table 8: Poverty and Inequality across State-wise Occupation Groups with Old and New Methods, 2004-05, Rural and Urban

\begin{tabular}{|c|c|c|c|c|c|c|c|c|c|c|c|c|c|c|c|c|c|}
\hline \multirow{4}{*}{$\begin{array}{l}\text { NSS } \\
\text { Region }\end{array}$} & \multicolumn{6}{|c|}{ Rural } & & & \multicolumn{9}{|c|}{ Urban } \\
\hline & \multicolumn{6}{|c|}{ Poverty } & \multicolumn{2}{|c|}{ Inequality } & \multirow{3}{*}{$\begin{array}{l}\text { NSS } \\
\text { Region }\end{array}$} & \multicolumn{6}{|c|}{ Poverty } & \multicolumn{2}{|c|}{ Inequality } \\
\hline & \multicolumn{3}{|c|}{ Old Method } & \multicolumn{3}{|c|}{ New Method } & \multirow[t]{2}{*}{ Old } & \multirow[t]{2}{*}{ New } & & \multicolumn{3}{|c|}{ Old Method } & \multicolumn{3}{|c|}{ New Method } & \multirow[t]{2}{*}{ Old } & \multirow[t]{2}{*}{ New } \\
\hline & $\alpha=0$ & $\alpha=1$ & $\alpha=2$ & $\alpha=0$ & $\alpha=1$ & $\alpha=2$ & & & & $\alpha=0$ & $\alpha=1$ & $\alpha=2$ & $\alpha=0$ & $\alpha=1$ & $\alpha=2$ & & \\
\hline RA-01 & 12.61 & 1.86 & 0.40 & 27.79 & 5.05 & 1.29 & 0.2432 & 0.2158 & RA-01 & 37.75 & 7.24 & 2.04 & 31.88 & 5.20 & 1.34 & 0.3003 & 0.2811 \\
\hline RA-O2 & 37.03 & 6.17 & 1.44 & 61.85 & 13.61 & 4.04 & 0.2264 & 0.1742 & RA-O2 & 18.27 & 3.91 & 1.14 & 17.83 & 3.37 & 0.86 & 0.4078 & 0.3141 \\
\hline RA-O3 & 34.72 & 5.57 & 1.39 & 60.34 & 12.87 & 3.77 & 0.2371 & 0.1978 & RA-O3 & 63.41 & 19.20 & 7.40 & 62.52 & 16.69 & 5.78 & 0.2427 & 0.2401 \\
\hline RA-O4 & 14.09 & 2.32 & 0.60 & 29.75 & 5.51 & 1.57 & 0.2389 & 0.2083 & RA-O4 & & & - & - & & & - & 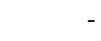 \\
\hline RA-O9 & 7.49 & 1.20 & 0.34 & 18.72 & 2.93 & 0.86 & 0.2440 & 0.2378 & RA-09 & 12.58 & 3.06 & 1.57 & 19.72 & 3.31 & 1.47 & 0.3968 & 0.4155 \\
\hline $\mathrm{SI}-\mathrm{O} 1$ & 10.36 & 1.72 & 0.48 & 16.85 & 2.74 & 0.80 & 0.2141 & 0.2127 & $\mathrm{SI}-\mathrm{O1}$ & 2.63 & 0.64 & 0.17 & 40.64 & 4.86 & 1.07 & 0.2257 & 0.2177 \\
\hline $\mathrm{SI}-\mathrm{O} 3$ & 22.87 & 3.82 & 0.85 & 31.68 & 6.39 & 1.78 & 0.2445 & 0.2411 & $\mathrm{SI}-\mathrm{O} 3$ & 11.55 & 1.21 & 0.23 & 20.98 & 5.74 & 1.86 & 0.1236 & 0.1253 \\
\hline $\mathrm{SI}-\mathrm{O} 4$ & 32.27 & 4.92 & 1.05 & 45.15 & 7.89 & 1.95 & 0.1858 & 0.1599 & $\mathrm{SI}-\mathrm{O} 4$ & - & - & - & - & - & - & - & 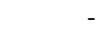 \\
\hline SI-O9 & 2.98 & 0.53 & 0.13 & 9.21 & 1.06 & 0.22 & 0.2877 & 0.2625 & $\mathrm{Sl}-09$ & 4.68 & 1.85 & 0.83 & 5.38 & 2.57 & 1.53 & 0.2713 & 0.2492 \\
\hline TN-O1 & 12.72 & 1.84 & 0.44 & 24.65 & 4.00 & 1.02 & 0.3703 & 0.2982 & $\mathrm{TN}-\mathrm{O} 1$ & 21.09 & 4.24 & 1.25 & 18.61 & 3.96 & 1.18 & 0.3436 & 0.3435 \\
\hline $\mathrm{TN}-\mathrm{O} 2$ & 33.64 & 5.74 & 1.46 & 54.30 & 11.23 & 3.25 & 0.2140 & 0.1873 & $\mathrm{TN}-\mathrm{O} 2$ & 15.36 & 2.95 & 0.84 & 12.21 & 2.21 & 0.59 & 0.3448 & 0.3393 \\
\hline $\mathrm{TN}-\mathrm{O} 3$ & 20.86 & 3.36 & 0.79 & 34.25 & 6.78 & 1.91 & 0.2672 & 0.2297 & $\mathrm{TN}-\mathrm{O} 3$ & 53.01 & 11.99 & 3.95 & 49.88 & 10.90 & 3.53 & 0.2037 & 0.2159 \\
\hline TN-O4 & 15.65 & 1.84 & 0.33 & 23.84 & 4.06 & 0.94 & 0.3144 & 0.2605 & TN-O4 & - & - & - & - & - & - & - & . \\
\hline TN-O9 & 10.60 & 3.01 & 1.56 & 17.12 & 3.98 & 1.69 & 0.4115 & 0.3346 & TN-O9 & 10.35 & 3.02 & 1.33 & 10.14 & 2.55 & 1.07 & 0.3985 & 0.4199 \\
\hline TR-01 & 15.99 & 2.49 & 0.56 & 33.90 & 7.16 & 2.06 & 0.2204 & 0.2182 & TR-O1 & 2.56 & 0.31 & 0.05 & 26.15 & 3.70 & 0.85 & 0.2940 & 0.2752 \\
\hline TR-O2 & 30.92 & 3.81 & 0.81 & 74.85 & 13.38 & 3.35 & 0.1502 & 0.1235 & TR-O2 & 1.24 & 0.08 & 0.01 & 7.35 & 1.00 & 0.21 & 0.2968 & 0.2958 \\
\hline TR-O9 & 5.24 & 0.64 & 0.11 & 13.11 & 2.07 & 0.57 & 0.2372 & 0.2365 & TR-O9 & 2.86 & 0.70 & 0.26 & 33.38 & 5.51 & 1.43 & 0.4378 & 0.3091 \\
\hline UP-O1 & 34.36 & 6.21 & 1.70 & 45.61 & 8.98 & 2.57 & 0.3055 & 0.2476 & UP-01 & 32.27 & 7.69 & 2.58 & 37.19 & 8.53 & 2.77 & 0.3700 & 0.3564 \\
\hline UP-O2 & 55.30 & 12.02 & 3.80 & 65.95 & 16.07 & 5.36 & 0.2289 & 0.2036 & UP-O2 & 20.84 & 3.63 & 0.97 & 19.58 & 3.60 & 0.95 & 0.3532 & 0.3263 \\
\hline UP-O3 & 48.87 & 10.07 & 3.08 & 59.77 & 14.37 & 4.63 & 0.2458 & 0.2109 & UP-O3 & 52.96 & 15.71 & 5.92 & 68.17 & 19.10 & 7.04 & 0.2545 & 0.2397 \\
\hline UP-O4 & 26.37 & 4.62 & 1.23 & 34.77 & 7.02 & 2.01 & 0.2786 & 0.2458 & UP-O4 & - & - & - & - & - & - & - & 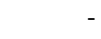 \\
\hline UP-09 & 19.25 & 3.54 & 0.98 & 26.08 & 5.56 & 1.66 & 0.3399 & 0.2972 & UP-09 & 21.41 & 5.79 & 2.03 & 28.33 & 6.16 & 2.03 & 0.3421 & 0.3625 \\
\hline UT-01 & 36.81 & 7.67 & 2.02 & 32.18 & 5.45 & 1.27 & 0.2965 & 0.2672 & UT-O1 & 36.23 & 7.60 & 2.10 & 25.61 & 4.53 & 1.13 & 0.2605 & 0.2581 \\
\hline UT-O2 & 66.74 & 13.71 & 3.89 & 59.00 & 10.75 & 2.84 & 0.3007 & 0.2135 & UT-O2 & 32.89 & 6.97 & 2.13 & 18.24 & 3.08 & 0.94 & 0.3443 & 0.3373 \\
\hline UT-O3 & 69.47 & 16.82 & 5.41 & 63.65 & 13.32 & 3.96 & 0.2388 & 0.1840 & UT-O3 & 75.69 & 23.71 & 8.22 & 76.30 & 18.42 & 5.34 & 0.2221 & 0.2209 \\
\hline UT-O4 & 36.15 & 6.22 & 1.54 & 30.22 & 4.40 & 0.94 & 0.2619 & 0.2053 & UT-O4 & & & - & - & - & & - & - \\
\hline UT-09 & 23.91 & 3.59 & 1.01 & 21.25 & 3.19 & 0.80 & 0.2925 & 0.2889 & UT-09 & 11.66 & 2.40 & 0.76 & 7.56 & 1.42 & 0.36 & 0.3453 & 0.2810 \\
\hline WB-O1 & 23.18 & 3.91 & 0.98 & 33.81 & 6.12 & 1.63 & 0.3010 & 0.2527 & WB-O1 & 15.97 & 3.05 & 0.81 & 28.24 & 6.25 & 1.97 & 0.3584 & 0.3534 \\
\hline WB-O2 & 45.58 & 8.94 & 2.52 & 56.65 & 12.84 & 4.02 & 0.2084 & 0.1942 & WB-O2 & 3.92 & 0.68 & 0.19 & 13.24 & 2.12 & 0.54 & 0.3603 & 0.3489 \\
\hline WB-O3 & 30.12 & 6.06 & 2.09 & 40.51 & 8.80 & 2.99 & 0.2316 & 0.2187 & WB-O3 & 39.02 & 6.73 & 1.81 & 54.32 & 13.50 & 4.39 & 0.2692 & 0.2196 \\
\hline WB-O4 & 17.59 & 3.06 & 0.73 & 27.40 & 5.06 & 1.35 & 0.2397 & 0.2348 & WB-O4 & - & - & - & - & - & - & - & - \\
\hline WB-09 & 13.19 & 2.49 & 0.75 & 15.86 & 3.32 & 0.93 & 0.3263 & 0.3142 & WB-09 & 5.48 & 1.29 & 0.54 & 7.69 & 1.95 & 0.82 & 0.4035 & 0.3744 \\
\hline
\end{tabular}


Table 8: Poverty and Inequality across State-wise Occupation Groups with Old and New Methods, 2004-05, Rural and Urban

\begin{tabular}{|c|c|c|c|c|c|c|c|c|c|c|c|c|c|c|c|c|c|}
\hline \multicolumn{9}{|c|}{ Rural } & \multicolumn{9}{|c|}{ Urban } \\
\hline \multirow{3}{*}{$\begin{array}{l}\text { NSS } \\
\text { Region }\end{array}$} & \multicolumn{6}{|c|}{ Poverty } & \multicolumn{2}{|c|}{ Inequality } & \multirow{3}{*}{$\begin{array}{l}\text { NSS } \\
\text { Region }\end{array}$} & \multicolumn{6}{|c|}{ Poverty } & \multicolumn{2}{|c|}{ Inequality } \\
\hline & \multicolumn{3}{|c|}{ Old Method } & \multicolumn{3}{|c|}{ New Method } & \multirow[t]{2}{*}{ Old } & \multirow[t]{2}{*}{ New } & & \multicolumn{3}{|c|}{ Old Method } & \multicolumn{3}{|c|}{ New Method } & \multirow[t]{2}{*}{ Old } & \multirow[t]{2}{*}{ New } \\
\hline & $\alpha=0$ & $\alpha=1$ & $\alpha=2$ & $\alpha=0$ & $\alpha=1$ & $\alpha=2$ & & & & $\alpha=0$ & $\alpha=1$ & $\alpha=2$ & $\alpha=0$ & $\alpha=1$ & $\alpha=2$ & & \\
\hline Al-01 & 23.81 & 4.26 & 1.17 & 36.27 & 7.16 & 2.10 & 0.3148 & 0.2810 & $\mathrm{Al}-\mathrm{O} 1$ & 27.13 & 6.30 & 2.11 & 27.44 & 5.97 & 1.88 & 0.3621 & 0.3534 \\
\hline Al-O2 & 44.13 & 9.27 & 2.82 & 63.11 & 15.48 & 5.20 & 0.2330 & 0.2101 & $\mathrm{Al}-\mathrm{O} 2$ & 16.35 & 3.39 & 1.05 & 15.25 & 2.92 & 0.82 & 0.3591 & 0.3390 \\
\hline $\mathrm{Al}-\mathrm{O} 3$ & 32.61 & 6.50 & 1.96 & 48.55 & 11.12 & 3.60 & 0.2788 & 0.2563 & $\mathrm{Al}-\mathrm{O} 3$ & 58.06 & 16.37 & 6.32 & 58.72 & 15.49 & 5.55 & 0.2663 & 0.2461 \\
\hline Al-O4 & 21.66 & 3.92 & 1.08 & 33.20 & 6.64 & 1.97 & 0.2845 & 0.2611 & $\mathrm{Al}-\mathrm{O} 4$ & - & - & - & - & - & - & - & . \\
\hline Al-09 & 14.46 & 3.10 & 1.16 & 21.76 & 4.83 & 1.69 & 0.3692 & 0.3471 & Al-09 & 14.96 & 4.05 & 1.67 & 15.90 & 3.92 & 1.58 & 0.4183 & 0.4155 \\
\hline $\mathrm{Al}$ & 28.12 & 5.50 & 1.63 & 41.80 & 9.24 & 2.94 & 0.3045 & 0.2808 & Al & 25.84 & 6.21 & 2.16 & 25.68 & 5.78 & 1.88 & 0.3764 & 0.3643 \\
\hline
\end{tabular}

Note: The first two letters represent the state codes as in Table 5 and the last two are houschold type indicating the major occupation as follows. Rural Areas: 01-Self-employed in Non-Agriculture, O2Agricultural Labour, 03-Other Labour, 04-Self-employed in Agriculture, O9-Others; Urban Areas: O1-Self-employed, O2-Regular wage/salary earning, 03-Casual Labour, 09-Others. All estimates are based on unit level data, see notes in Tables 1 and 5.

Source: Unit level data, Schedule 1.0, NSS $61^{\text {st }}$ Round, 2004-05. 


\subsection{Household Type (Occupation Groups)}

In rural India the poorest occupation group across states is agricultural labourers from Dadra \& Nagar Haveli with the incidence of poverty at 93 per cent under the new method. There are ten more state-specific occupation groups with incidence of poverty greater than 70 per cent - they are agricultural labourers from Bihar, Chhattisgarh, Jharkhand, Madhya Pradesh, Odisha, Sikkim and Tripura, other labourers from Bihar and Odisha and selfemployed in agriculture from Dadra \& Nagar Haveli. With incidence of poverty between 50 to 70 per cent there are 29 state-specific occupation groups of which 14 are from agricultural labourers, 10 are from other labourers, two each from self-employed in agriculture and self-employed in non-agriculture and one from 'other' occupational group. There are twenty more state-specific occupation groups with an incidence of poverty greater than 40 per cent. Overall, agricultural labourers are the poorest in 25 states/union territories, other labourers are the poorest in seven (Arunachal Pradesh, Assam, Daman \& Diu, Delhi, Jammu \& Kashmir, Manipur and Uttarakhand), self-employed in agriculture in two (Lakshadweep and Mizoram) and self-employed in non-agriculture in one (Chandigarh), but we should be cautious in the smaller states/union territories where sample size for such occupation groups is small.

In urban areas the poorest state-specific occupation group is casual labourers from Bihar with an incidence of poverty of 83 per cent in the new method. Including this, incidence of poverty is greater than 50 per cent for 25 state-specific groups and all are casual labourer occupation groups. Another 27 state-specific occupation groups have an incidence of poverty greater than 25 per cent of which five are casual labourers, 15 are self-employed, six are 'others' and one is regular wage/salary earners. In fact, in 34 states/union territories casual labourers is the poorest occupation group, it is only in Sikkim that self-employed have a greater incidence of poverty, but this could be because of the small sample estimate for this sub-group in this state.

Comparing the new method to the old, in rural areas for occupation groups of agricultural labour, other labour, self-employed in non-agriculture, self-employed in agriculture, and others the percentage point increase in incidence of poverty is 19.0 per cent, 16.0 per cent, 12.5 per cent, 11.5 per cent and 7.3 per cent respectively; whereas the simple percentage 
increase in incidence of poverty is 43.0 per cent, 48.9 per cent, 52.3 per cent, 53.3 per cent and 50.5 respectively. Similarly, in urban areas for occupation groups of casual labourers, self-employed, regular wage/salary earners and others the change in incidence of poverty is around one percentage point - it has decreased for regular wage/salary earners and increased for the three other occupation groups.

The sub-group specific discussion on NSS regions, social groups and occupation groups has been brief, as the basic purpose is to give estimates of poverty and inequality. Some concluding remarks are in order.

\section{Concluding Remarks}

The Planning Commission accepted the suggestions by an Expert Group that it had constituted leading to a new method for estimating poverty in India using NSS's consumption expenditure data for 2004-05. The new method replaces the uniform recall of 30 days for all consumption items to a mixed recall where consumption of five low frequency items were collected for the last year (365 days) and appropriately adjusted to get a monthly per capita expenditure. It also takes into consideration health and education needs that the old method had not incorporated in its calorie norm. While doing these, it also opened up a number of other issues.

First, it did away with the benchmarking of a poverty line with a calorie norm that the old method was based on. They did not let the calorie norm go away totally. A reference is made to an FAO calorie norm being achievable around its poverty line, but then this norm is for light and sedentary activities that may not adequately capture the energy needs of the poor who put in hard labour. Second, while factoring in health and education expenditure is a positive step, using median expenditure as a norm for a positively skewed expenditure distribution may not represent the actual requirement of a poor person. Third, having done away with a calorie norm, it begins with the poverty ratio for urban India from the old method as given. Using this ratio on the mixed recall it generates a consumption basket at the aggregate level for urban India and then uses this to generate a poverty line for states around this basket. This means that instead of using state estimates to compute a weighted all India average, it begins with the latter. A bottom-up method is replaced with a top-down 
approach. Fourth, the computation of consumption basket requires use of data from other rounds of NSS as also from other sources. The whole procedure is quite cumbersome and replicating it for earlier rounds or even for thin rounds is difficult and in many cases not possible. This will also have implications on the usage of time series poverty trends in macro modelling.

From a policy perspective, the new method will lead to change in share of poor. If financial transfers across states do not account for an increase in the number of poor or have a budget constraint then this means that the poorer states would end up getting less.

Despite these limitations, on account of pragmatic considerations as also for parsimony and prudence, the state-specific poverty lines have been used for computation of poverty at various sub-groups. This has been attempted in this paper for NSS regions, social groups and occupation groups for both the old and new methods. The relatively higher incidence of poverty among scheduled tribes in rural areas and scheduled castes in urban areas for social groups and that of agricultural labourers and other labourers in rural areas and casual labourers in urban areas for occupation groups have been discussed.

Though they do not play any active role in poverty estimation, yet the poor have maximum stake in poverty analysis as they are at the receiving end. Thus, a move towards a bottomup approach where the poor get involved in the understanding of vulnerability, particularly in the implementation of policies (including on identification of poor and poverty alleviation) so as to bring in greater accountability and transparency is called for (Rao, 2010; Suryanarayana, 2011). In its absence, every attempt to define and measure poverty is like treading on the dreams of poor. If poverty measure chosen is going to help them, at least some of these dreams would become a reality. Otherwise they dry like leaves fallen from trees. 


\section{References}

Betéille, A. (Ed.) (2000) Special Issue on the Scheduled Castes: An Inter-Regional Perspective. Journal of Indian School of Political Economy, 12 (3\&4).

Datta, K. (2010). Index of Poverty and Deprivation in Context of Inclusive Growth. Indian Journal of Human Development, 4 (1), 45-73.

Deaton, A. (2003). Prices and Poverty in India, 1987-2000. Economic and Political Weekly, 38 (4), 362-368.

Deaton, A. (2008). Price Trends in India and Their Implications for Measuring poverty. Economic and Political Weekly, 43 (6), 43-49.

Deaton, A., \& Drèze, J. (2009). Food and Nutrition in India: Facts and Interpretations, Economic and Political Weekly, 44 (7), 42-65.

Dev, S.M. (2011). A Mentor beyond D-school. Economic and Political Weekly, 46 (32), 113114.

Foster, J., Greer, J., \& Thorbecke, E. (1984). A Class of Decomposable Poverty Measures. Econometrica, 52 (3), 761-766.

Government of India (1979). Report of the Task Force on Projection of Minimum Needs and Effective Consumption Demands. New Delhi: Planning Commission.

Government of India (1993). Report of the Expert Group on Estimation of Proportion and Number of Poor. New Delhi: Planning Commission.

Government of India (2007), Poverty Estimates for 2004-05, New Delhi: Press Information Bureau, http://pib.nic.in/newsite/erelease.aspx?relid=26316 (accessed: 18 July 2011).

Government of India (2009). Report of Expert Group to Review the Methodolgy for Estimation of Poverty. New Delhi: Planning Commission.

Gupta, J.R., \& Kalra, M. (2005) Federal Transfers and Inter-State Disparities in India. New Delhi: Atlantic Publishers and Distributors.

Himanshu (2009). Toward New Poverty Line for India (Background Paper for the Expert Group to Review the Methodology for Estimation of Poverty). New Delhi: Planning Commission.

Jenkins, S. P., \& Lambert, P. J. (1997) Three 'I's of Poverty Curves, with an Analysis of UK Poverty Trends, Oxford Economic Papers, New Series 49 (3), 317-327.

Mishra, S. (2009a) Socioeconomic Inequities in Maharashtra: An Update, in N. Sardeshpande, A. Shukla \& K. Scott (Eds.), Nutritional Crisis in Maharashtra, Pune: SATHI, pp.53-81.

Mishra, S. (2009b) Poverty and Agrarian Distress in Orissa, in The Indian Economic Association, 92 ${ }^{\text {nd }}$ Annual Conference, Vol.II, pp.309-316. IGIDR working paper version is http://www.igidr.ac.in/pdf/publication/WP-2009-006.pdf (accessed: 12 August 2011). 
Mishra, S., \& Hari, L. (2009) Calorie Deprivation in Maharashtra: Analysis of NSS Data, in N. Sardeshpande, A. Shukla and K. Scott (Eds.), Nutritional Crisis in Maharashtra, Pune: SATHI, pp.83-98.

Mishra, S. Reddy, D.N. (2011) Persistence of Crisis in Indian Agriculture: Need for Technological and Institutional Alternatives, in D.M. Nachane (Ed.) India Development Report 2011, New Delhi: Oxford University Press, pp.48-58.

Pathak, D.C. (2010) Poverty and Inequality in Uttar Pradesh during 1993-94 to 2004-05: A Decomposition Analysis. Working paper No. WP-2010-014. Mumbai: Indira Gandhi Institute of Development Research, http://www.igidr.ac.in/pdf/publication/WP2010-014 (accessed: 12 August 2011).

Radhakrishna, R., Ravi, C., \& Reddy, B.S. (2010). State of Poverty and Malnutrition in India. in Coucil for Social Development (Ed.) India: Social Development Report 2010 - The Land Question and the Marginalized. New Delhi: Oxford University Press, pp.19-31.

Rao, V.M. (2010). Policy Making in India for Rural Development: Data Base and Indicators for Transparency and Accountability. International Journal of Economic Policy in Emerging Economies, 3(3), 222-236.

Raveendran, G. (2010). New Estimates of Poverty in India: A Critique of the Tendulkar Commtee Report. Indian Journal of Human Development, 4 (1), 75-89.

Subramanian, S. (2010). Identifying the Income-Poor: Some Controversies in India and Elsewhere. Discussion Paper, Courant Research Centre.

Suryanarayana, M. (2009). Nutritional Norms for Poverty: Issuses and Implications (Background Paper for the Expert Group to Review the Methodology for Estimation of Poverty). New Delhi: Planning Commission

Suryanarayana, M. (2011). Policies for the Poor: Verifying the Information Base. Journal of Quantitative Economics, New Series 9 (1), 73-88.

Suryanarayana, M. H., \& Silva, D. (2007). Is Targeting the Poor a Penalty on the Food Insecure? Poverty and Food Insecurity in India. Journal of Human Development, 8 (1), 89-107.

Swaminathan, M. (2010). The New Poverty Line: A Methodology Deeply Flawed. Indian Journal of Human Development, 4 (1), 121-125.

Thorat, S., \& Newman, K.S. (Eds.) (2009) Blocked by Caste: Economic Discrimination in Modern India, New Delhi: Oxford University Press. 